\title{
Modeling of the Surface Marks Formation in an Immovable Mold during Continuous Casting of Steel
}

\author{
by \\ Serguei Mikloukhine \\ Master of Engineering \\ A thesis submitted to the Faculty of Graduate Studies and Research \\ in partial fulfillment of the requirements for the degree of \\ Master of Applied Science \\ Ottawa-Carleton Institute for Mechanical and Aerospace Engineering \\ Department of Mechanical and Aerospace Engineering \\ Carleton University \\ Ottawa, Ontario \\ Canada
}

March, 2007C 


$\begin{array}{ll}\begin{array}{l}\text { Library and } \\ \text { Archives Canada }\end{array} & \begin{array}{l}\text { Bibliothèque et } \\ \text { Archives Canada }\end{array} \\ \begin{array}{l}\text { Published Heritage } \\ \text { Branch }\end{array} & \begin{array}{l}\text { Direction du } \\ \text { Patrimoine de l'édition }\end{array} \\ \begin{array}{l}\text { 395 Wellington Street } \\ \text { Ottawa ON K1A 0N4 }\end{array} & \begin{array}{l}\text { 395, rue Wellington } \\ \text { Ottana ON K1A ON4 } \\ \text { Canada Oa }\end{array}\end{array}$

Your file Votre référence ISBN: 978-0-494-26999-2 Ourfile Notre référence ISBN: 978-0-494-26999-2

NOTICE:

The author has granted a nonexclusive license allowing Library and Archives Canada to reproduce, publish, archive, preserve, conserve, communicate to the public by telecommunication or on the Internet, loan, distribute and sell theses worldwide, for commercial or noncommercial purposes, in microform, paper, electronic and/or any other formats.

The author retains copyright ownership and moral rights in this thesis. Neither the thesis nor substantial extracts from it may be printed or otherwise reproduced without the author's permission.
AVIS:

L'auteur a accordé une licence non exclusive permettant à la Bibliothèque et Archives Canada de reproduire, publier, archiver, sauvegarder, conserver, transmettre au public par télécommunication ou par l'Internet, prêter, distribuer et vendre des thèses partout dans le monde, à des fins commerciales ou autres, sur support microforme, papier, électronique et/ou autres formats.

L'auteur conserve la propriété du droit d'auteur et des droits moraux qui protège cette thèse. $\mathrm{Ni}$ la thèse ni des extraits substantiels de celle-ci ne doivent être imprimés ou autrement reproduits sans son autorisation.
In compliance with the Canadian

Privacy Act some supporting forms may have been removed from this thesis.

While these forms may be included in the document page count, their removal does not represent any loss of content from the thesis.
Conformément à la loi canadienne sur la protection de la vie privée, quelques formulaires secondaires ont été enlevés de cette thèse.

Bien que ces formulaires aient inclus dans la pagination, il n'y aura aucun contenu manquant. 


\begin{abstract}
Continuous casting is the main process used today for manufacturing of billets. During continuous casting the surface marks (SM) are forming on the surface of continuous casting billets. The surface marks can cause cracking and can decrease the yield of the casting process because the billet surface containing marks has to be grinded away to avoid crack growth. Using a mathematical model, it is possible to understand how to decrease the negative impact of the SM formation process.

Most of previously developed models of surface mark formation had a phenomenological, qualitative character and the major factor determining process of mark formation in these models was the mold oscillation. The basic mathematical model of SM formation in which the surface of the liquid metal in the mold is free from additional factors such as reciprocating mold movement does not exist. The objective of this work is to create the mathematical model of the SM formation during continuous casting in an immovable mold.

In order to numerically describe the complex process of SM formation the two stage approach for the description of the cycle of SM formation was developed. For the thermal analysis the equation of transient heat transfer with the source function has been derived. An initial condition and boundary conditions were formulated based upon a physical conception of SM formation process. The temperature distribution on meniscus during first stage was calculated. Adequacy testing of the mechanical part of model (using mathematical statistics) demonstrates excellent correspondence between the model and experimental data.
\end{abstract}


The developed model can be considered as a basic model for the simulation of the initial solidification process under different conditions during continuous casting. 


\section{Acknowledgments}

I would like to thank Doctor V. Tsukerman for his help in research and useful discussion. I would like also to thank my Supervisor, Professor A. Artemev for his continued guidance and support of my work. Finally, I would like to thank Professor J. Beddoes for support of my research. 


\section{Contents}

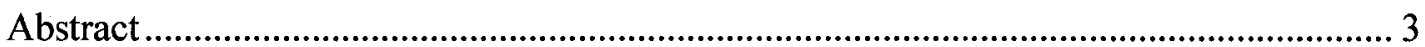

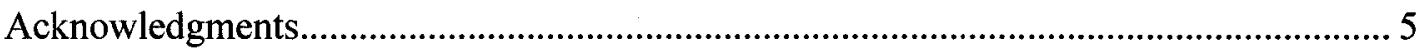

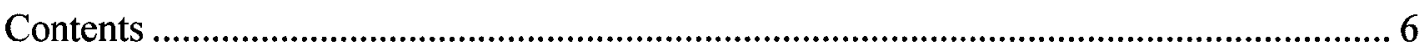

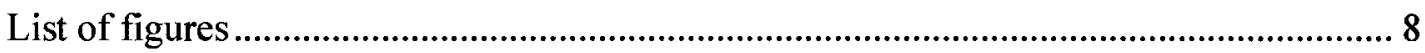

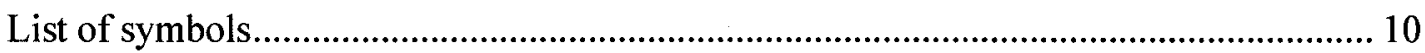

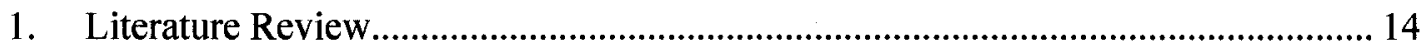

1.1. Introduction. A brief history of the continuous casting process ...................... 14

1.2. Factors influencing the initial process of the shell solidification: mold slag and

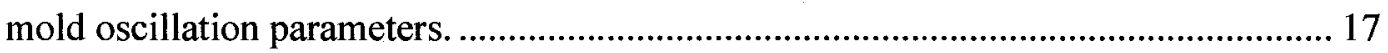

1.3. Formation of Ripples \& Oscillation marks ................................................. 19

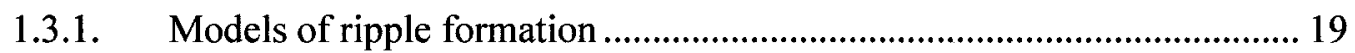

1.3.2. Models of oscillation mark formation.................................................. 21

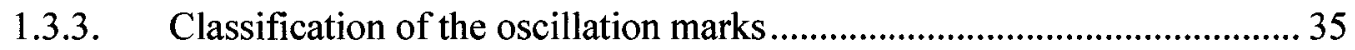

1.4. Conclusions. Objectives of the thesis .............................................................. 39

2. Qualitative description of the proposed model ................................................... 40

2.1. The first stage of the mark formation ........................................................ 40

2.2. The second stage of mark formation........................................................... 42

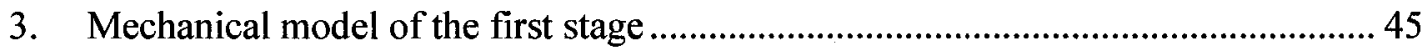

3.1. Basic assumptions. Forces acting on meniscus................................................ 45

3.2. Differential equation of equilibrium and its solution in parametrical form ...... 47

3.3. Meniscus line equation and it solution in Cartesian coordinate system ........... 49

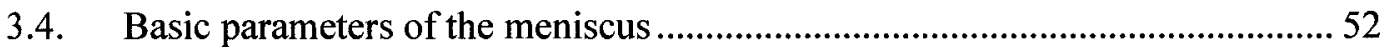


3.5. Numerical simulation of the mechanical model at the first stage

4. The model of the thermal processes on the meniscus at the first stage of mark

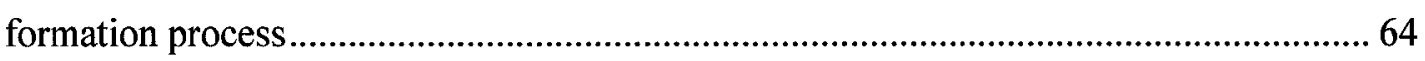

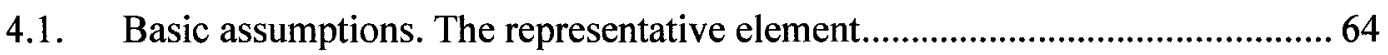

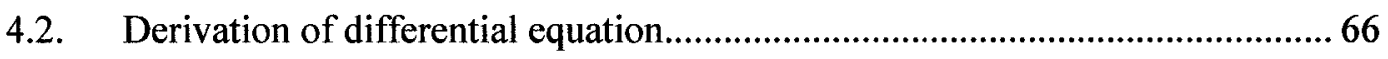

4.3. Equations which describe the dynamics of RE............................................. 70

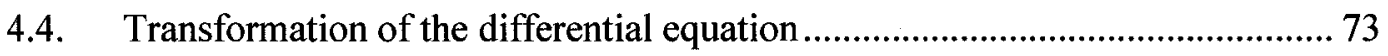

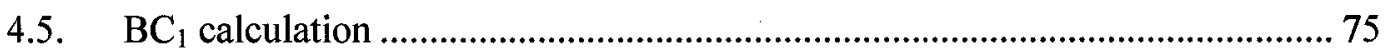

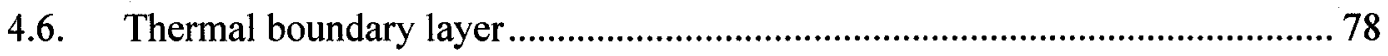

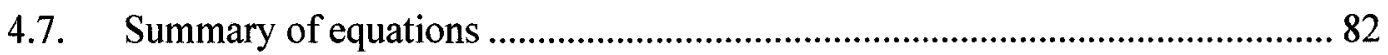

4.8. Analysis of the model of thermal processes on meniscus................................ 83

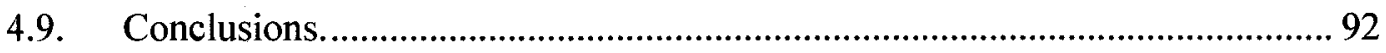

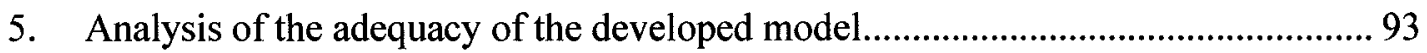

5.1. Analysis of the adequacy of the mechanical model of the first stage of mark

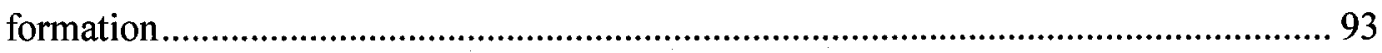

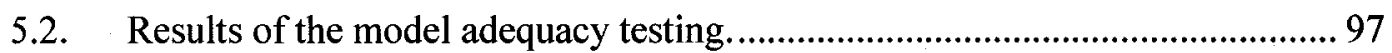

6. Conclusions. Advantages of the developed model .............................................. 99

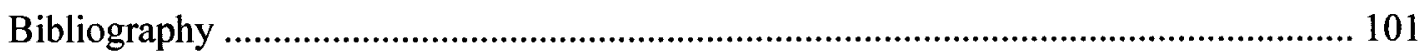

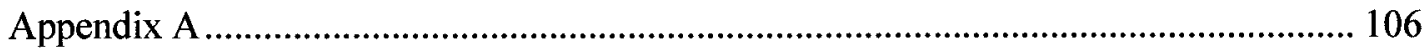

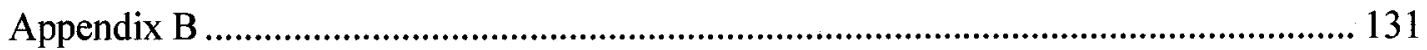




\section{List of figures}

Figure 1.1 The twin-roll caster suggested by Bessemer [1] ......................................... 14

Figure 1.2 Process following rupture of billet skin in the mold [2] ............................... 15

Figure 1.3 A vertical and radial continuous casting machine [4] ................................. 16

Figure 1.4 Schematic of the meniscus region ....................................................... 17

Figure 1.5 Ripple formation mechanism in ingots [24] .......................................... 20

Figure 1.6 Reciprocation mark formation mechanism in steel billet [25] ...................... 22

Figure 1.7 The mark formation starts with solidification of the meniscus [30] .............. 25

Figure 1.8 Takeuchi and Brimamacombe model of OM ............................................ 27

Figure 1.9 Takeuchi and Brimacombe model of OM ................................................. 28

Figure 1.10 Schematic drawing for ripple mark formation [34].................................2 29

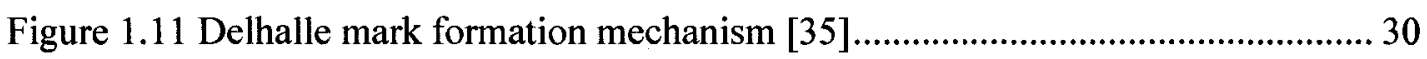

Figure 1.12 E.L.V. solidification model ................................................................. 31

Figure 1.13 The formation of oscillation marks in continuous casting with .................... 32

Figure 1.14 Meniscus shell attachment mechanism [13] ............................................ 33

Figure 1.15 The concept of electromagnetic casting of steel [39] ................................... 34

Figure 1.16 Bending of the originally lapped interface, x15 [29] …............................... 35

Figure 1.17 a) Reciprocation mark showing strong outward bending of solid shell ........ 36

Figure 1.18 Remelting of the reciprocation mark valley and bleeding .......................... 36

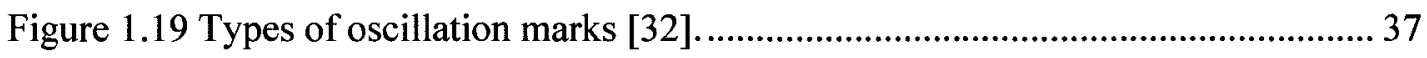

Figure 1.20 Schematics illustrating formation of curved hook....................................... 38

Figure 2.1 The scheme of the $1^{\text {st }}$ stage mark formation process................................... 41 


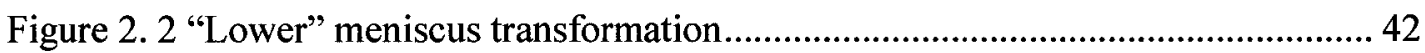

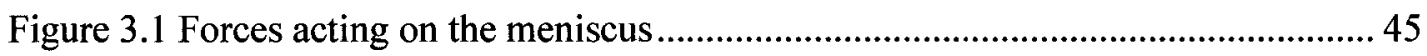

Figure 3.2 Diagram of the forces acting on an infinitesimally small section of the

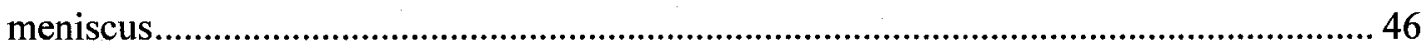

Figure 3.3 Notations used in mechanical model ..................................................... 50

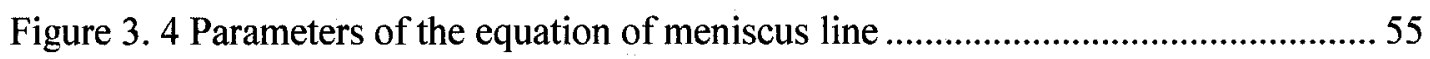

Figure 3.5 Calculated intermediate positions of the meniscus ...................................62

Figure 4.1 The RE geometry changes as a result of meniscus growth ...........................65

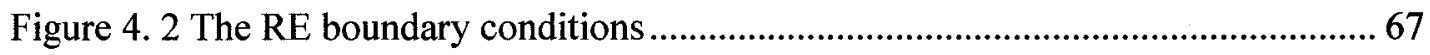

Figure 4. 3 Distribution of the liquid metal flows in the mold [40]............................. 79

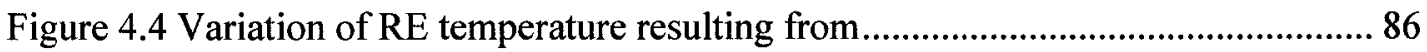

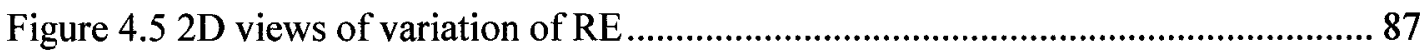

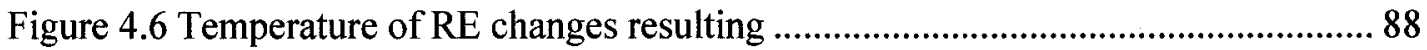

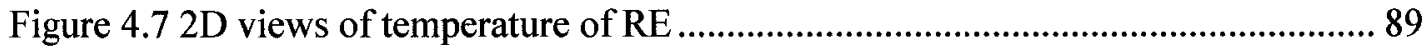

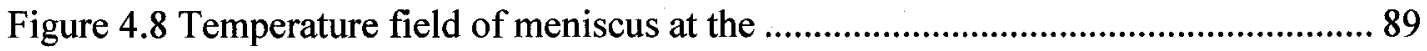

Figure 4.9 Temperatures of the meniscus at the end of first stage ..................................90

Figure 4.10 Calculated shape of meniscus (blue) and............................91

Figure 5.1 Photo of template with position of ................................................................ 93

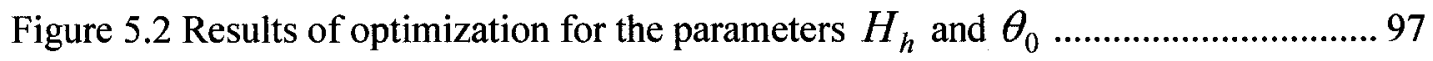




\section{List of symbols}

\begin{tabular}{|c|c|}
\hline$V_{m}$ & instantaneous mold velocity, $\mathrm{mm} / \mathrm{min}$; \\
\hline$V_{\text {average }}$ & average mold velocity, $\mathrm{mm} / \mathrm{min}$; \\
\hline$V_{C}$ & the casting velocity, $\mathrm{mm} / \mathrm{min}$ \\
\hline$s$ & the stroke length, mm; \\
\hline$f$ & the oscillation frequency, $1 / \mathrm{min}$ \\
\hline$t$ & the cycle time, $s$ \\
\hline$t_{c}$ & total cycle time, s; \\
\hline$t_{N}$ & negative strip time interval in each cycle of mold, s; \\
\hline$a$ & the Laplace capillary constant; \\
\hline$S, R_{S}$ & forces acting on meniscus, $\mathrm{N}$ \\
\hline$R$ & radius of curvature, $\mathrm{mm}$; \\
\hline$\varphi$ & angle of inclination at any point on the meniscus, rad; \\
\hline$d l$ & length of the infinitely small section of meniscus, $\mathrm{mm}$; \\
\hline$T$ & transverse force, $\mathrm{N}$ \\
\hline$M$ & bending moment, $\mathrm{N}^{*} \mathrm{~m}$ \\
\hline$d \varphi, d X, d Y$ & increments of the angle and coordinate; \\
\hline
\end{tabular}


the pressure of liquid metal (distributed load) - from the side of liquid metal, $\mathrm{N} / \mathrm{m}^{2}$; the pressure of liquid slag (distributed load) - from the side of liquid slag, $\mathrm{N} / \mathrm{m}^{2}$ longitudinal reaction at the beginning of a meniscus section, $\mathrm{N}$;

$R_{S}^{\text {end }}$ longitudinal reaction at the end of a meniscus section, $\mathrm{N}$; width of the considered section of meniscus in the direction, perpendicular to the plane of drawing, $\mathrm{mm}$; the coefficient of interphase tension between liquid metal and liquid slag, $\mathrm{N} / \mathrm{m}$; the resultants of distributed load $Q, \mathrm{~N}$;

$R_{q}$ the resultants of distributed load $q, \mathrm{~N}$; gravity acceleration, $\mathrm{N} / \mathrm{m}^{*} \mathrm{~s}^{2}$;

$\rho_{m}$ the density of liquid metal, $\mathrm{Kg} / \mathrm{m}^{3}$;

$\rho_{s l}$ the density of fluid slag, $\mathrm{Kg} / \mathrm{m}^{3}$;

$\theta_{0}$ initial angle, rad;

$\delta x$ the height of the not solidifying part of the meniscus (initial section of meniscus), mm;

$\Delta h_{s l} \quad$ slag rim thickness, $\mathrm{mm}$; solid slag thickness on the mold wall (below slag rim), $\mathrm{mm}$; 
$\Delta h_{s l-f}$

$l_{0}$

$\delta_{T}$

$\Delta l$

$\Delta Q_{V}$

$\Delta Q_{F}$

$\Delta Q_{\Delta}$

$c$

$\lambda$

$T_{M}$

$T$

$T_{s l-f}$

$T_{c r-s l}$

$T_{s l}$

thickness of the liquid layer between the meniscus and the solid slag and rim, $\mathrm{mm}$;

initial base's length of RE, mm;

size of prism in the direction, perpendicular to the tangent to the meniscus (thickness of the layer of thermal perturbation), $\mathrm{mm}$;

the RE (control section of meniscus) extension during meniscus stretching, $\mathrm{mm}$;

the summary heat content of the RE; J

the RE heat content due to the substance, which left from the core

during the meniscus stretching, $\mathrm{J}$;

heat transfer from the RE to the mold wall, J;

the coefficient of the liquid metal heat capacity, $\mathrm{kJ} /\left(\mathrm{kg}^{\circ} \mathrm{C}.\right)$;

the coefficient of the thermal conductivity, $\mathrm{W} /\left(\mathrm{m}^{\circ} \mathrm{C}\right)$;

the metal temperature in the core of ingot, ${ }^{\circ} \mathrm{C}$;

temperature of metal on the boundary RE - liquid slag ${ }^{\circ} \mathrm{C}$;

liquid slag temperature ${ }^{\circ} \mathrm{C}$;

temperature on the boundary liquid slag - solid slag, the

temperature of the liquid slag crystallization ${ }^{\circ} \mathrm{C}$;

temperature of solid slag on the boundary solid slag - the mold wall ${ }^{\circ} \mathrm{C}$; 


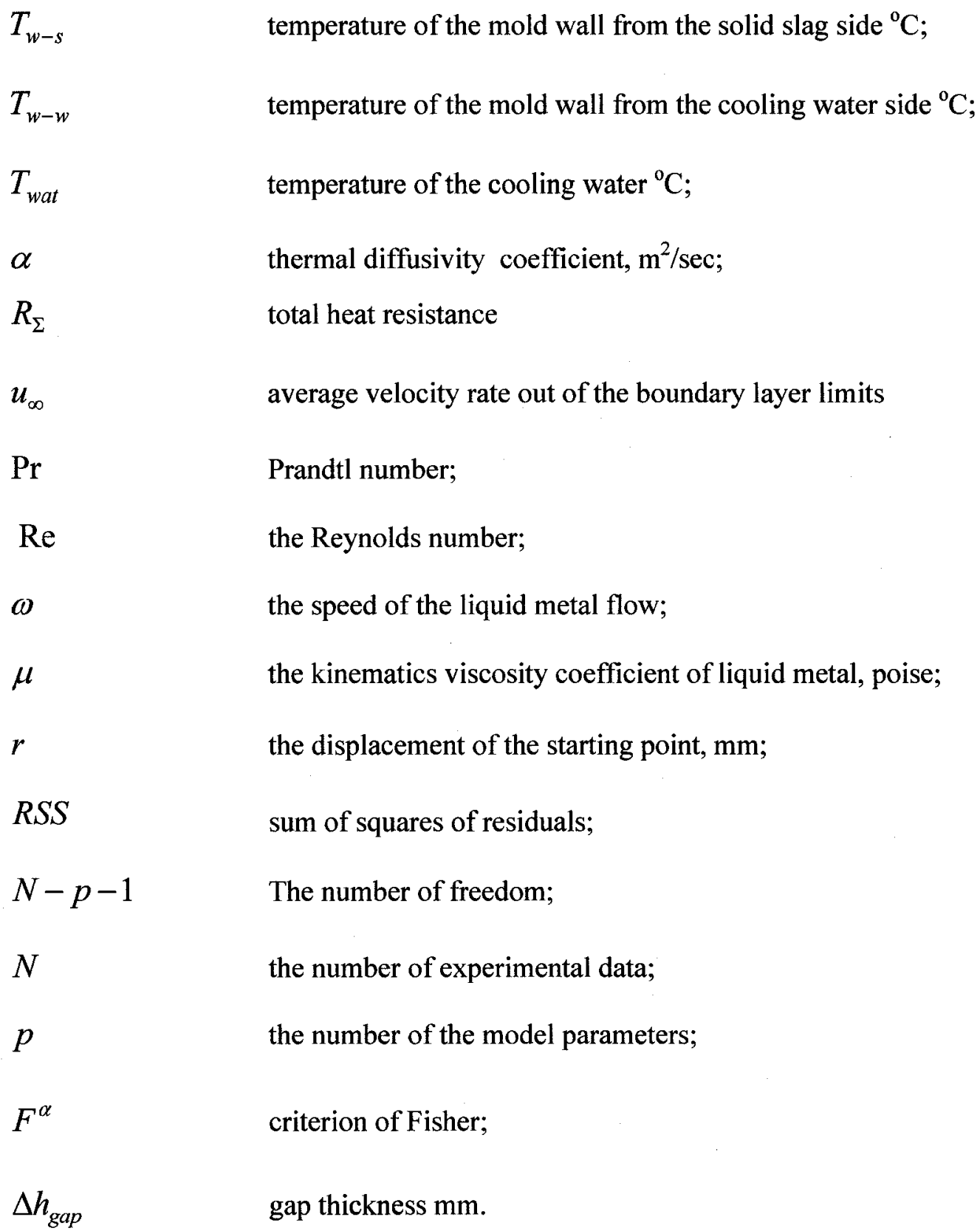




\section{Literature Review}

\subsection{Introduction. A brief history of the continuous casting process}

There are two basic casting methods used today for billets manufacturing: ingot casting and continuous casting. The benefits of the latter, such as:

- Higher yield

- Smaller number of necessary manufacturing steps

- More mechanized casting process

- More even composition

- Better surface finish.

make it the main process for billets manufacturing. The first continuous strip casting process was proposed by Bessemer in 1856 (Figure 1.1).

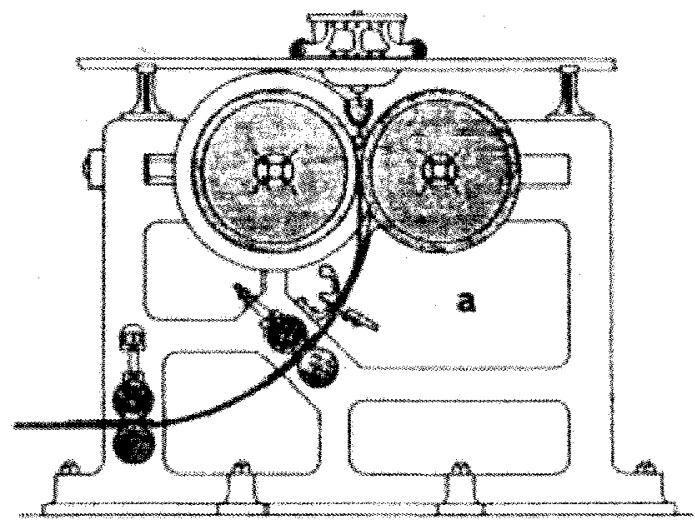

Figure 1.1 The twin-roll caster suggested by Bessemer [1] 
At that time the major problem was "breakouts"(Figure 1.2), which occur when the solidifying steel shell sticks to the mold, tears, and allows molten steel to pour out from the mold [2] . This problem was overcome by Junghans in 1934 by introducing a vertically oscillating mold, utilizing the concept of "negative strip" wherein the mold travels downward faster than the steel shell during some portion of the oscillation cycle to dislodge any sticking. A similarly important development was the introduction of

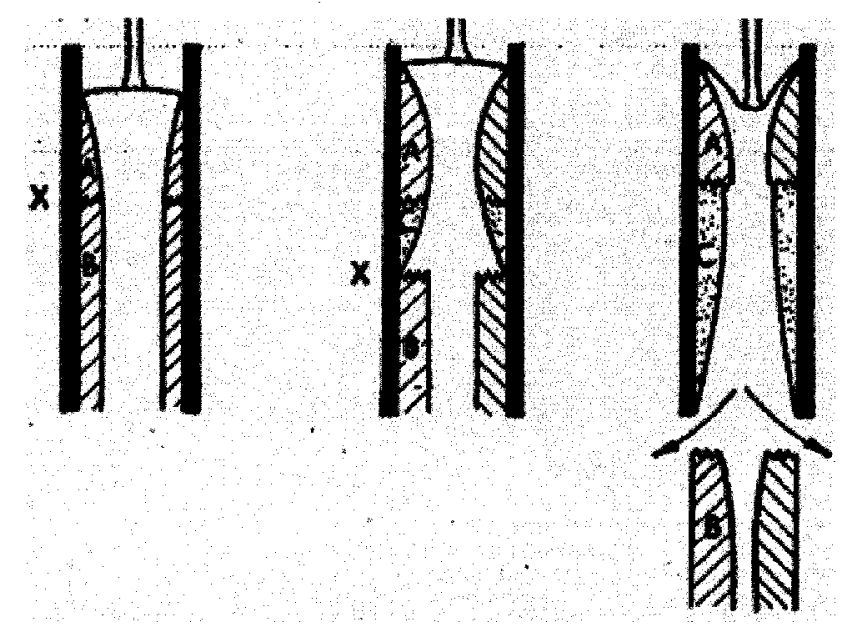

Figure 1.2 Process following rupture of billet skin in the mold [2]

sinusoidal oscillation, first used on two Russian slab casters in 1959 [3]. Now the sinusoidal mode is the standard regime of oscillation worldwide. It is relatively simple to design, provides easy implementation and features a smooth character of movement. Many other developments and innovations have transformed the continuous casting process into the sophisticated process currently used to produce over $90 \%$ of steel in the world, including plain carbon, alloy and stainless steel grades [4]. 
The scheme of the modern continuous casting machines is shown in Figure 1.3 [4]. Melt flows through ceramic tubes (nozzles) from a ladle to a tundish and further to a mold. The nozzles are submerged in the melt. In the mold, the mold slag (flux) covers the melt surface. The mold slag protects the metal from contact with air and may act as a lubricant. Once in the mold, the molten steel freezes in the water-cooled copper oscillating mold and forms a solid shell. During solidification the defects, such as oscillation marks (OM) are produced on the surface of the billets.

Driving rolls continuously withdraw the shell from the mold at a rate or "casting speed" that matches the flow of incoming metal, so the process ideally runs in steady state. Beneath the mold are a secondary cooling zone and a straightening zone. Water or air

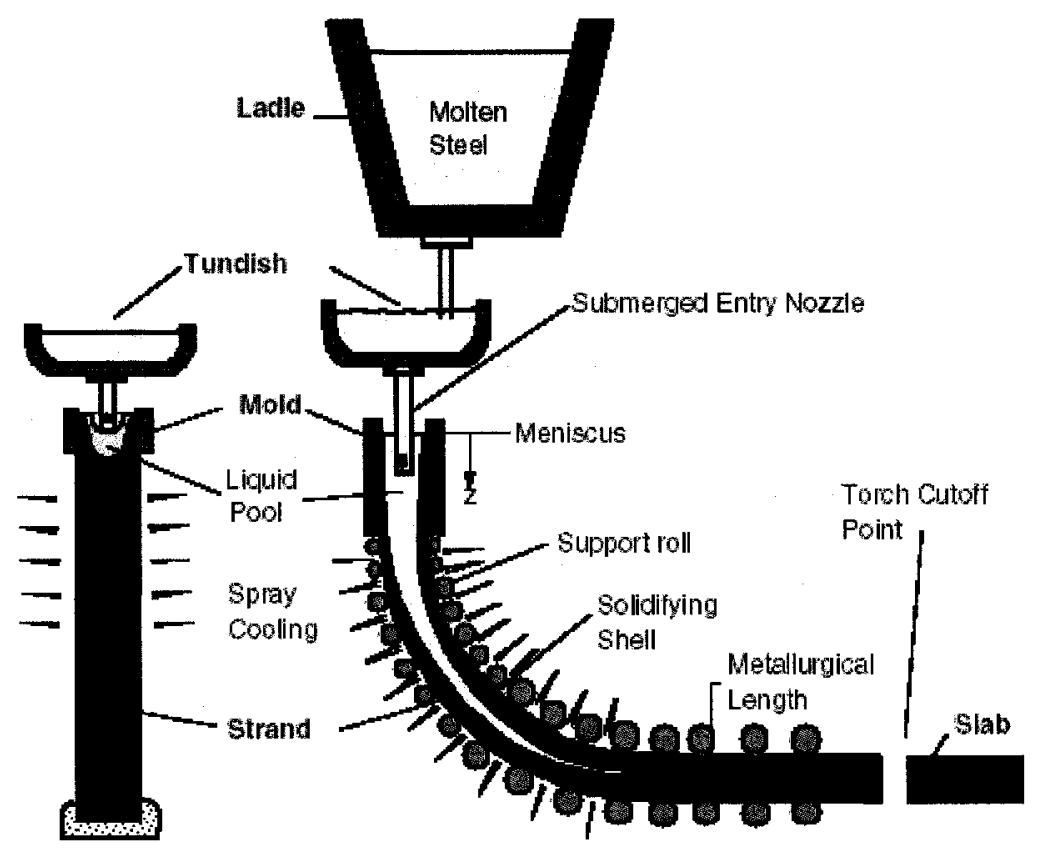

Figure 1.3 A vertical and radial continuous casting machine [4] 
mist sprays cool the surface of the strand between the support rolls. The spray flow rates are adjusted to control the strand surface temperature until the molten core becomes solid. After the center of the strand is completely solid (at the "metallurgical length" of the caster, which is $10-40 \mathrm{~m}$ ) the strand is cut with oxyacetylene torches into slabs or billets of any desired length.

\subsection{Factors influencing the initial process of the shell solidification: mold slag and mold oscillation}

\section{parameters.}

The most critical part of the continuous casting process is the initial solidification at the meniscus (Figure 1.4). The meniscus is the free surface of a liquid which is near the walls of vessel and which is curved because of surface tension [5]. This is the location where the surface of the final product is created, and where defects such as oscillation marks and surface cracks can form.

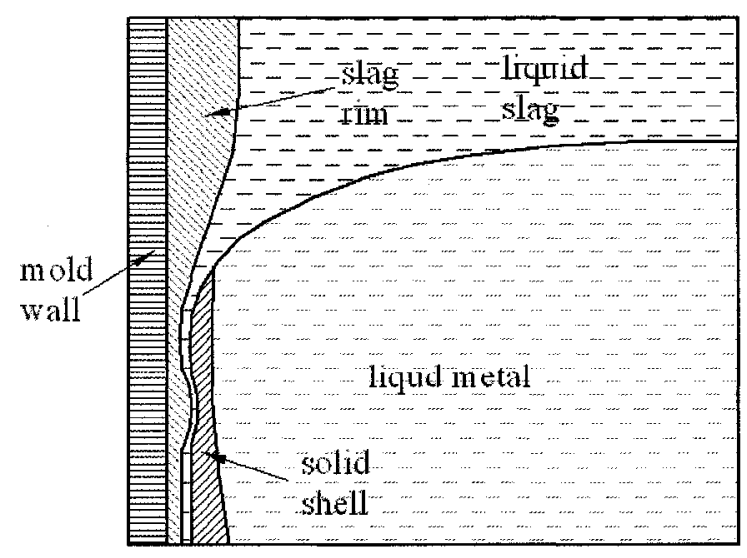

Figure 1.4 Schematic of the meniscus region 
Mold flux powder, normally consisting of silica $\left(\mathrm{SiO}_{2}\right)$, lime $(\mathrm{CaO})$, sodium oxide $\left(\mathrm{Na}_{2} \mathrm{O}\right)$, spar $\left(\mathrm{CaF}_{2}\right), \mathrm{MgO}, \mathrm{Al}_{2} \mathrm{O}_{3}$, covers the surface of liquid metal in the mold. Graphite is also used as a flux material to control the flux melt rate. The casting flux serves [6 - 12] to:

- Prevent oxidation

- Provide thermal insulation, prevent meniscus solidification

- Absorb inclusions

- Provide lubrication

- Determine the meniscus shape

The following major flux properties must be controlled to give optimum flux performance: row flux insulation, rate of inclusion absorption, flux melting rate, flux viscosity and crystallization temperature.

The oscillation of the mold is one of the most important factors influencing the OM formation process $[3,6,13,14]$. There are a number of parameters that describe the oscillation, the most important are:

Instantaneous mold velocity for sinusoidal cycle [3]:

$$
V_{m}=2 \cdot \pi \cdot s \cdot f \cdot \cos (2 \pi \cdot f \cdot t / 60), \quad(\mathrm{mm} / \mathrm{min})
$$

where $S$ - is the stroke length, $\mathrm{mm}, f$ - is the oscillation frequency, $1 / \mathrm{min}$ and $t-$ is the cycle time, s.

Average mold velocity [3]: 


$$
V_{\text {average }}=2 \cdot s \cdot f, \quad(\mathrm{~mm} / \mathrm{min})
$$

Total cycle time [3]:

$$
t_{c}=60 / f, \quad(\mathrm{~s})
$$

Negative strip time is the interval in each cycle of mold oscillation when downward velocity of the mold exceeds the withdrawal rate of the strand. Positive strip time is the interval in each cycle of mold oscillation when withdrawal rate of the strand exceeds the downward velocity of the mold.

Negative strip time interval in each cycle of mold [13]:

$$
t_{N}=(60 / \pi \cdot f) \cdot \arccos \left(V_{C} / \pi \cdot f \cdot s\right)
$$

where $V_{C}$ - is the casting velocity.

The depth of oscillation marks decrease with increasing oscillation frequency [15 - 18] and increases with increasing oscillation stroke length $[16,18,19]$ and negative-strip time $[20,21]$.

\subsection{Formation of Ripples \& Oscillation marks}

\subsubsection{Models of ripple formation}

A particular group of defects characterized by ripples and laps in the ingots (ingot casting) and OM in strands (continuous casting) have been studied previously and a number of possible mechanisms were introduced to explain their formation. Waters [23] and Thornton [24] described a qualitative model which involves meniscus solidification during casting. Figure 1.5 illustrates the mechanism proposed by Thornton. As there is no 
mold/liquid steel contact, the meniscus tends to build up until, when the internal pressure becomes too great, the meniscus bends to the mold wall at the limit of the frozen surface layer, as shown in Figure 1.5.

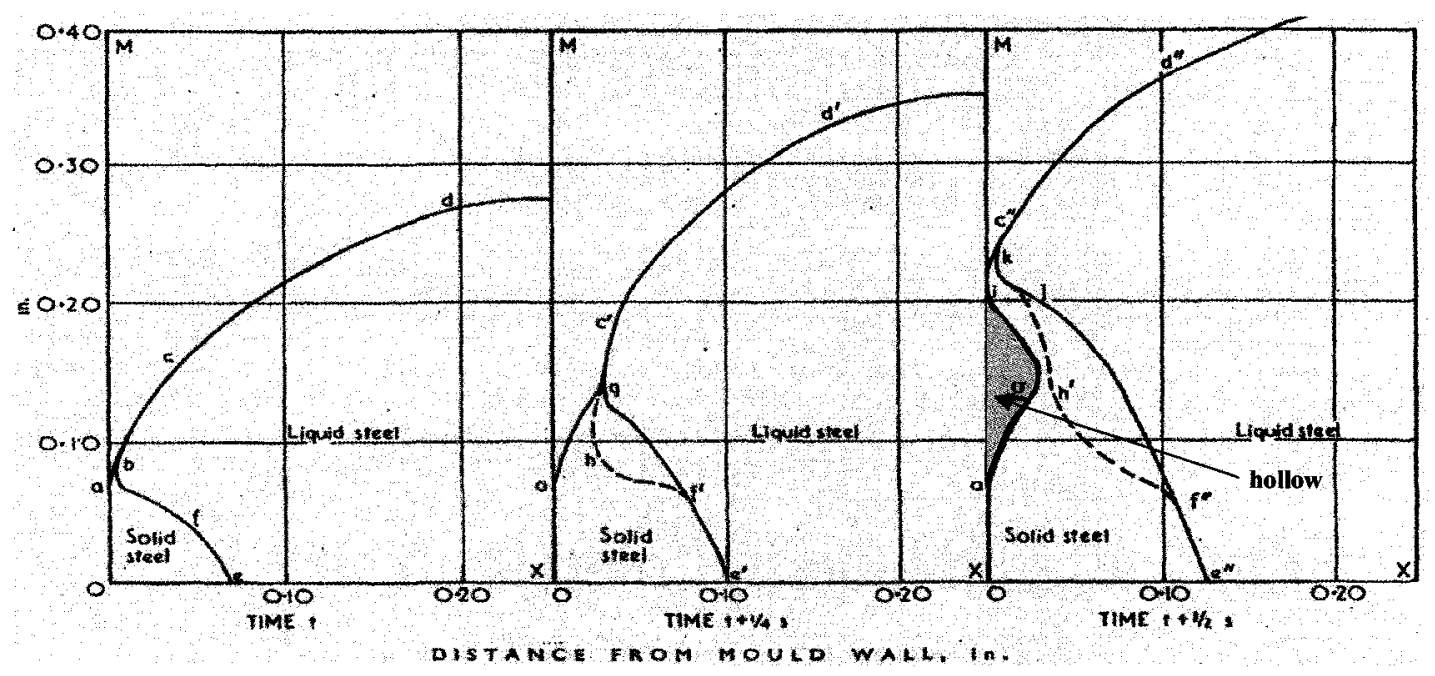

Figure 1.5 Ripple formation mechanism in ingots [24]

The steel surface is shown by:

$a b c d \quad$ at time $\mathrm{T}$;

ag $c^{\prime} d^{\prime} \quad$ at time $\mathrm{T}+(1 / 4) \mathrm{sec}$;

ag' Ic' 'd' at time $\mathrm{T}+(1 / 2) \mathrm{sec}$.

The position of the boundary between solid and liquid steel is shown as:

efb at time T

$e^{\prime} f^{\prime} g \quad$ at time $\mathrm{T}+(1 / 4) \mathrm{sec}$

$e^{\prime \prime} f^{\prime \prime} j k \quad$ at time $\mathrm{T}+(1 / 2) \mathrm{sec}$ 
The precise position of the boundary cannot be determined. The dashed lines f'hg and $f^{\prime}$ ' $h$ 'g show an estimate of its position allowing for the reduced rate of chilling at the hollow (Figure 1.5 at time $\mathrm{T}+(1 / 2) \mathrm{s})$ ) of the ripple where there is a gap between steel and mold.

Saucedo I, Beech J and Davis G.J. [29] studied ripples formation in the ingots during ingot casting. Their conclusions were:

1. The cooling factor (rate of heat extraction) of the mold is the major factor in the formation of the laps and ripples in ingot.

2. An increase of superheat and casting speed reduce these defects.

3. All of the observations made are consistent with solidification over the meniscus being the main step in the formation of surface rippling.

\subsubsection{Models of oscillation mark formation}

With the development of the continuous casting of steel, the mold reciprocation needed to be taken into account in the OM formation models. It has been proposed that mold reciprocation represented an additional mechanical effect. Consequently the model proposed by Savage [25] (see Figure 1.6) and Sato [26] incorporated mechanical and thermal mold - metal interactions.

Figure 1.6a illustrates a shell of the solidifying ingot in the mold at the time the mold is just beginning its upstroke. It is postulated that when the stress rate and maximum stress are sufficiently high, the thin and weak shell is broken near the meniscus level at position $\mathbf{P}_{1}$. 


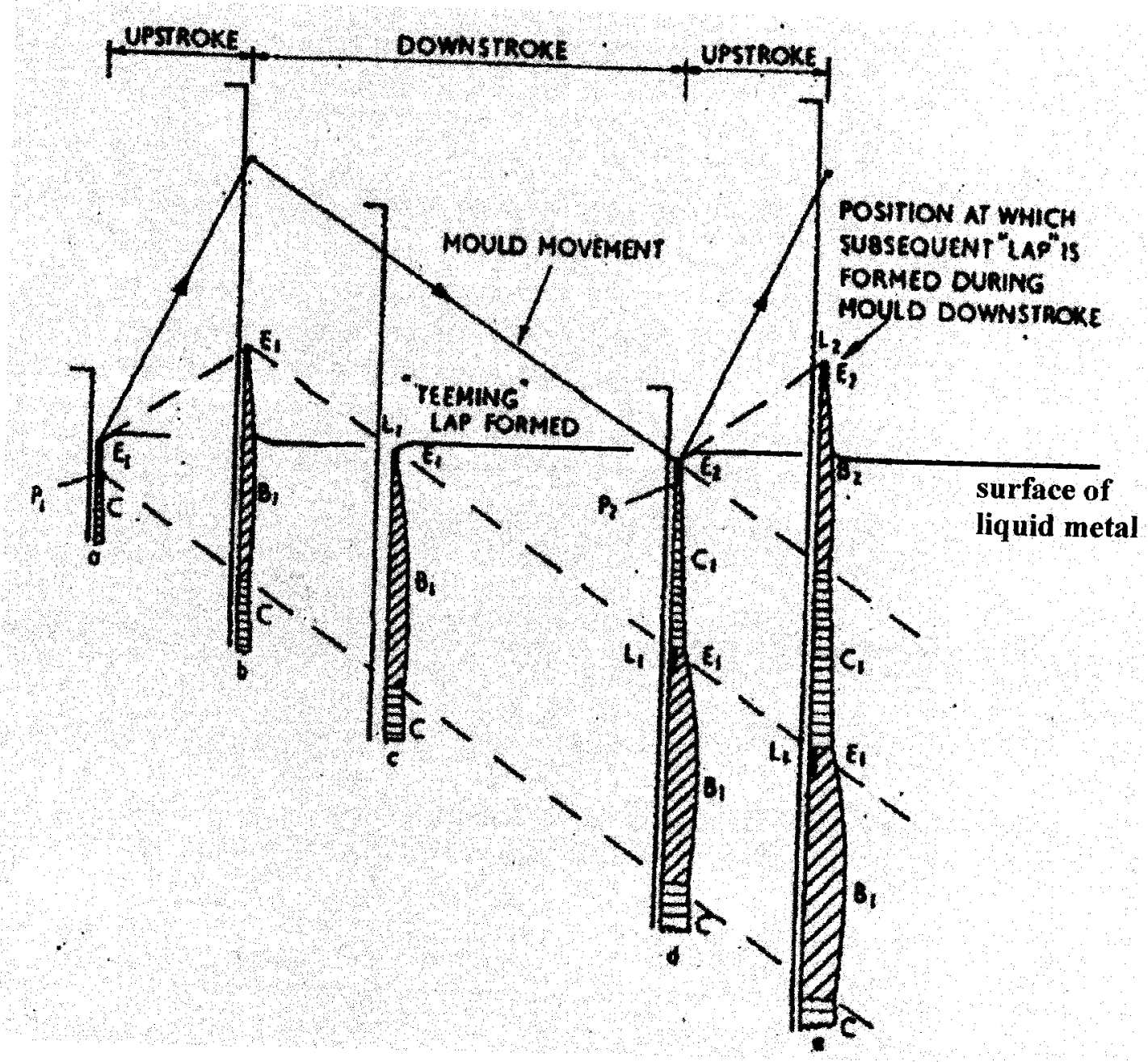

Figure 1.6 Reciprocation mark formation mechanism in steel billet [25]

The top element of the shell is then carried upwards by the mold, and it is assumed that during the upstroke some slipping may occur between the surface of the mold and the element $E_{1}$. Consequently, $E_{1}$ is carried upwards by a smaller distance than the mold stroke, and arrives at the position shown in Figure 1.6b. In this time, element $\mathrm{C}$ has continued its downward movement at the casting speed. Consequently, a substantial gap 
between $E_{1}$ and $C$ is formed, which begins to freeze as the element $B_{1}$, Figure 1.6b. The mold downstroke then begins, and continuous to the point shown in Figure 1.6d. In this period the stress applied by the mold to the ingot shell is either zero or slightly compressive, depending on whether the mold moves at the same or at a slightly greater speed than the ingot. Consequently, only a very weak mechanical link such as $B_{1}$ is required to permit the element $C$ to move the element $E_{1}$. Now when the upper edge $E_{1}$ penetrates the liquid steel meniscus, it is suggested that a fine lap $L_{1}$ is produced, as indicated in Figure 1.6c. During the reminder of downstroke, the lap $L_{1}$ passes beyond the meniscus level to reach the position shown in Figure 1.6d. When the mold is again reversed on the subsequent cycle, it is proposed that tearing occurs again as shown at $\mathrm{P}_{2}$, and the cycle of events is repeated.

The use of flux in the slab casting of steel introduced a further complexity. In this case it has been proposed that a mechanical interaction exists between flux and mold that changes the conditions under which the solid shell was formed. The next mechanism proposed by Davies and Sharp [28] for slabs considers that the negative strip in combination with the encapsulating effect of the solid flux can give rise to a pressure in the molten slag between strand and mold. The pressure acts so as to bend the solid shell inwards, producing an overflow of the liquid metal so forming the reciprocation mark.

In 1979 Saucedo I, Beech J and Davis G.J. suggested that the simple consideration of the casting speed can be used to understand how and when reciprocation marks are formed. [29]. The strongest rippling occurs at the point where mold and strand speed are equal. Lesser rippling would also be expected before and after this stage. 
Meniscus solidification can account for the formation of reciprocation marks and the presence of smaller ripples in the region between them. After analyzing the model and experiments they suggested [29]:

1. Metallographic evidence shows that the same basic meniscus solidification mechanism is responsible for the formation of the reciprocation marks in continuous casting and ripples in ingots. In the former case this mechanism is modified by the mechanical effects produced by the mold reciprocation.

2. The final shape and size of the surface feature depends upon both the casting conditions and the rate of the heat transfer. For example the solidifying meniscus shell may be bent back towards the mold walls or it may be ruptured and bleeding can occur.

In 1980 Saucedo et al. [29] explained that the oscillation marks, or ripples, form because the meniscus solidifies. No marks will form if the rate of heat extraction is lowered. In 1991 Saucedo [30] presents the theory in more detail. The oscillation marks form when oscillation forces the liquid metal to regain contact with the mold wall. This can happen in two ways, either an overflow occurs, or the shell is bent towards the mold by the metallostatic pressure, or that these two processes combine. Figure1.7 shows the different ways the liquid metal can come into contact with the mold wall above the frozen meniscus. The left mark is usually termed the folding mark (1), and the mark in the middle is called an overflow mark (2). 


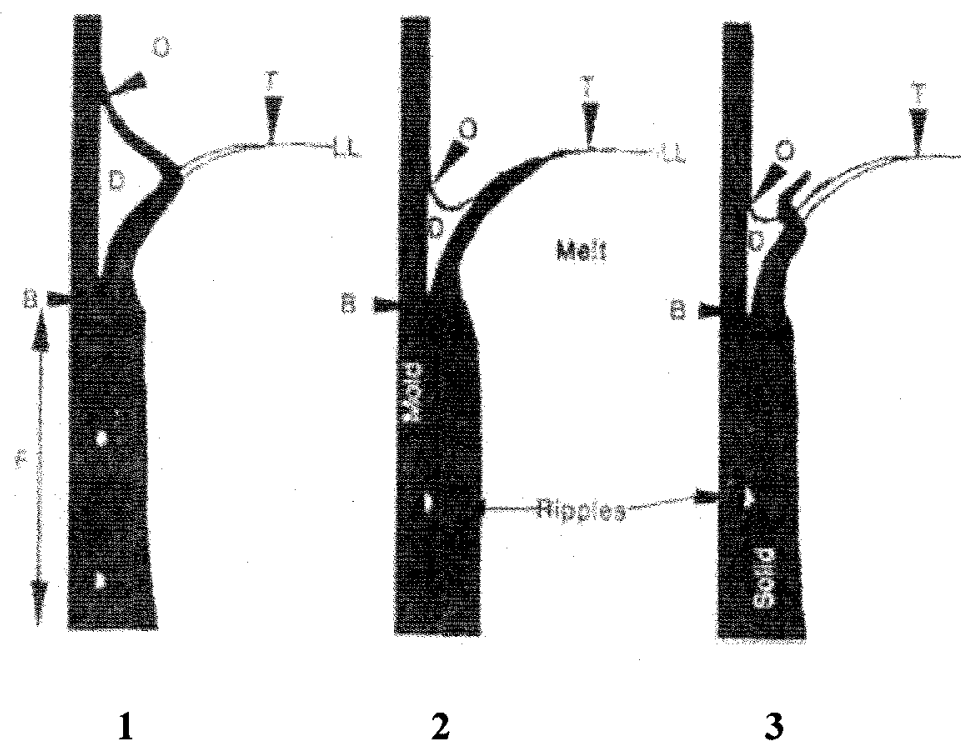

Figure 1.7 The mark formation starts with solidification of the meniscus [30]

1. The rising liquid pushes the solid shell towards the wall

2. The liquid overflows the shell

3. The first two are combined

The following conclusions were given [30]:

1. Samples indicate that initial solidification and oscillation mark formation are strongly influenced by meniscus effects.

2. The surface topography of oscillation marks has dendritic features, indicating that they were formed by meniscus solidification, without contacting the mold.

3. Oscillation marks produced in turbulent conditions can "split" in two, indicating that they are not produced by mechanical deformation effects.

4. Oscillation marks can have multiple depressions, indicating that there are not solely the products of mechanical effects during the mold downstroke.

5. Longitudinal streak lines on the surface of as-cast strands are produced by 
meniscus solidification effects.

In 1980 Tomono et al [31] performed experiments with organic substances. They observed the formation of surface marks and concluded that the two mark types, i.e. folding marks and overflow marks are formed differently. They suggested that oscillation marks were formed when the meniscus was subjected to compressive force by particles sticking to the wall, and folding marks were formed independently of the oscillation. They used the Bikerman equation [31] for calculating the meniscus shape and connected the oscillation mark properties to the discrepancy between observed and calculated meniscus shape $[3,31]$.

In 1984 Takeuchi and Brimacombe [22] described a mechanism in which the meniscus is covered with a rigid solid skin (or without, depending on superheat and local convection) and the pressure generated in the liquid slag channel varies and draws the meniscus back towards the mold wall during the negative strip. The pressure is positive when the mold is moving downward faster than the strand and is negative when the strand is moving faster. The difference between marks with and without hooks is assumed to be caused by the difference in strength of the meniscus skin. If the skin is strong, an overflow will occur, and a hook forms (Figure 1.8). If the skin is weaker, the shell is pressed against the wall and no overflow is needed, and no hook forms (Figure 1.9). Takeuchi and Brimacombe described how the meniscus follows the oscillation and suggested the classification of oscillation marks $[22,32,33]$. 


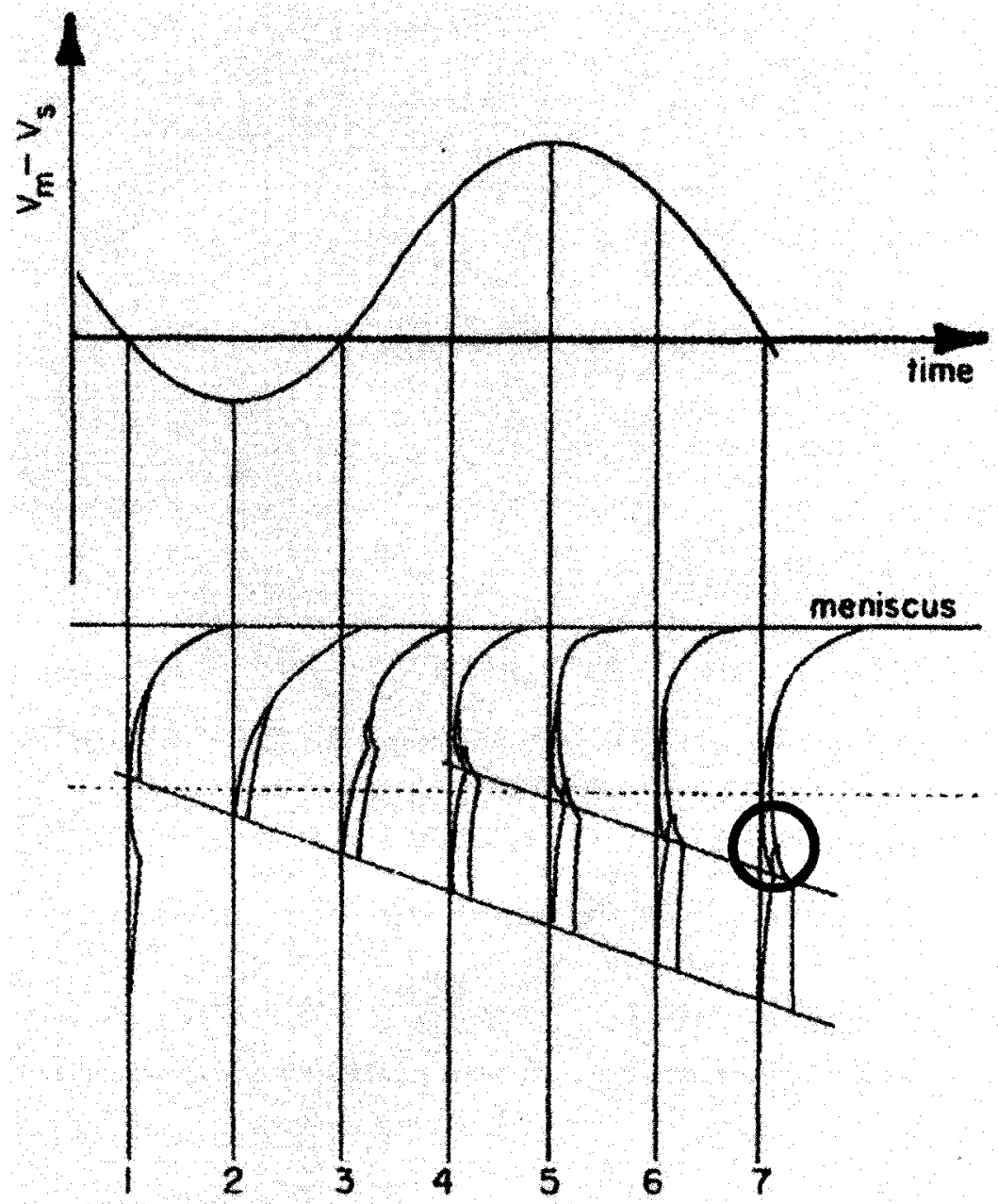

Figure 1.8 Takeuchi and Brimamacombe model of OM formation with subsurface hook [22] 


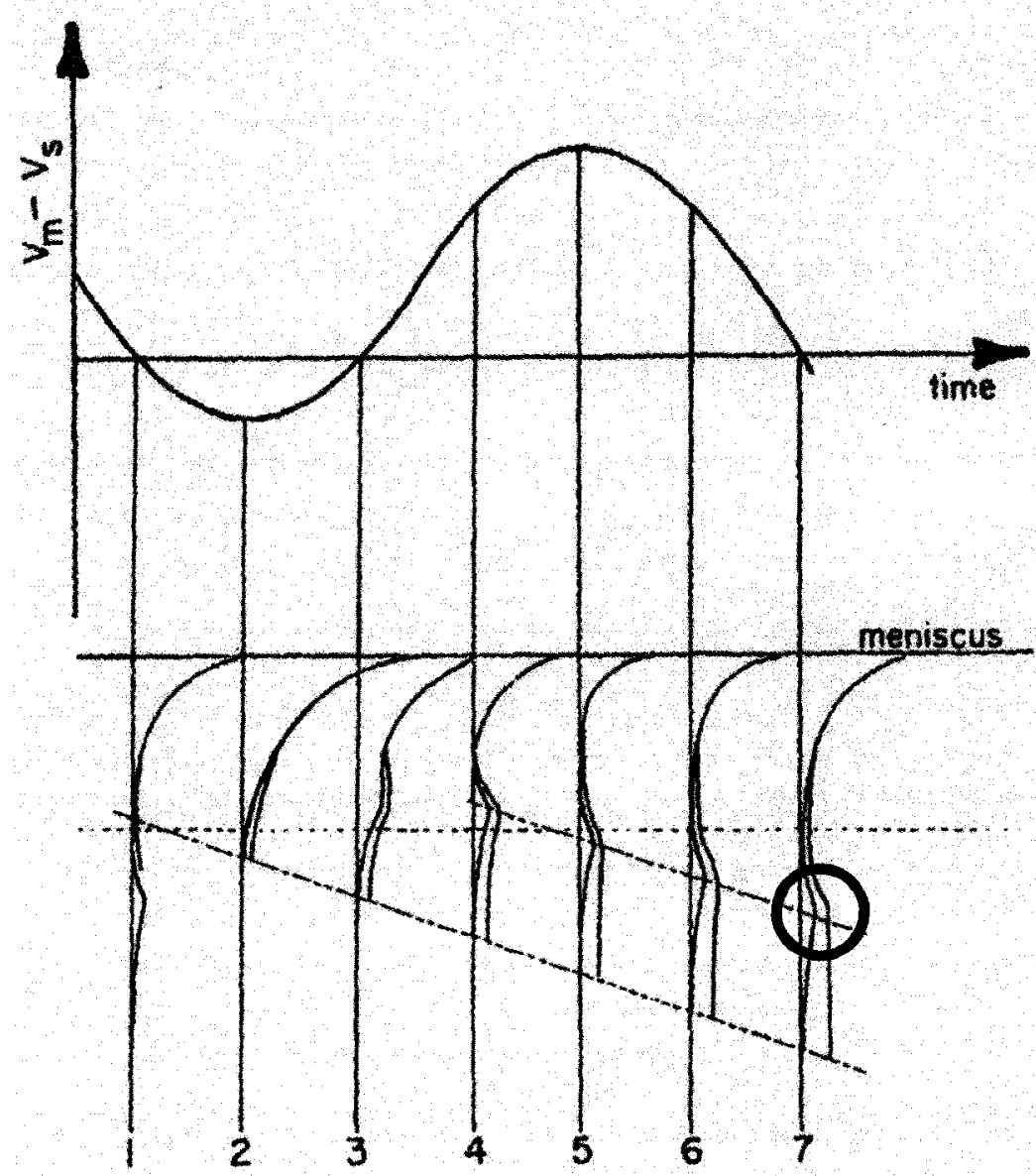

Figure 1.9 Takeuchi and Brimacombe model of OM formation without subsurface hook [22] 


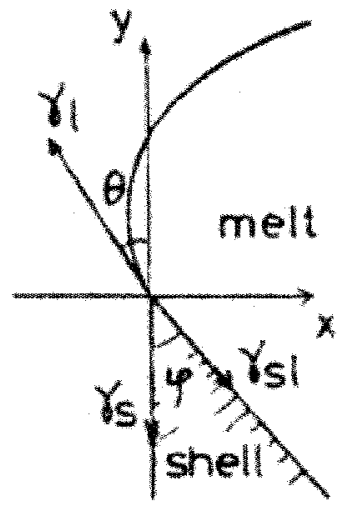

a)

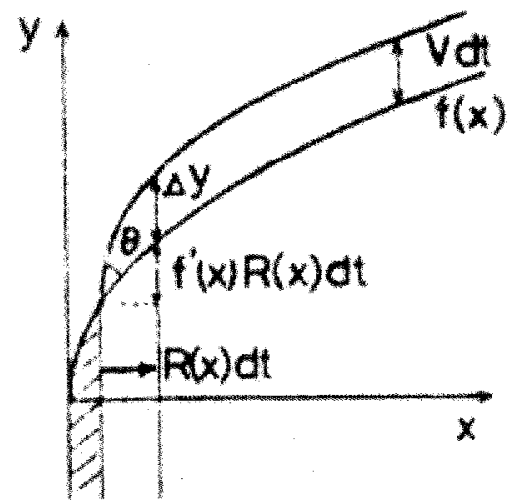

b)

Figure 1.10 Schematic drawing for ripple mark formation [34]

a) Balance of forces at the tip of solidified shell

b) Growth of shell and movement of melt surface

Suzuki et al [34] suggested that the meniscus in surface tension balance with the shell moves upwards as the solid shell grows inwards (see figure 1.10). Further J. Elfsberg [3] used this idea for her calculation.

In 1989 Delhalle et al. [35] described three different mechanisms for the formation of oscillation marks, as shown in Figure 1.11. The three mechanisms are based upon meniscus solidification. The size and shape of the oscillation marks is said to depend on the heat extraction, the oscillation parameters and the interfacial properties [35].

Based on the results of three experiments Lanez and Busturia [36] suggested that solidification does not start at the meniscus, but further down in the mold, at the lower part of the solid slag rim (Figure 1.12). The oscillation mark formation was connected to 
this region and it has been noted that marks formed under "positive strip" (where the mold downward speed is at maximum). They termed their model E.L.V. ("Extra Liquid Volume") solidification model, Figure 1.12.

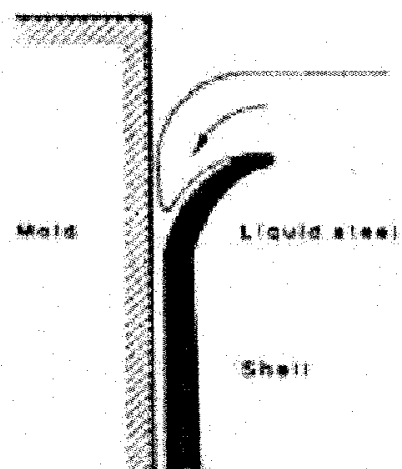

A

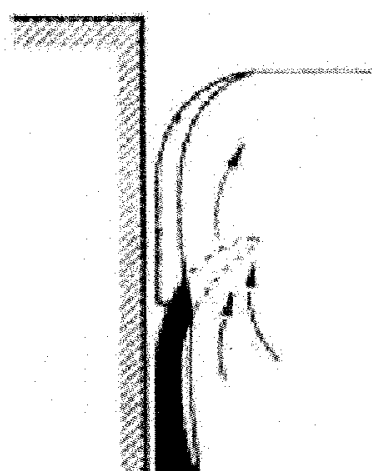

B

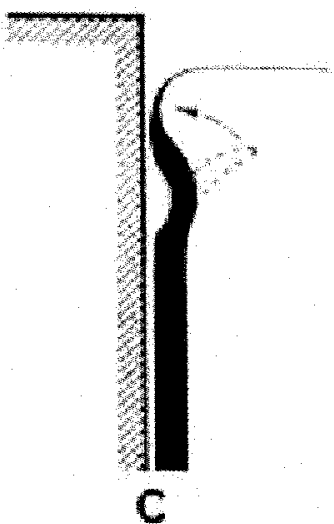

C

Overllow

Ovarllow + Remelling Manlecus bent back

Figure 1.11 Delhalle mark formation mechanism [35]

A. Mold oscillation and product withdrawal cause liquid steel to overflow the solid hook. The overflowing liquid freezes against the mold wall and a new shell tip forms.

B. Same as A, but here partial or total remelting of the solid shell tip is assumed.

C. The metallostatic pressure bends the solid shell back against the mold [35]

In $2003 \mathrm{~J}$. Elfsberg [3] proposed that there can be two types of oscillation marks: overflow marks and folding marks. It was suggested that they both were caused by overflows. The difference in their appearance depends on that they formed at different times of the oscillation cycle. The overflow marks are formed during the down strokes, and the folding marks during the upstrokes. The oscillation marks may form patterns. One deeper mark is followed by some shallow marks. 


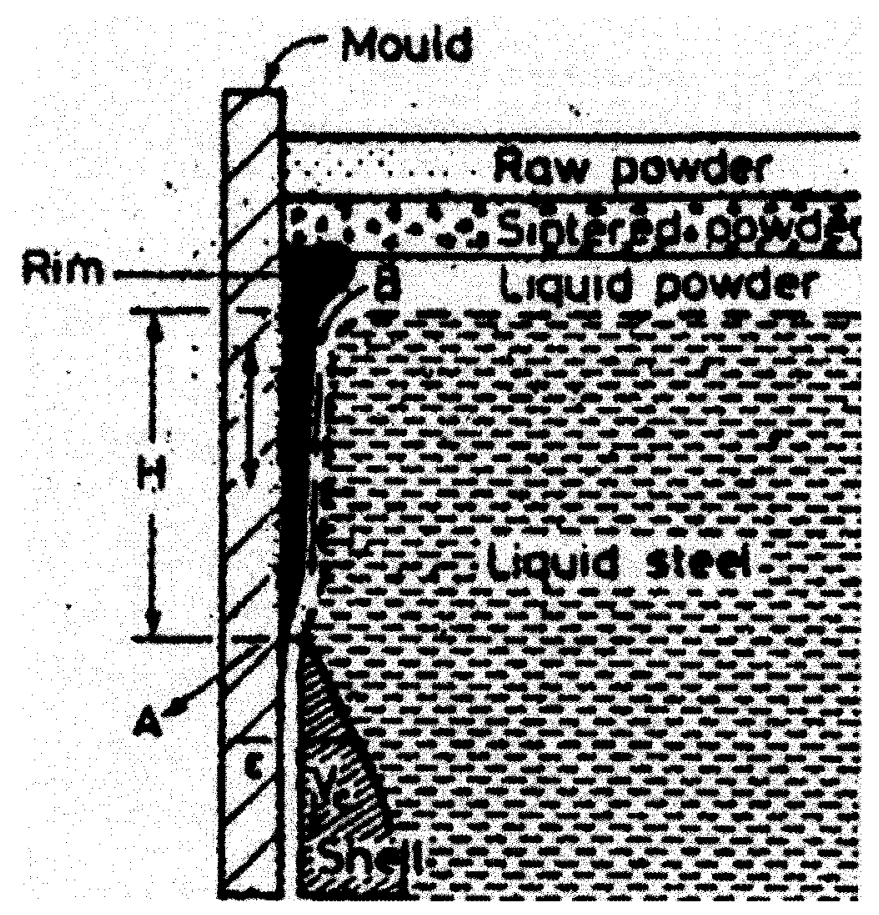

Figure 1.12 E.L.V. solidification model ("Extra Liquid Volume") [36]

Then there comes a deep one and so on. She suggested that the deeper marks form when the interfacial tension and the oscillation co-operates (acting in the same direction). Also J. Elfsberg suggested that it is possible to avoid the oscillation mark formation by avoiding the overflows. If the oscillation frequency is chosen so that the maximum meniscus height is never reached, the overflows will not occur. In other words, if the mold is switching to upward movement just as the maximum meniscus height is reached, the overflow will be suppressed. The optimal oscillation frequency was suggested to be [3]:

$$
f=V_{C} /(\sqrt{2} \cdot a)
$$


Sato $[26,27]$ suggests that the marks are formed in two steps, first the solid meniscus shell is lifted by the upward moving mold. This lift causes the formation of two convex surfaces, $a b$ and $b c$ in Figure 1.13. Then, as the mold turns, the two convex surfaces are forged together and the mark is formed. Figure 1.13 shows the conditions for casting with the use of mold slag. The presence of the slag will cause a different pressure [27].
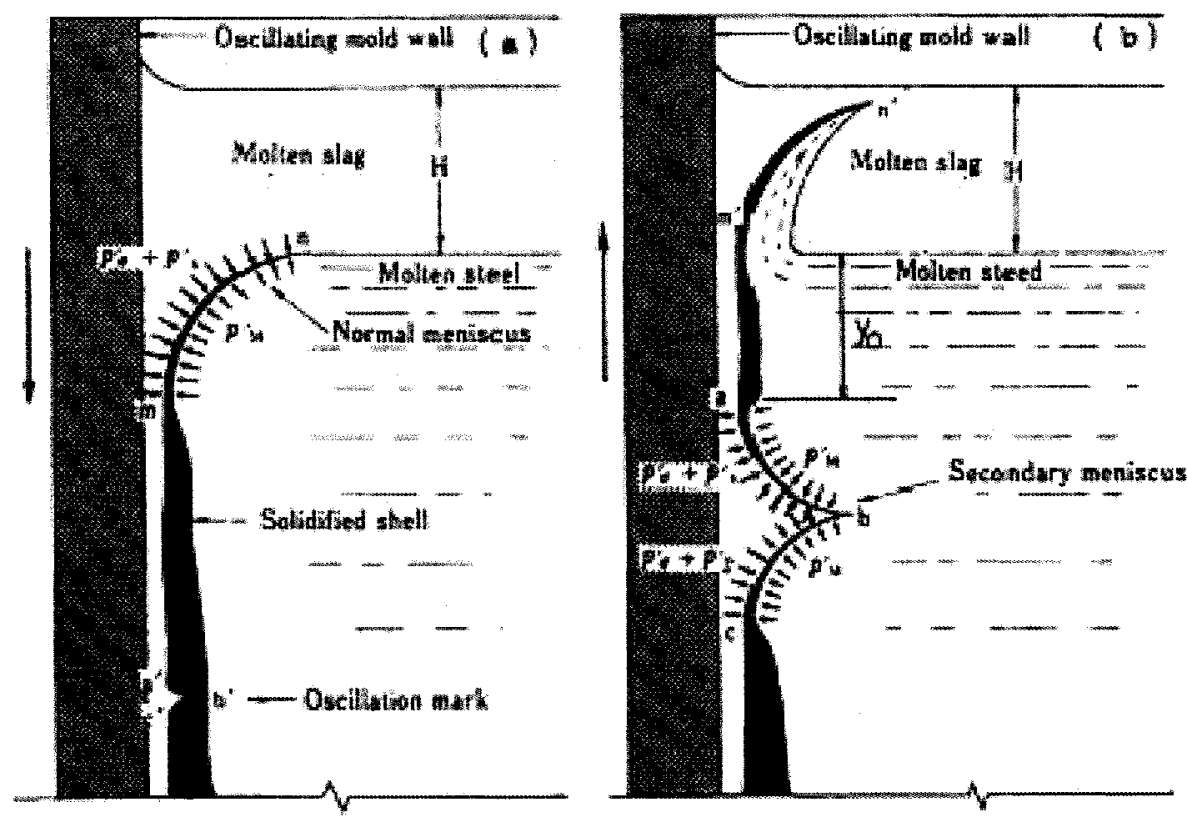

Figure 1.13 The formation of oscillation marks in continuous casting with the use of mold slag. The mark forms during the upstroke. The solid meniscus lifted by the mold movement [27]

Edward S. Szekeres [13] suggested "the secondary meniscus mechanism". According to [13] the oscillation mark forms at a secondary meniscus, not at the primary meniscus. In Figure 1.14 section A demonstrates the state just after the start of the cycle and an element of solid steel is assuming to be adhered to the mold wall and moving 
upward with the mold. The surface of liquid metal between the meniscus shell and downward moving strand shell is a secondary meniscus. There is no tearing at this junction because the meniscus shell is not yet connected to the strand shell. Section B represents the start of negative strip. It is possible that the secondary meniscus freezes over as early as the start of negative strip which establishes a solid bridge between the meniscus shell and the strand shell.

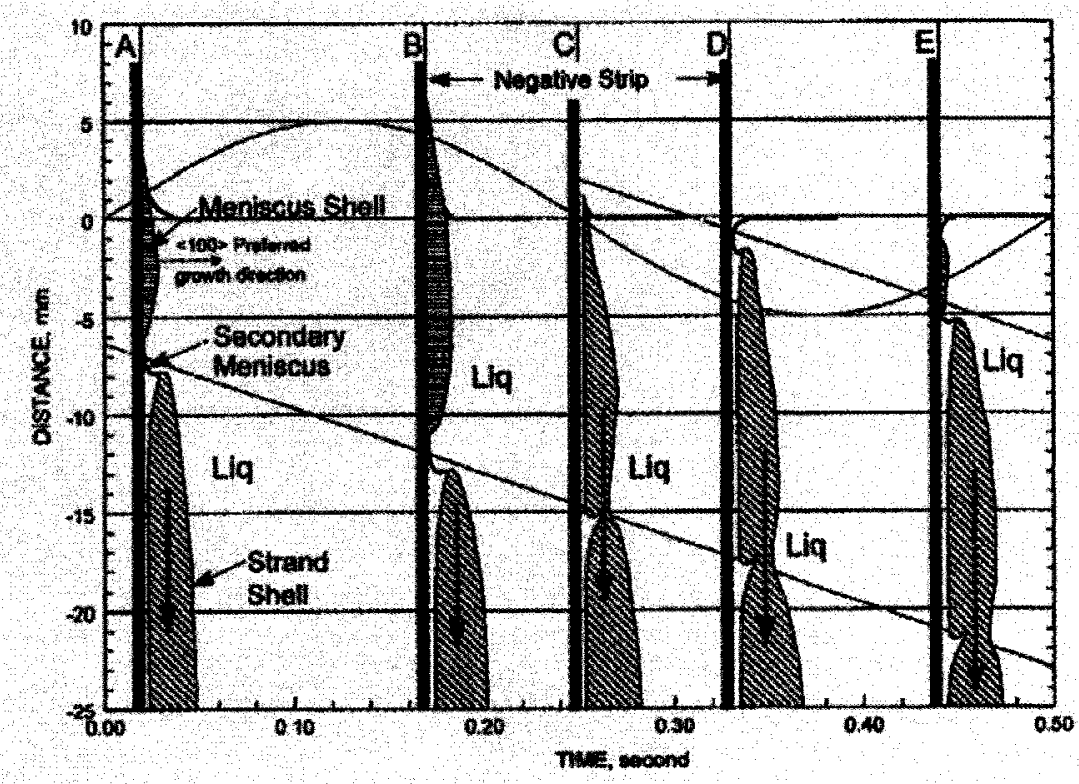

Figure 1.14 Meniscus shell attachment mechanism [13]

As the negative strip condition intensifies, the meniscus shell breaks free from the mold wall. Also the author pointed out that the Savage model included a tearing healing action at the junction between upward - moving solid and the downward - moving strand. Although the tear and heal mechanism was referred to for many years, it has been abandoned because "Metallographic examinations of as-cast surfaces have revealed no evidence of tearing" [13]. 
Information about SM formation in an immovable mold was presented in 1990 [38]. The mechanism of slag film renewal during continuous casting in an immovable mold was suggested. The new research was published in 2002. After experiments with electro magnetic casting (EMC) of steel (Figure 1.15) Joonpyo Park et al. [39] concluded: in ordinary casting, the mold is oscillated to prevent sticking between the mold and the billet. In EMC, the magnetic pressure increased a curvature form in the meniscus, thus

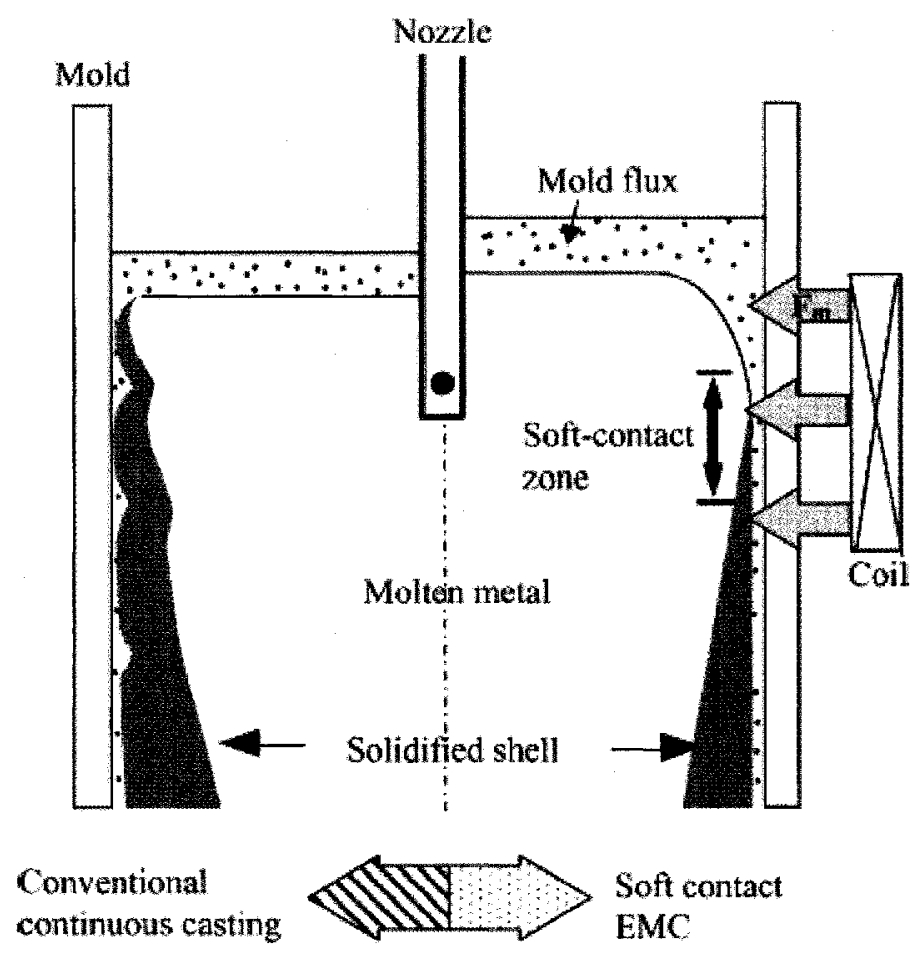

Figure 1.15 The concept of electromagnetic casting of steel [39]

the inflow of the mold flux was improved. Therefore, it was suggested that EMC could be performed without mold oscillation. If the casting can be performed without mold oscillation, the casting plant could be dramatically simplified [39]. 


\subsubsection{Classification of the oscillation marks}

In 1979 Saucedo I, Beech J and Davis G.J. [29] described the different types of the OM (presented in Figures 1.16 - 1.18) and their formation. It is possible to observe that the lap can be covered by liquid overflow (Figure1.16), also it is possible to observe an outward bending of an originally inward-growing shell (Figure 1.17), solid formation outside reciprocation marks, remelting of the reciprocation mark valley and bleeding through (Figure 1.18).

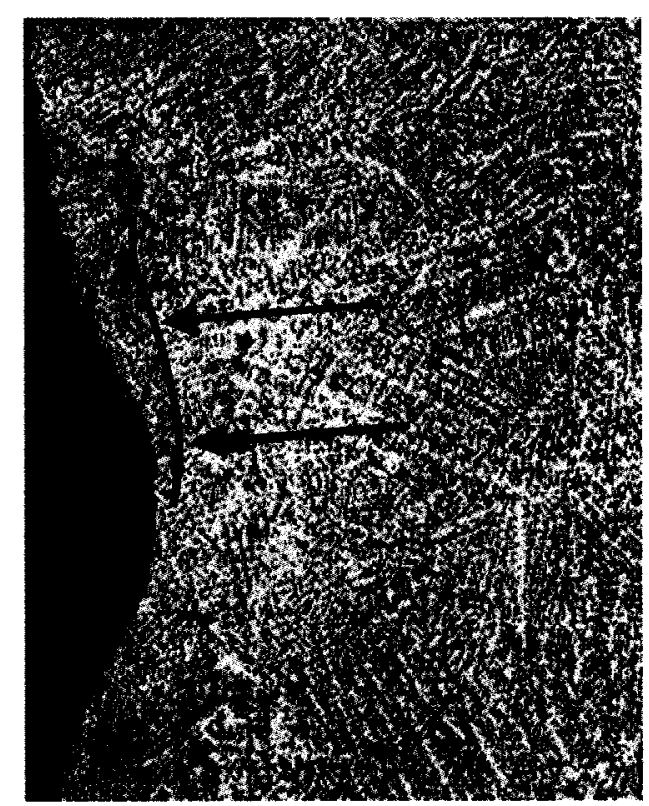

Figure 1.16 Bending of the originally lapped interface, x15 [29] 


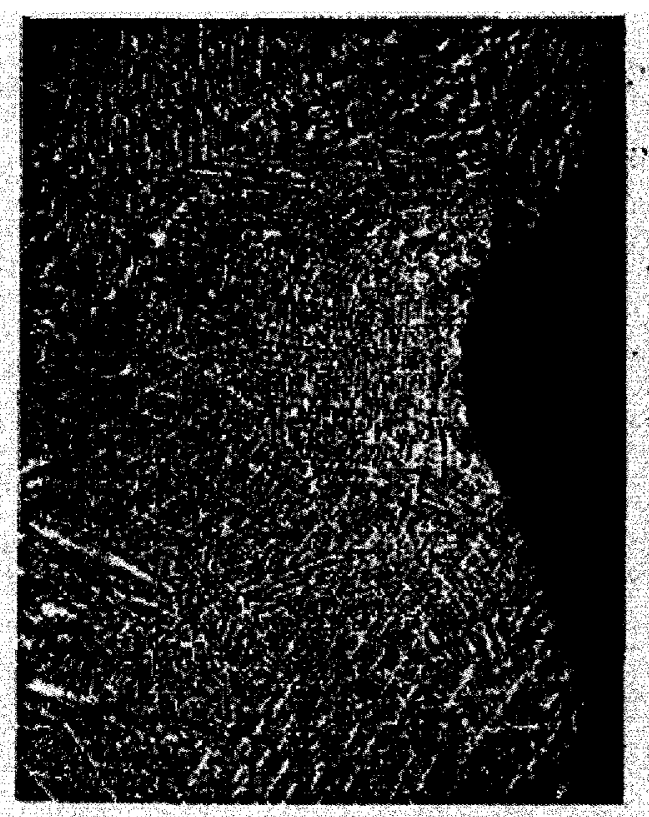

a)

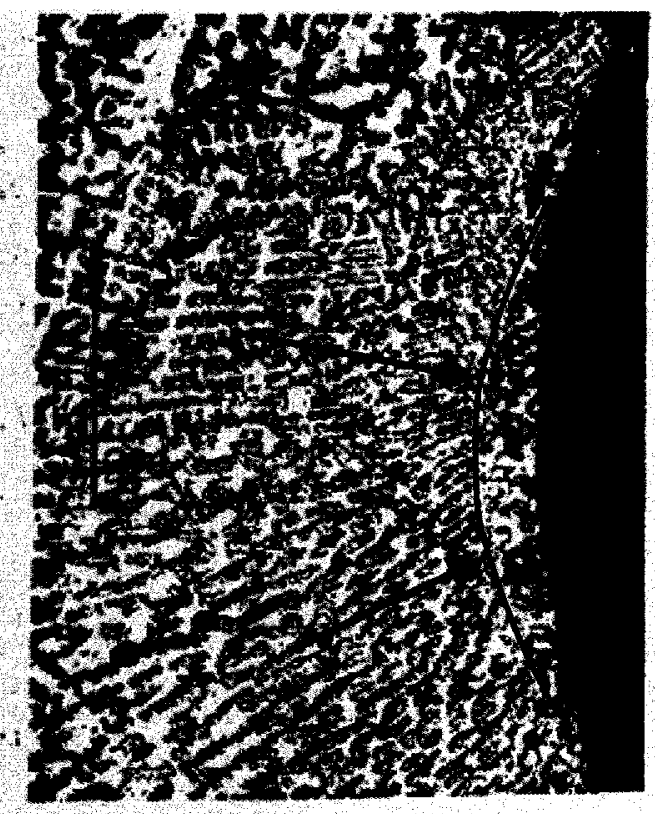

b)

Figure 1.17 a) Reciprocation mark showing strong outward bending of solid shell, $x 24$;

b) Solidification outside the reciprocation mark, x60 [29]
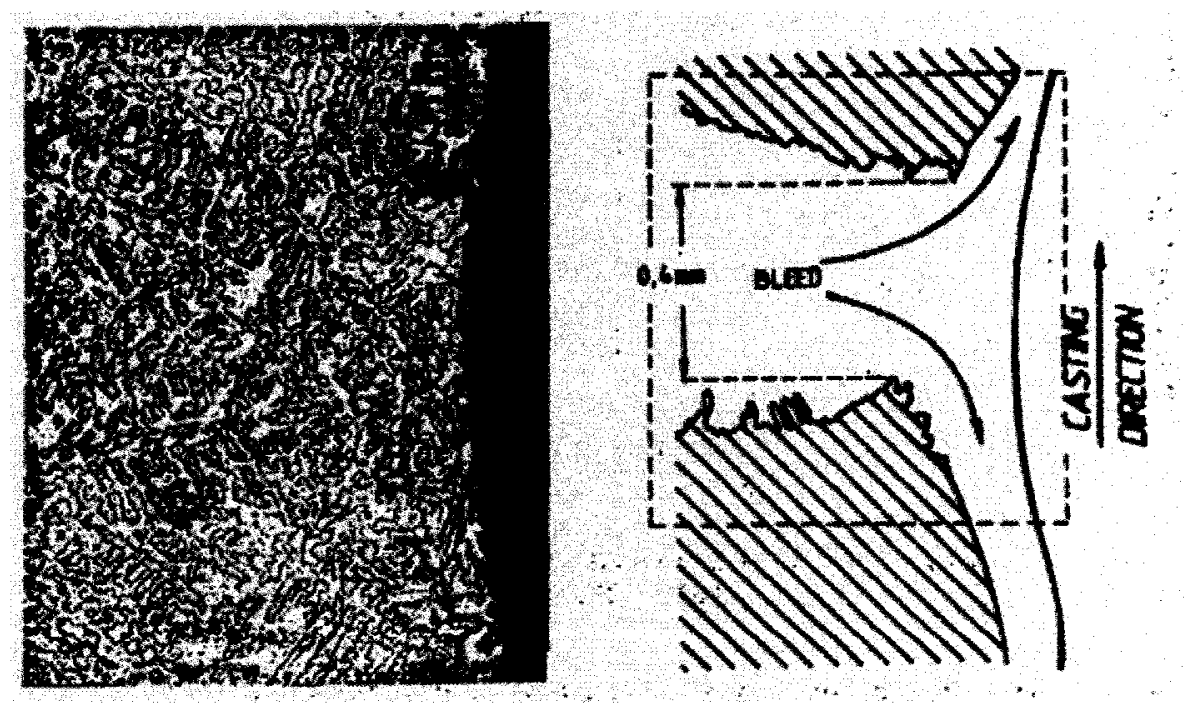

Figure 1.18 Remelting of the reciprocation mark valley and bleeding through, $\mathrm{x} 60$ [29] 
Later, in 1985 Brimacombe J.K. et al. [32] suggested the following classification of OM (Figure 1.19):

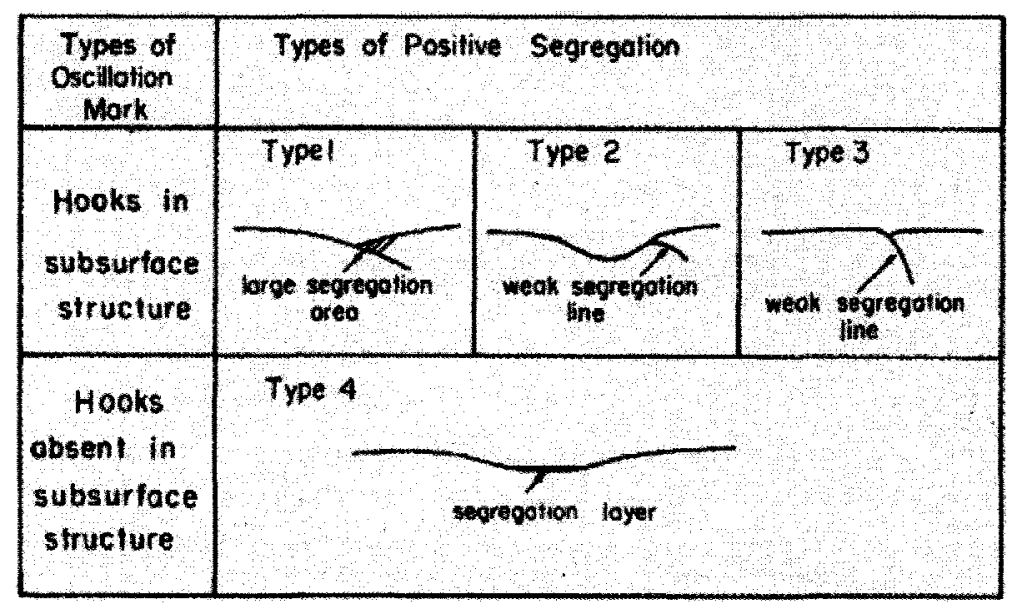

Figure 1.19 Types of oscillation marks [32].

The OM with subsurface hooks were studied by B.G Thomas et al.[37] in details. Hook formation is initiated by meniscus solidification. The instantaneous shape of the meniscus dictates the curvature of the line of hook origin. It has been established that hooks formation usually occur at the beginning of the negative strip period [37] as schematically illustrated in Figure1.20. 

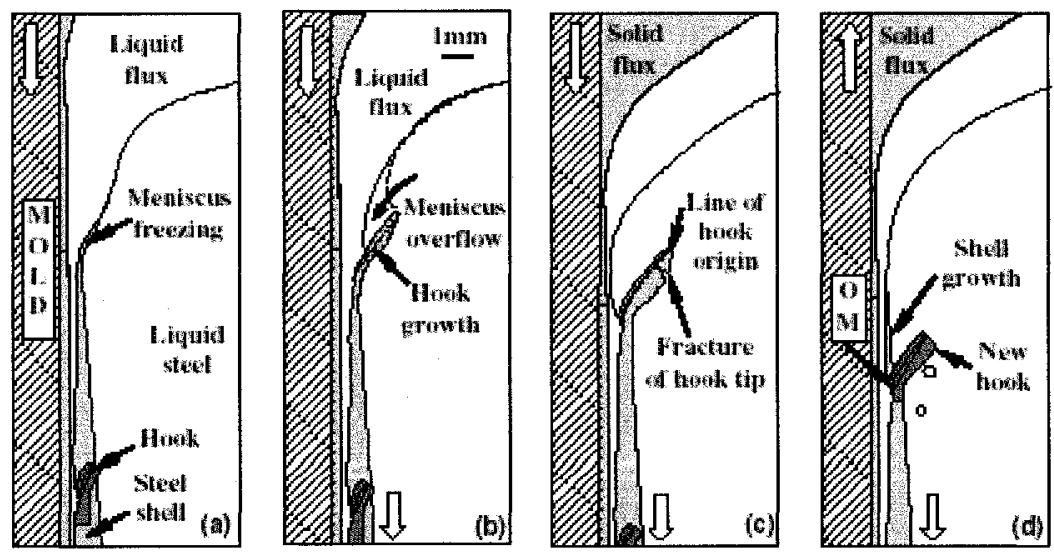

Figure 1.20 Schematics illustrating formation of curved hook in an ultralow -carbon steel slab by meniscus solidification and subsequent liquid steel overflow [37]
a) meniscus freezing;
b) meniscus overflow;
c) line of hook origin;
d) shell growth.

Oscillation marks (OM) are formed by steel shell growth after overflow. The meniscus subsequently overflows the line of hook origin, as shown in Figure 1.20(b). The final shape of the hook is formed as the hook tip fractures and is carried away, as shown in Figure $1.20(\mathrm{c})$. The hook protruding from the solidifying shell captures inclusions and bubbles in the liquid steel until the shell finally solidifies past the hook. These events are illustrated in Figure 1.20(d). 


\subsection{Conclusions. Objectives of the thesis}

As has been demonstrated in the review, the most of the presented OM models have a qualitative character $[13,23,24,25,27,29,30]$, i.e. there is no numerical simulation of the meniscus behavior. Therefore it is difficult to utilize them in specific applications. Usually, such models are based on a particular experimental data (templates with the sections of the billets surface, on which the meniscus was fixed). All these models have lack of completeness. There is no connection of the observed phenomenon to the previous history of process. Most researchers proposed models in which mold oscillation is the major factor determining the OM process [3, 33]. A large number of different models exist because there is no basic model of initial solidification wherein the meniscus is free from additional forces. The objective of this work is to create a mathematical model describing the mechanical behavior of the meniscus and the thermal processes acting upon the meniscus during continuous casting in an immovable mold. 


\section{Qualitative description of the proposed model}

The developed in this thesis model gives a picture of the process of initial shell formation through a description of the mark formation process. The model contains a description of meniscus movement and deformations that are used in calculations of the temperature distribution on meniscus. Behavior of the meniscus was considered during the stationary process of ingot formation. The stationary process means that at the end of a mark formation cycle the next cycle started from the same point that the previous cycle began. In the developed model the mark formation process was divided into two stages, which followed each other successively, thus making a cycle.

\subsection{The first stage of the mark formation}

The scheme of the $1^{\text {st }}$ stage of process is shown in Figure 2.1. This stage begins when the previous cycle comes to an end and solidified shell starts to move downwards relatively to the slag rim. At this moment solidified shell looses contact with the rim. The point on the boundary between the solidified portion of the meniscus and liquid (the top of solid mark) becomes the support for the meniscus of the liquid metal (Figure 2.1). Surface tension force keeps the liquid metal above the solid mark and prevents contact with solid slag on the mold wall. The meniscus stretches and moves in accordance with the balance of surface tension forces and gravity. The meniscus growth arises from two processes: the meniscus moving as a whole and the meniscus stretching. The initial condition of the $1^{\text {st }}$ stage is shown in Figure 2.1(a). The top of the solid mark started moving downwards with the billet (Figure 2.1 (b). The curved liquid meniscus (CLM) 
expanded between two points: the first point is the top of the solid mark (T) and the second point is point of junction ( $\mathrm{J}$ ) between the curved meniscus and the flat portion of surface of liquid metal in the mold. The CLM started stretching and moving. The gap between the meniscus and rim increases and liquid slag flows into the gap (Figure 2.1 (b). When the top of the solid mark moved, the meniscus height increased. Under the action of the ferrostatic pressure, growing meniscus is pressed to join the slag rim again. In addition, liquid slag is forced to move out from the gap (Figure 2.1 (c). Thus, at the first stage, the billet grows due to the meniscus height increasing and overflow of the liquid metal over the solid mark. The first stage is divided into two phases.

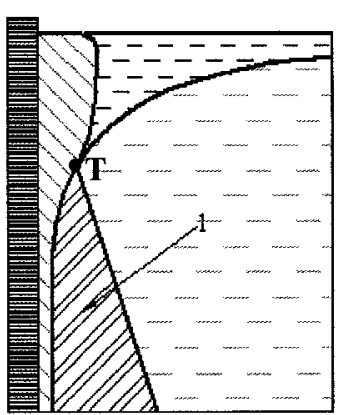

a)

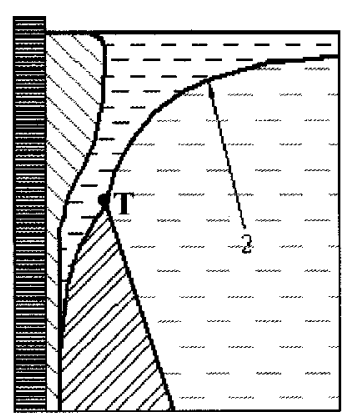

b)

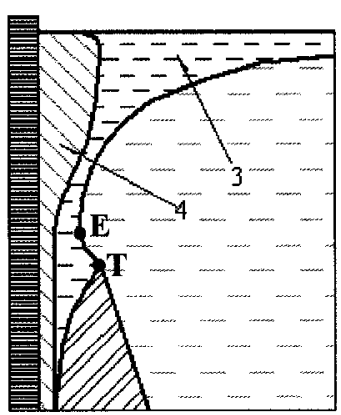

c)

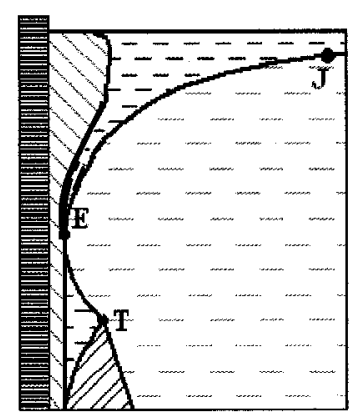

d)

Figure 2.1 The scheme of the $1^{\text {st }}$ stage mark formation process

1- solid mark; 2 - meniscus; 3 - liquid slag; 4 - slag rim

The first one - when the meniscus moves from the slag rim, as shown in Figure 2.1(a-b) and second one when meniscus moves to the slag rim as show in Figure 2.1(c-d). When the meniscus contacted the slag rim the upper part of the meniscus stops. The contact of liquid metal and solid slag (Figure 2.1 (d)) leads to splitting of the meniscus into upper 
and lover parts. We called this moment the sticking of meniscus and this is the end of stage 1 . The lower meniscus still continues to follow the movement of the solid mark.

At the first stage we assume that up to the moment when meniscus stops at the mold wall it has not been solidified: less heat escapes the meniscus than accrues to it. This happens because new portions of superheated liquid metal are being added to the external surface of meniscus.

\subsection{The second stage of mark formation}

The second stage begins when the meniscus touched the mold wall and two menisci formed: upper and lower. The lower meniscus continues to follow the movement of the solid mark. After the meniscus had made contact with solid slag, part of the liquid slag becomes closed (under the point E, see Figure 2.1 (d). From this moment liquid slag cannot move upward on the liquid metal surface in the mold from the gap.

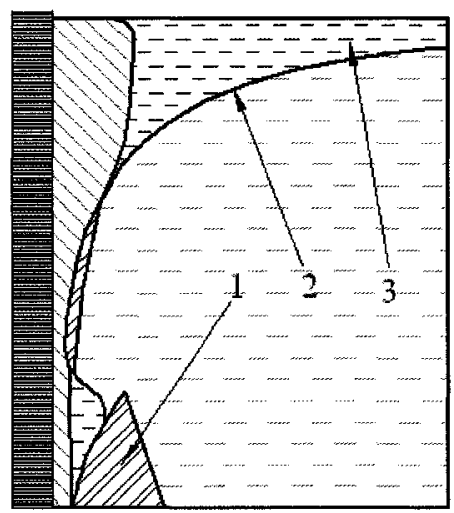

a)

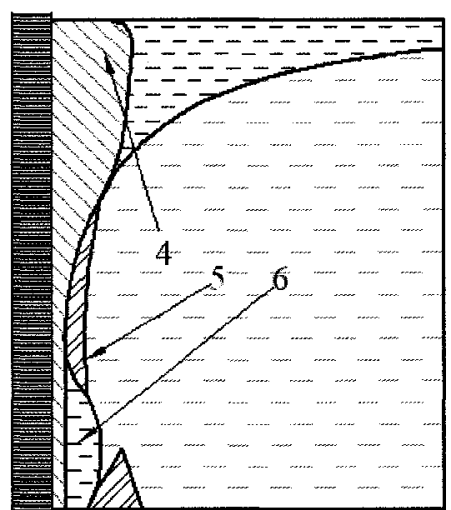

b)

Figure 2.2 "Lower" meniscus transformation

1 - solid mark; 2 - meniscus of the liquid metal; 3 - liquid slag;

4 - slag rim; 5 - solid part of meniscus; 6 - closed slag. 
The slag closing inside liquid metal leads to a changing of the forces which had provided a balanced interaction on the lower meniscus at the second stage. Thus, at the moment of slag closing the meniscus changes its shape very rapidly i.e. there is a transition from the form shown in Figure 2.1 (d), to that shown in Figure 2.2 (a). The lower meniscus becomes convex on the side of liquid metal. The top of the solid mark continues to move, therefore the ferrostatic pressure acting on the lower meniscus increases. The lower meniscus moves and deforms as a result of the increasing force. The process of the lower meniscus transformation is shown in Figure $2.2(a, b)$. The bottom support point of the lower meniscus moves along the solid mark. The upper support point of lower meniscus moves down and its position is defined by the solidification and deformation processes. As the solid mark moved downwards the lower meniscus leaned on it, and following the solid mark became extended. As a result, fresh portions of liquid metal contact the external surface of the lower meniscus thereby adding superheat. If during the movement of the lower meniscus the heat extraction rate does not exceed the rate of the heat supply via fresh portions of liquid metal, the casting process became unstable. The liquid core is poured out under the mold through the non-solidified lower meniscus. On the contrary, if the level of heat withdrawal from the lower meniscus exceeds the level of incoming additional superheat then the gap between the sticking upper meniscus and solid mark solidifies. In the thesis we considered only the first stage of surface mark formation. To 
describe the evolution of upper meniscus shape and its heat state we need to develop the mechanical and thermal models of the meniscus state. Based on the model of meniscus mechanical behavior (Chapter 3), the model of its thermal condition will be discussed in Chapter 4. 


\section{Mechanical model of the first stage}

The mechanical model is formulated based on the equilibrium existing at the surface of meniscus between surface tension forces and the pressure of the liquid metal and slag (Figure 3.1).

\subsection{Basic assumptions. Forces acting on meniscus}

Meniscus is considered to be an interphase film. The coefficient of interphase tension assumed to be constant along meniscus length. To evaluate the mechanical state of meniscus we consider the unit width element of the meniscus along the ingot axis.

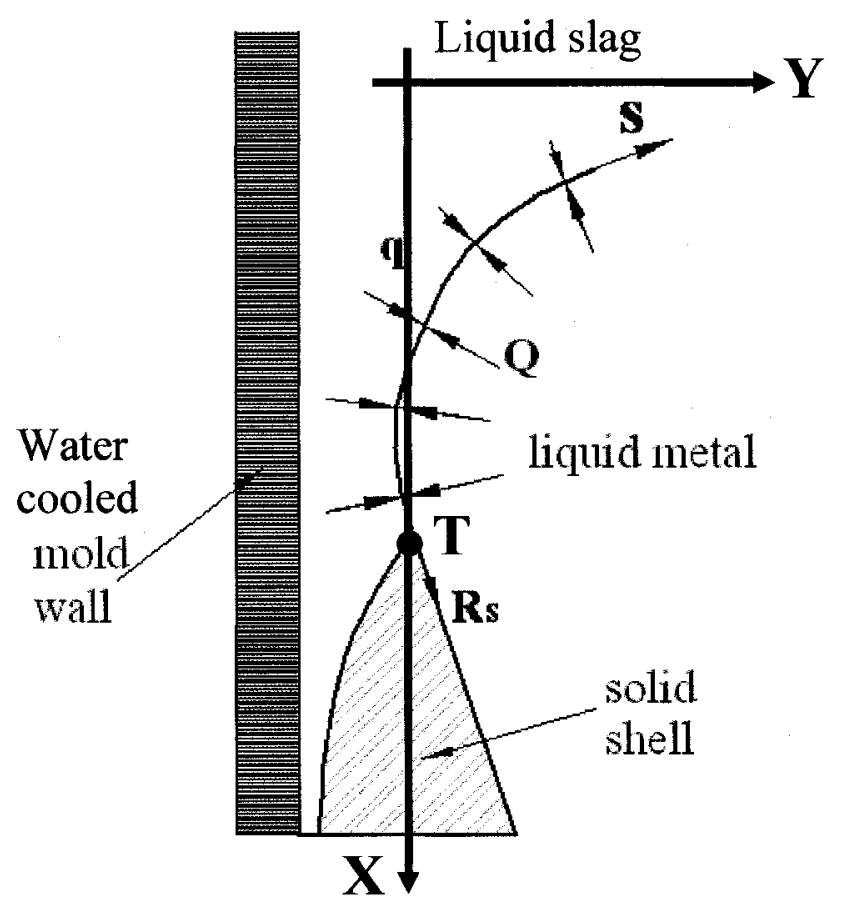

Figure 3.1 Forces acting on the meniscus

$S, R_{S}, Q, q$ - forces acting on meniscus. 
The forces, which act on this element from the remaining part of the meniscus, perpendicular to the plane of the drawing direction are neglected and only the forces, which act in the plane of drawing (Figure 3.1), are discussed, hence a 2-dimensional problem is considered. We assume, that the top of the solidified mark (point T) moves along an axis $X$ (Figure 3.1), without changing coordinate $Y$.

Such an assumption is equivalent to the assumption that within the limits of the mark formation cycle neither solidification, nor a melting at the top of the solid mark occur.

To derive a mathematical model describing the mechanical behavior of the liquid metal meniscus, we examine the equilibrium of the forces acting on an infinitely small section of meniscus (Figure 3.2).

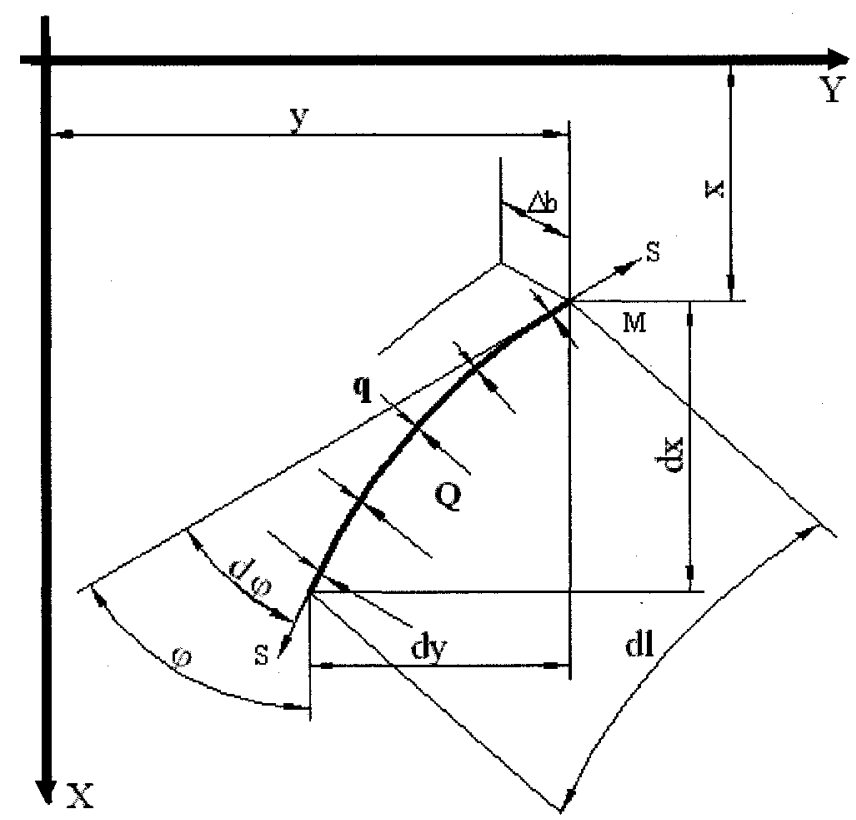

Figure 3.2 Diagram of the forces acting on an infinitesimally small section of the meniscus

$\Delta b$ - unit width of the considered section of meniscus in the direction, 
perpendicular to the plane of drawing;

$\varphi$ - angle between tangent to the meniscus and axis X;

$d l$ - length of the infinitesimally small section of meniscus;

$S$ - longitudinal force - is always directed tangential to the surface of the

considered

section; at any point of meniscus always has one and the same value (the surface tension force);

$d \varphi, d x, d y-$ increments of the appropriate values.

$Q$ - the pressure of liquid metal (distributed load), acts from the side of liquid metal;

$q$ - the pressure of liquid slag (distributed load), acts from the side of liquid slag.

Within the limits of an infinitesimally small section of meniscus with the length $d l$ we neglect the changes of $Q$ and $q$.

\subsection{Differential equation of equilibrium and its solution in parametrical form}

Distributed loads $Q$ and $q$ can be presented by the resultant forces

$R_{Q}=Q \cdot d l \cdot \Delta b$ and $R_{q}=q \cdot d l \cdot \Delta b . R_{Q}$ and $R_{\mathbf{q}}$ are applied in the middle of the infinitesimally section of meniscus. The forces of interphase tension are equal to $S=\sigma \cdot \Delta b$ where $\sigma$ - the coefficient of interface tension between liquid metal and liquid slag. Equation of equilibrium forces (sum of the forces projections on the direction of the resultants of distributed forces): 
$2 S \cdot \sin \frac{d \varphi}{2}-(Q-q) \cdot \Delta b \cdot d l=0$

To simplify this expression we use

$S=\sigma \cdot \Delta b$ and $\Delta b=1$

For small $d \varphi, \sin d \varphi \approx d \varphi$, we have:

$$
(Q-q)-\sigma \cdot \frac{d \varphi}{d l}=0 \text {. }
$$

Here $(Q-q)$ is a function of meniscus height $x: Q(x)=\rho_{m} \cdot g \cdot x ; q(x)=\rho_{s l} \cdot g \cdot x$.

Finally differential equation of the force balance looks like:

$$
\left(\rho_{m}-\rho_{s l}\right) \cdot g \cdot x-\sigma \cdot \frac{d \varphi}{d l}=0,
$$

where $g$ - the gravity acceleration;

$\rho_{m}$ - the density of liquid metal;

$\rho_{s l}$ - the density of fluid slag.

At a certain point on the meniscus with the coordinates $(x, y)$ the projection of elementary section $d l$ on axis $X$ is equal to $d x=d l \cdot \cos \varphi$, where $\varphi$ - angle of tangent inclination to the meniscus at point on the meniscus with coordinates $(x, y)$.

The curvature of the considered section is determined by the known expression:

$$
\begin{aligned}
& \frac{1}{R}=\frac{d \varphi}{d l}=\frac{\frac{d \varphi}{d x}}{\frac{d l}{d x}} \\
& R \text {-radius of curvature; }
\end{aligned}
$$


from which after the transformation follows:

$$
\frac{d \varphi}{d l}=\cos \varphi \cdot \frac{d \varphi}{d x}
$$

then equation (3.1) becomes:

$$
\left(\rho_{m}-\rho_{s l}\right) \cdot g \cdot x \cdot d x-\sigma \cdot \cos \varphi \cdot d \varphi=0
$$

To simplify we introduce the variable: $B=\frac{\left(\rho_{m}-\rho_{s l}\right) \cdot g}{2 \cdot \sigma}$.

Integrating (3.3) over the meniscus height $x_{h}$

$$
\int_{0}^{x_{h}} 2 B \cdot x \cdot d x-\int_{\theta_{0}}^{\varphi_{h}} \cos \varphi \cdot d \varphi=0 ;
$$

$$
\text { we get: } \quad B \cdot x_{h}^{2}=\left(\sin \varphi_{h}-\sin \theta_{0}\right),
$$

where $\theta_{0}$ - initial angle at the point $\mathrm{J}$ (paragraph 2.1) where $x=0$ (see Figure 3.3).

\subsection{Meniscus line equation and it solution in Cartesian coordinate system}

Notations for the description of the meniscus line are shown in Figure 3.3. An axis $Y$ is directed along the flat portion of molten metal surface. An increase in the $y$ values occurred to the right side from the beginning of coordinates. 


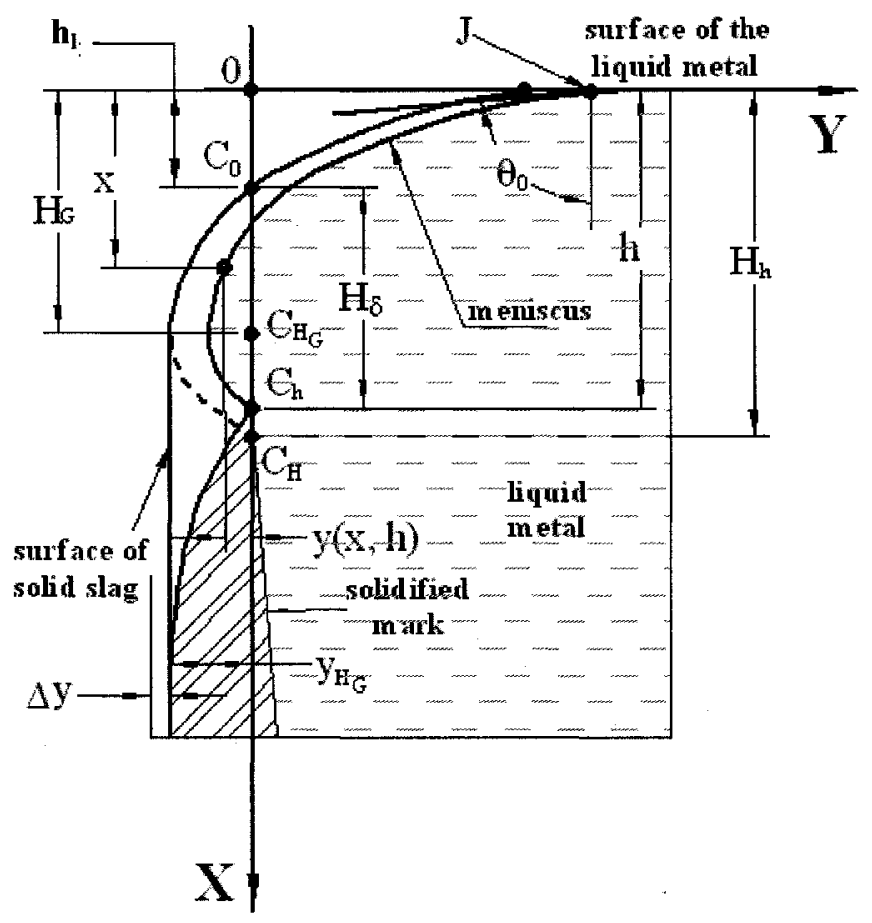

Figure 3.3 Notations used in mechanical model

The axis $X$ is parallel to the strand's axis and crosses the top of the solidified mark (point $C_{0}$ - point where the new cycle of the mark formation begins), directed downward.

$C_{H_{G}}$ - the point corresponds to an extremum on the meniscus line;

$C_{h}$ - a certain point on the meniscus at a distance $h$ from the beginning of coordinates; $C_{H}$ - the top of solidified mark in the end of the first stage (height of the meniscus = $\max )$;

$h$ - the current height of meniscus $\delta x \leq h \leq H_{\max }$, which corresponds to the displacement of the mark top $C_{0}$ on the distance $h_{c}$; $H_{\delta}$ - displacement of the top of solid mark; $H_{h}$ - limiting height of meniscus for concrete conditions; 
$h_{l}$ - the height of the not solidifying part of the meniscus (initial section of meniscus);

$H_{G}$ - distance from the beginning of coordinates (along the axis $X$ ) to

the point of extremum on the meniscus $C_{H_{G}}$;

$x$ - coordinate of the current point on meniscus;

$y(x, h)$ - coordinate of the current point on meniscus;

$y_{H_{G}}$ - coordinate of point $H_{G}$;

$\Delta y$ - the thickness of solid slag on the mold wall (out of the slag rim zone);

$\theta_{0}$ - initial angle; theoretically this angle should be constant and equal to $-\pi / 2$, but in reality the surface of the liquid metal in the mold is not absolutely plane surface (liquid metal continuously moving) therefore we assume $\theta_{0}$ is one of the fitting parameters close to $-\pi / 2$;

$\mathrm{J}$ - junction point (Paragraph 2.1).

The solution of the equation (3.4) we present as function $y=f(x)$.

From Figure $3.2 \frac{d y}{d x}=\tan \varphi=\frac{\sin \varphi}{\cos \varphi}$

substituting from equation (3.4):

$$
\frac{d y}{d x}=\frac{\sin \varphi}{\cos \varphi}=\frac{B \cdot x^{2}+\sin \theta_{0}}{\sqrt{1-\left(B \cdot x^{2}+\sin \theta_{0}\right)^{2}}}
$$

then

$$
d y=\frac{\left(B \cdot x^{2}+\sin \theta_{0}\right)}{\sqrt{1-\left(B \cdot x^{2}+\sin \theta_{0}\right)^{2}}} \cdot d x
$$


or in integral form:

$$
y(x)=y\left(x_{0}\right)+\int_{x_{0}}^{x} \frac{\left(B \cdot x^{2}+\sin \theta_{0}\right)}{\sqrt{1-\left(B \cdot x^{2}+\sin \theta_{0}\right)^{2}}} \cdot d x
$$

\subsection{Basic parameters of the meniscus}

\section{Maximum height of the meniscus}

The maximum height of meniscus can be found from equation (3.4):

$$
x=\sqrt{\frac{\sin \varphi-\sin \theta_{0}}{B}} .
$$

The height of meniscus is maximal if the residual $\left(\sin \varphi-\sin \theta_{0}\right)$ is maximal. In this case $\left(\sin \varphi-\sin \theta_{0}\right)_{\max }=2$ when $\varphi=\pi / 2, \theta_{0}=-\pi / 2$

Substituting these values and expression for $B$ in equation (3.4):

$$
\frac{\left(\rho_{m}-\rho_{\mathrm{sh}}\right) \cdot g \cdot H_{\max }^{2}}{2}=2
$$

From last equation we get:

$$
H_{\max }=\sqrt{\frac{4 \cdot \sigma}{\left(\rho_{m}-\rho_{s l}\right) \cdot g}}=\sqrt{\frac{2}{B}} .
$$

Substituting the numerical values of the parameters:

$\rho_{m}=7200 \mathrm{~kg} / \mathrm{M}^{3} ; \rho_{s l}=2667,3 \mathrm{~kg} / \mathcal{M}^{3} ; g=9,81 \mathrm{M} / \mathrm{s}^{2} ; \sigma=1,2058 \mathrm{H} / \mathrm{M}$,

We obtain the following: 


$$
H_{\max }=\sqrt{\frac{4 \cdot 1,2058}{(7200-2667,3) \cdot 9,81}}=10.42 \mathrm{~mm}
$$

We assumed that the height of the studied meniscus is less than the maximum possible (in this case the random fluctuations will not lead to the destruction of the meniscus). In the further descriptions we accept the height of the meniscus $H_{h}=0.985 \cdot H_{\max }$.

\section{Points of the extremum on the line of meniscus}

The position of the extremum of function $y(x)$ can be found from condition:

$$
\frac{d y}{d x}=\frac{\left(B \cdot x^{2}+\sin \theta_{0}\right)}{\sqrt{1-\left(B \cdot x^{2}+\sin \theta_{0}\right)^{2}}}=0,
$$

therefore $\quad d y=\left(B \cdot x^{2}+\sin \theta_{0}\right)=0$,

the position of the extremum point is:

$$
x=H_{G}=\sqrt{\frac{-\sin \theta_{0}}{B}} .
$$

After substitution $\theta_{0}=-\pi / 2$, and finally we obtain $H_{G}=\sqrt{\frac{1}{B}}$.

The $J$-point coordinates at the maximum height of the meniscus

The coordinate $y\left(x_{0}\right)$ of the junction point $\mathrm{J}$, (Figure 3.3) can be found from equation (3.9):

$$
y(x)=y\left(x_{0}\right)+\int_{x_{0}}^{x} \frac{\left(B \cdot x^{2}+\sin \theta_{0}\right)}{\sqrt{1-\left(B \cdot x^{2}+\sin \theta_{0}\right)^{2}}} \cdot d x .
$$


Substituting $x_{0}=0, x=H_{\max }$ and the point on meniscus with coordinate $x=H_{\max }$ has the coordinate $y\left(H_{\max }\right)=0$ :

$$
y\left(H_{\max }\right)=y(0)+\int_{0}^{H_{\max }} \frac{\left(B \cdot x^{2}+\sin \theta_{0}\right)}{\sqrt{1-\left(B \cdot x^{2}+\sin \theta_{0}\right)^{2}}} \cdot d x=0
$$

then

$$
y(0)=-\int_{0}^{H_{\max }} \frac{\left(B \cdot x^{2}+\sin \theta_{0}\right)}{\sqrt{1-\left(B \cdot x^{2}+\sin \theta_{0}\right)^{2}}} \cdot d x
$$

\section{The height of the initial section of the meniscus}

The initial section of meniscus is a part of the meniscus (higher than point $C_{0}$ ), which does not solidify during the period of mark formation. At the beginning of the new cycle and at the end of the stage 1 , the $y\left(h_{l}\right)$ is equal to 0 .

From (3.9)

$$
y\left(h_{l}\right)=y\left(x_{0}\right)+\int_{x_{0}}^{h_{l}} \frac{\left(B \cdot x^{2}+\sin \theta_{0}\right)}{\sqrt{1-\left(B \cdot x^{2}+\sin \theta_{0}\right)^{2}}} \cdot d x=0
$$

From (3.11) $y\left(x_{0}\right)=y(0)=-\int_{0}^{H_{\max }} \frac{\left(B \cdot x^{2}+\sin \theta_{0}\right)}{\sqrt{1-\left(B \cdot x^{2}+\sin \theta_{0}\right)^{2}}} \cdot d x$, then

$$
\int_{x_{0}}^{h_{l}} \frac{\left(B \cdot x^{2}+\sin \theta_{0}\right)}{\sqrt{1-\left(B \cdot x^{2}+\sin \theta_{0}\right)^{2}}} \cdot d x=\int_{x_{0}}^{H_{\max }} \frac{\left(B \cdot x^{2}+\sin \theta_{0}\right)}{\sqrt{1-\left(B \cdot x^{2}+\sin \theta_{0}\right)^{2}}} \cdot d x
$$


This equation 3.12 is implicit relatively to $h_{l}$ and solved by the numerical methods, where $y(0)$ can be found from (3.11).

\section{Parametric equation for the meniscus line}

It is important to note that dependence (3.9) has two parameters, i.e. in addition to the determination of the coordinate of the observation point $x$, the value of the meniscus height $h$ at the given moment of time is required (equation 3.11, Figure 3.4).

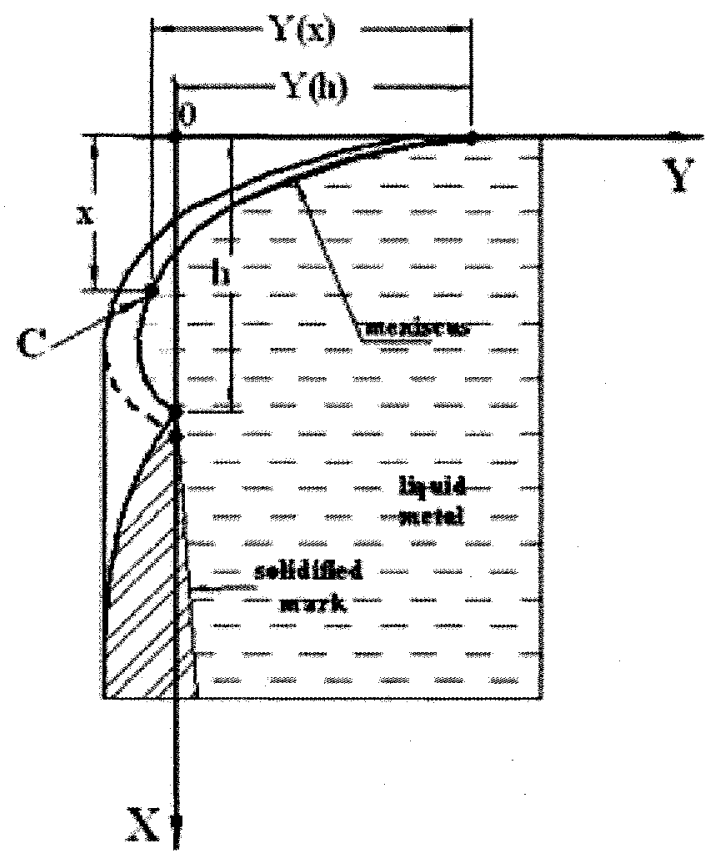

Figure 3. 4 Parameters of the equation of meniscus line

For the considered point $C$ the dependence (3.9) can be presented as two-parametrical:

$$
y(x, h)=y(C)=-Y(h)+Y(x),
$$

where $Y(h)$ - depends only on the height of the meniscus at considered moment in time 
as:

$$
Y(h)=\int_{0}^{h} \frac{\left(B \cdot x^{2}+\sin \theta_{0}\right)}{\sqrt{1-\left(B \cdot x^{2}+\sin \theta_{0}\right)^{2}}} \cdot d x
$$

Function $Y(x)$ depends only on coordinate $x$ of the point of observation:

$$
Y(x)=\int_{0}^{x} \frac{\left(B \cdot x^{2}+\sin \theta_{0}\right)}{\sqrt{1-\left(B \cdot x^{2}+\sin \theta_{0}\right)^{2}}} \cdot d x
$$

The depth of the mark (3.13):

$$
\begin{aligned}
& \Delta Y=y\left(h_{l}, H_{h}\right)-y\left(H_{G}, H_{h}\right)=-Y\left(H_{h}\right)+Y\left(h_{l}\right)-\left[-Y\left(H_{h}\right)+Y\left(H_{G}\right)\right]= \\
& =Y\left(h_{l}\right)-Y\left(H_{G}\right)
\end{aligned}
$$

where $Y\left(h_{l}\right)$ and $Y\left(H_{G}\right)$ we determine from formula (3.15).

\section{The equation of the slag line}

Solid slag on the mold wall has two regions:

1.The slag rim (in the interval $H_{G}>x>0$ ), i.e. coordinates of points on this section can be described by functional dependence on coordinate $x$;

2. The solid slag with a constant thickness located under the slag rim (in the interval $\left.x>H_{G}\right)$.

Curve of the slag rim in the rim limits $\left(H_{G}>x>0\right)$ can be described by (3.9) when $h=H_{h}$ In parametric form the equations of the slag rim:

$$
y_{s l}\left(x, H_{h}\right)=-Y\left(H_{h}\right)+Y(x) ; \quad\left(H_{G}>x>0\right)
$$


for $x>H_{G}, \quad y_{s l}\left(x, H_{h}\right)=$ const .

The generalized description of the solid slag line $y_{s l}(x)$, which includes rim and solid slag with a constant thickness, can be done by symbols of Boolean algebra:

or

$$
\begin{gathered}
y_{s l}\left(x, H_{h}\right)=y_{s l}\left(x, H_{h}\right) \cap\left(H_{G}>x>0\right)+y\left(H_{G}, H_{h}\right) \cap\left(x>H_{G}\right), \\
y_{s l}\left(x, H_{h}\right)=\left[-Y\left(H_{h}\right)+Y(x)\right] \cap\left(H_{G}>x>0\right)+ \\
+\left[-Y\left(H_{h}\right)+Y\left(H_{G}\right)\right] \cap\left(x \geq H_{G}\right)
\end{gathered}
$$

where $Y\left(H_{h}\right), Y\left(H_{G}\right), Y(x)$ can be found from formula (3.14) and (3.15) and the sign $\bigcap$ indicates the union of sets - domain of existence of the functions values that simultaneously stand to the left and to the right of sign.

\section{The solid slag thickness}

Outside of the slag rim we assume the solid slag thickness is constant and equals to $\Delta y$. In the slag rim zone the thickness of the rim is added to the thickness of the solid slag. The slag rim thickness depends on the coordinate $x$ and $h$ as:

$$
\begin{aligned}
& \Delta h_{s l}(x, h)=\Delta y+y_{s l}\left(H_{G}, H_{h}\right)-y_{s l}\left(x, H_{h}\right)= \\
& =\Delta y+\left[-Y\left(H_{h}\right)+Y\left(H_{G}\right)\right]-\left[-Y\left(H_{h}\right)+Y(x)\right]= \\
& =\Delta y+Y\left(H_{G}\right)-Y(x)
\end{aligned}
$$

where $H_{G}>x>0$;

$\Delta h_{s l}(x, h)$ - slag rim thickness;

$\Delta y$ - solid slag thickness on the mold wall (below slag rim) $\Delta y=$ const ;

$Y\left(H_{G}\right), Y(x)$ - is defined by equation (3.14) and (3.15). 


\section{Thickness of the liquid slag layer}

Thickness of the liquid layer between the meniscus and solid slag on the mold wall is the distance along an axis $Y$ between points on the solid slag and on the meniscus at constant $x$. To find this we use the equation (3.17) and (3.13). Thickness of the liquid layer between the meniscus and the solid slag and rim $\Delta h_{s l-f}$ can be expressed in the parametrical form as:

$$
\begin{aligned}
& \Delta h_{s l-f}=y(x, h)-y_{s l}\left(x, H_{h}\right)=Y(x)-Y(h)- \\
& -\left[\left(Y(x)-Y\left(H_{h}\right)\right) \cap\left(H_{G}>x>0\right)+\left(Y\left(H_{G}\right)-Y\left(H_{h}\right)\right) \cap\left(x \geq H_{G}\right)\right]= \\
& =\left[Y\left(H_{h}\right)-Y(h)\right] \cap\left(H_{G}>x>0\right)+ \\
& +\left[Y(x)-Y(h)+Y\left(H_{h}\right)-Y\left(H_{G}\right)\right] \cap\left(x \geq H_{G}\right)
\end{aligned}
$$

where $h$ - current height of meniscus;

$H_{h}$ - limiting height of meniscus for given conditions;

It can be noted that in the section of meniscus $\left(H_{G}>x>0\right)$, the $\Delta h_{s l-f}$ does not depend on $x$, but it depends only on the height of the meniscus $h$.

\section{The length of the meniscus}

The length of the meniscus is required for a description of the meniscus' thermal condition during moving and lengthening. The length of the line from a reference point $x_{0}$ up to some point $C_{x}$ is determined by the formula:

$$
L=\int_{0}^{x} \sqrt{1+\left(\frac{d y}{d x}\right)^{2}} \cdot d x,
$$


where $x_{0}$ and $x$ - the beginning and the end of the studying part of curve $y=f(x)$ accordingly.

After the substitution the value of derivative $\frac{d y}{d x}$ defined by (3.8) for $x_{0}=0 ; x=h$ we obtain:

$$
L_{C}=\int_{0}^{x} \sqrt{1+\left(\frac{\left(B \cdot x^{2}+\sin \theta_{0}\right)}{\sqrt{1-\left(B \cdot x^{2}+\sin \theta_{0}\right)^{2}}}\right)^{2}} \cdot d x
$$

Or for the meniscus with height h:

$$
L_{C}=\int_{0}^{h} \sqrt{1+\left(\frac{\left(B \cdot x^{2}+\sin \theta_{0}\right)}{\sqrt{1-\left(B \cdot x^{2}+\sin \theta_{0}\right)^{2}}}\right)^{2}} \cdot d x
$$

\subsection{Numerical simulation of the mechanical model at the}

\section{first stage}

The solution of differential equation (3.9) was done with the help of the mathematical package "MathCAD". For the best illustration of the meniscus displacements, the result of calculations has been represented as graphs. These graphs determined the form and position of solid slag, and also the end and intermediate positions of meniscus.

\section{The physical values for calculation}

The basic physical characteristics of the considered materials: 
Density of the liquid metal

Density of the liquid slag

Coefficient of the surface tension
$7500 \mathrm{~kg} / \mathrm{m}^{3}$

$2500 \mathrm{~kg} / \mathrm{m}^{3}$

$0.2 \mathrm{~kg} / \mathrm{m}^{2}$

We assumed that the metal remains liquid and neglected dependence of their basic physical properties on temperature. Furthermore, we assumed that the height of the studied meniscus is less than the maximum possible (in this case the random fluctuations will not lead to the destruction of the meniscus). In the further descriptions we accept the height of the meniscus $H_{h}=0.985 \cdot H_{\max }$.

\section{Influence of the basic parameters on the form and dimensions of the mark.}

The results of the calculations are shown in figures $3.4(\mathrm{a}-\mathrm{h})$, where solid slag is marked by green line. Dotted blue line is the $x$ coordinate of the point of extremum. The meniscus and solidified mark are blue. The top of solidified mark is located on an axis $X(y=0)$.

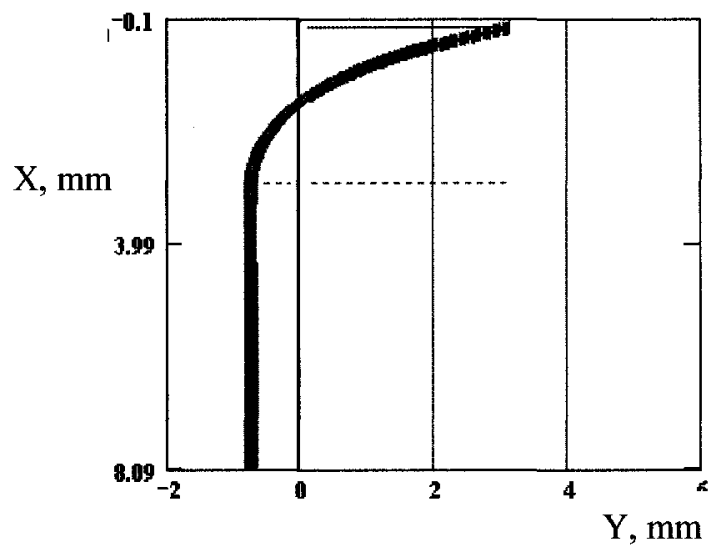

a)

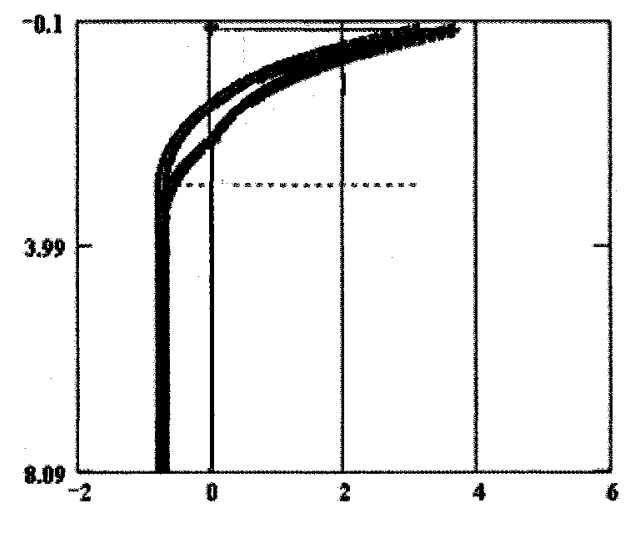

b) 


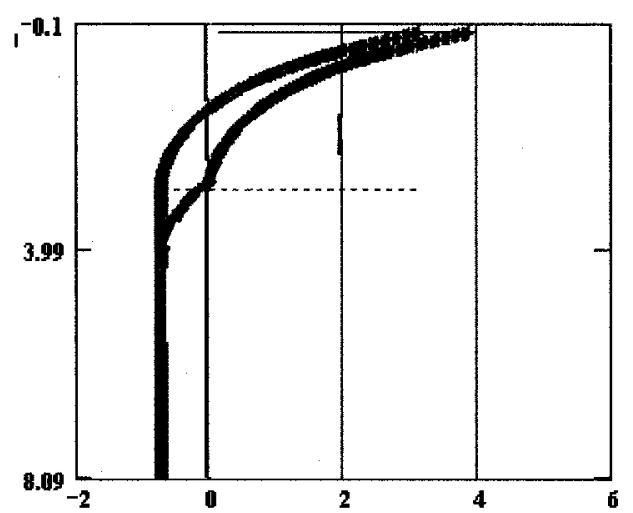

b)

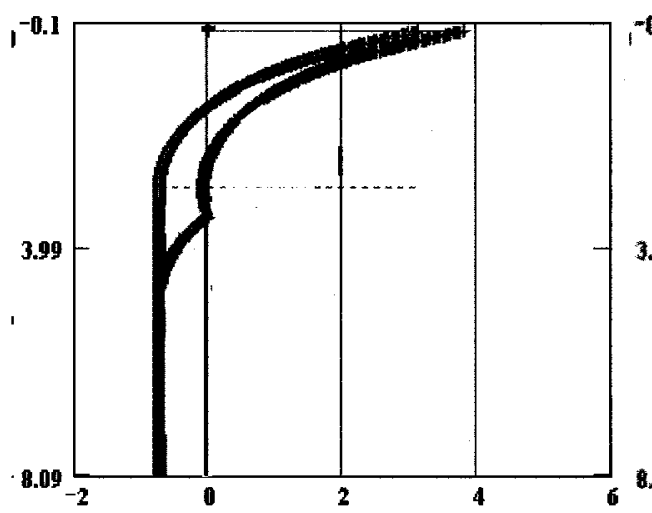

e)

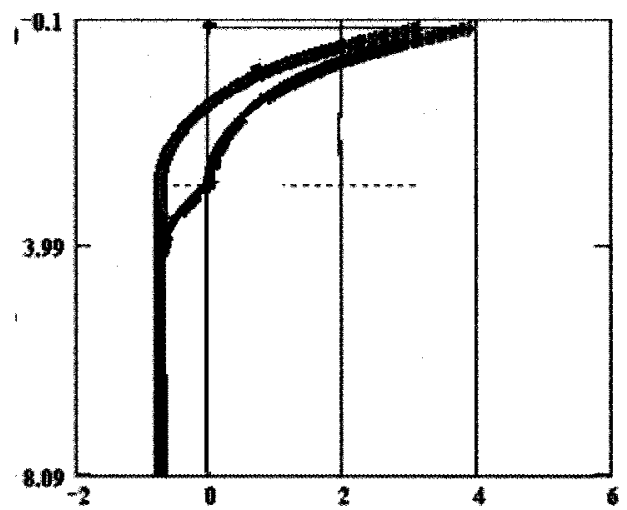

d)

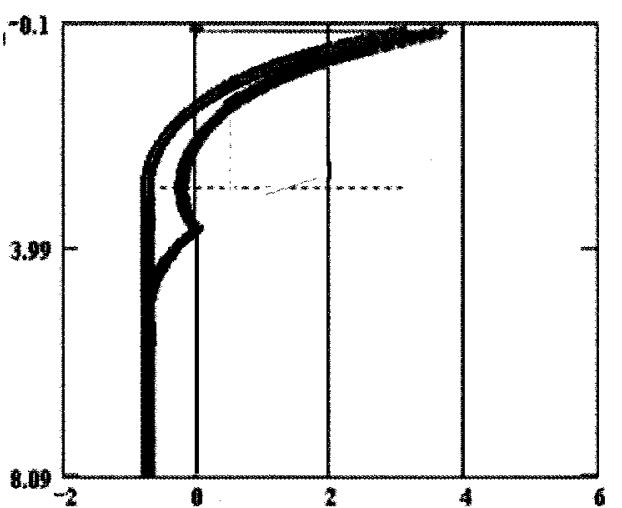

f) 


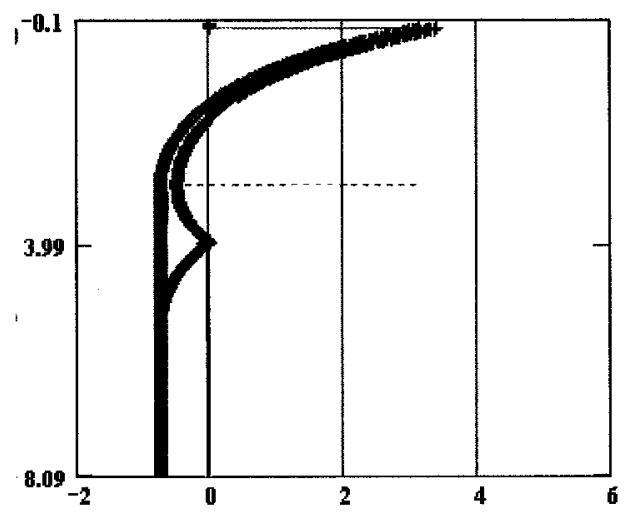

g)

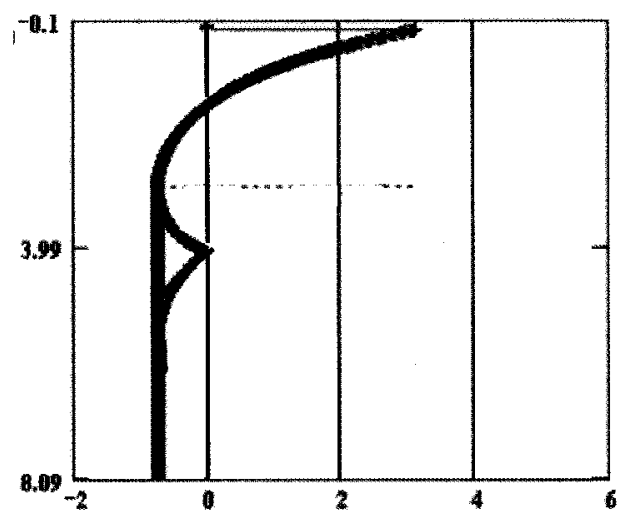

h)

Figure 3.5 Calculated intermediate positions of the meniscus

To the figure 3.4 :

a - $H_{\delta}=0$ - the initial position;

b $-H_{\delta}=0.25 \cdot\left(H_{h}-h_{l}\right)-25 \%$ of the solidified mark movement;

c $-H_{\delta}=0.50 \cdot\left(H_{h}-h_{l}\right)-50 \%$ of the solidified mark movement;

$\mathrm{d}-H_{\delta}=1.00 \cdot\left(H_{G}-h_{l}\right)-$ exactly on the line of solid slag lower boundary;

e $-H_{\delta}=0.75 \cdot\left(H_{h}-h_{l}\right)-75 \%$ of the solidified mark movement;

f - $H_{\delta}=0.85 \cdot\left(H_{h}-h_{l}\right)-85 \%$ of the solidified mark movement;

$\mathrm{h}-H_{\delta}=0.95 \cdot\left(H_{h}-h_{l}\right)-95 \%$ of the solidified mark movement;

$\mathrm{g}-H_{\delta}=1.00 \cdot\left(H_{h}-h_{l}\right)-100 \%$ of the solidified mark movement. 


\section{Two phases of the first stage}

From the previous numerical analysis of the meniscus displacement during the first stage of the mark formation, it is possible to separate two phases of meniscus movement, such as:

1. From the beginning of the mark formation cycle (point $C_{0}$ - see Figure 3.3) until the $x=H_{G}$ (interval $h_{l}>x>H_{G}$ ). During the first phase the line of the meniscus moves along

the axis $Y$ from the slag rim (Figure 3.4 a-d). The maximum distance $y\left(H_{G}\right)$ achieved at $x=H_{G}($ Figure $3.4 \mathrm{~d})$.

2. The second phase starts when the top of solidified mark passed through the point $x=H_{G}$ (Figure $3.4 \mathrm{~d}$ ) and continues until the meniscus contacts the slag rim, i.e. till the ending of the first stage mark formation (Figure 3.4g).

During the second phase the line of the meniscus, moving along an axis $Y$, comes nearer to the slag rim. Here the distance between meniscus and slag rim in the section $H_{G}>x>0$ varies from $y\left(H_{G}\right)$ up to zero. 


\section{The model of the thermal processes on the meniscus at the first stage of mark formation}

\section{process}

In the previous chapter the model of mechanical behavior of meniscus was described. In present chapter we consider how the temperature of each selected point of meniscus changes during the first stage of mark formation process.

\subsection{Basic assumptions. The representative element}

We can assume that it is possible to neglect the heat removal from the meniscus at the first phase of the first stage of mark formation. At the first phase when the meniscus moved away from the solid slag, the gap between meniscus and solid slag increased. The fresh portions of fluid slag with the high temperature moved into the gap. The temperature equalization occurred across the entire surface of meniscus, and became equal to temperature of the liquid metal in its core $T_{M}$. Reduction of the meniscus temperature starts only at the beginning of second phase after meniscus height became equal $H_{G}$. In the second phase the gap between the meniscus and the solid slag decreases. Fresh liquid slag stops coming into the gap and liquid slag starts to escape from the gap. It leads to appearance of a temperature gradient in the liquid slag providing intensive heat removal from the meniscus. For description of the meniscus thermal state during first stage, we consider the thermal state of $n$-points of observation on the meniscus starting from the end of the first phase.

First, we choose some point $B$ on the meniscus with coordinate $x=x_{0}$ and 
$y=y\left(x_{0}, H_{G}\right)$ (see Figure 3.3). At the point $B\left(x_{0}\right)$ we place the representative element (RE) with infinitesimally width (see figure 4.1) and from this point we start to consider changes of the heat state of RE. This RE is represented as orthogonal prism which is created by two planes parallel and two planes perpendicular to the plane of drawing. The centerline of the RE is perpendicular to tangent to the meniscus. One base of RE is located on the meniscus and the second base in the liquid metal (figure 4.1). The length of the RE is equal to the thickness of thermal boundary layer $\delta_{T}$ (see Chapter 4.6).

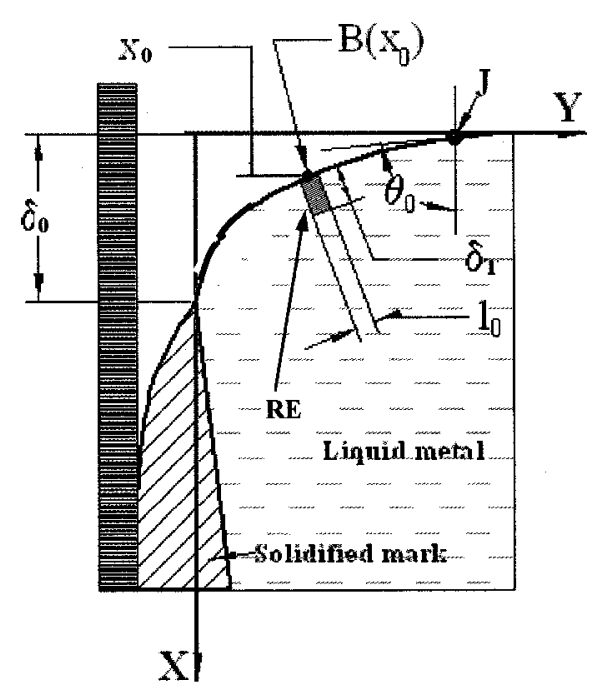

a)

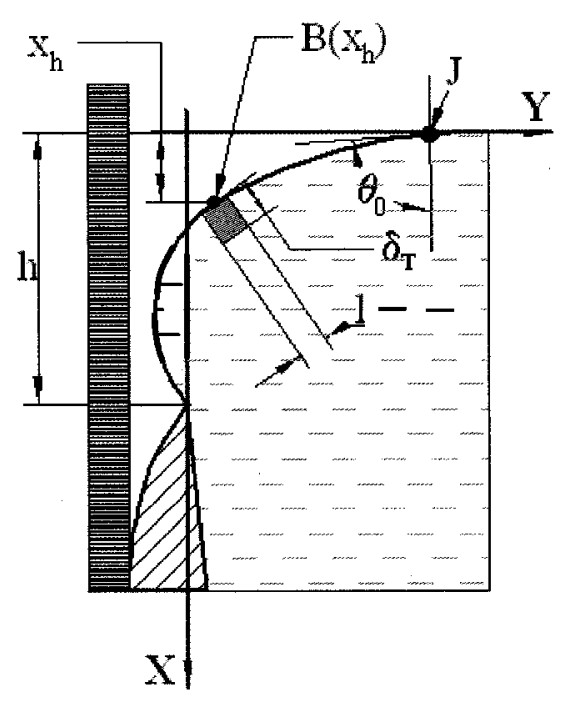

b)

Figure 4.1 The RE geometry changes as a result of meniscus growth

a) initial position (the beginning of the second phase);

b) current position.

$B\left(x_{0}\right)$ - initial position of point of observation;

$B\left(x_{h}\right)$ - current position;

$l_{0}$ - initial width of RE base;

$l=f(h)$ - current width; 
$\delta_{T}$ - length of RE (thickness of the thermal boundary layer);

$h$ - current height of meniscus;

$\delta_{0}$ - initial meniscus height;

$x_{0}$ - X- coordinate of point $B\left(x_{0}\right)$;

$x_{h}$ - X-coordinate of point $B\left(x_{h}\right)$;

$\mathrm{J}$ - junction point;

$\theta_{0}$ - initial angle.

Considering the process of the meniscus stretching the following special features of the RE stretching were taken into consideration:

- the RE stretched with the meniscus, the stretching is accompanied with liquid metal coming into RE from the core of the billet;

- the new portions of metal are evenly distributed throughout entire RE;

We study only $1 \mathrm{D}$ transient heat transfer, i.e. we consider heat transfer only in the direction of the RE axis. We neglect heat exchange between the RE and the adjacent sections of meniscus. The heat transfer occurs only through the bases of RE.

\subsection{Derivation of differential equation}

\section{The basic principles of the heat balance equation}

The infinitesimally element $d u$ was selected inside RE (see Figure 4.2). Thermal conditions for $d u$ determined by:

- heat transfer through the bases of $d u$;

- change of the $d u$ heat content;

- heat comes with fresh portion of metal from the core of billet 


\section{Heat balance for the $d u$}

The change of the $d u$ heat content during the time $d \tau$ (see Figure 4.2):

$$
d Q_{V}=d Q_{\Delta}+d Q_{F}
$$

where $d Q_{V}$ - the total change of the heat content in the $d u$ during $d \tau$;

$d Q_{\Delta}=\left(-d Q_{1}+d Q_{2}\right)$ - change of the heat transferred through the bases of the $d u$ during $d \tau$;

$d Q_{F}$ - change of the heat content of the RE which comes with the fresh portion of metal from the core of billet.

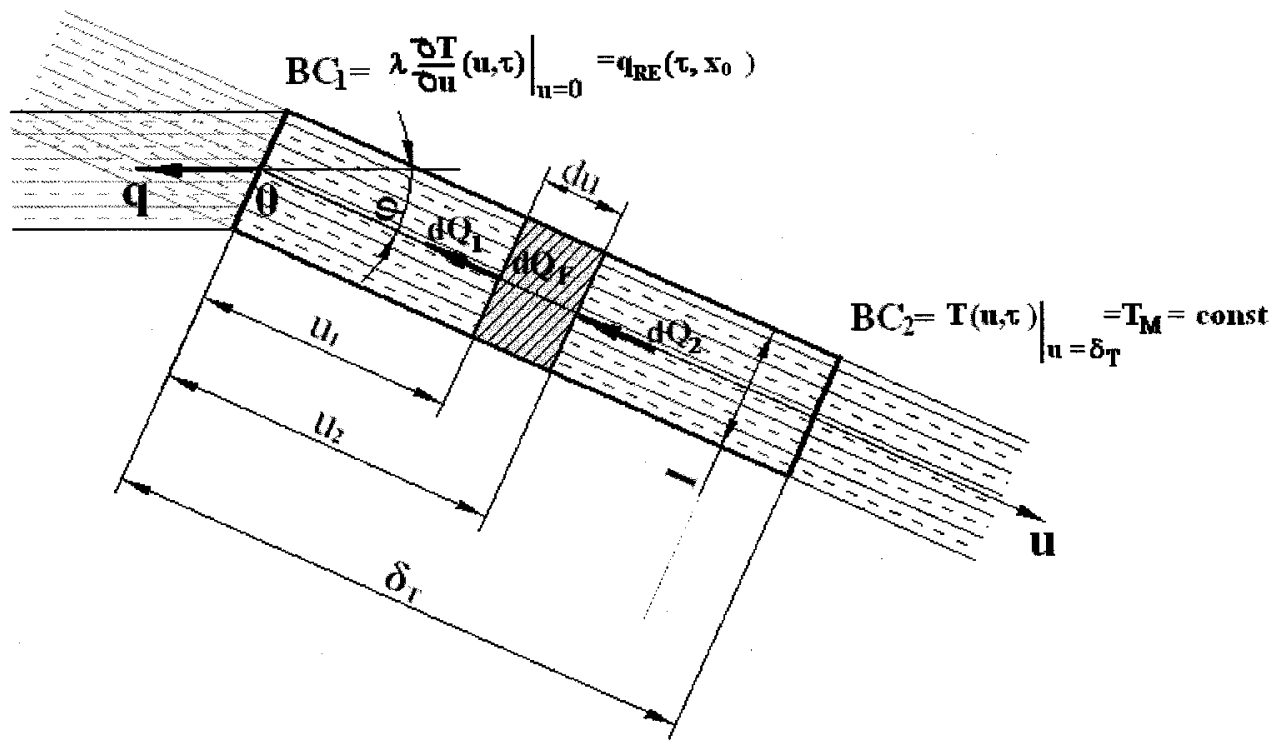

Figure 4. 2 The RE boundary conditions

The total change of the heat content in the du during $d \tau$

A change of the heat content in the $d u$ is determined by the equation:

$$
d Q_{V}(\tau)=c \cdot \rho \cdot b \cdot\left[l\left(\tau_{2}\right) \cdot T\left(u, \tau_{2}\right)-l\left(\tau_{1}\right) \cdot T\left(u, \tau_{1}\right)\right] \cdot d u,
$$


$c$ - coefficient of heat capacity of liquid metal;

$\rho$ - density of liquid metal;

$b$ - width of infinitesimally section of meniscus;

$u$ - the coordinate along the prism axes $\left(u_{1}<u<u_{2}\right)$.

\section{Change of the heat transfer through the bases of the du}

The notation of the coordinate of the RE bases: $u=0$ on the meniscus, and $u=\delta_{T}$ inside liquid metal area. For the $d u$ element respectively: at $u=u_{2}$ the heat enters in the $d u$, and at $u=u_{1}$ the heat exits from the $d u$. According to the Fourier law the heat transfer through the ends of the $d u$ for the time from $\tau_{1}$ to $\tau_{2}$ :

$$
d Q_{\Delta}=b \cdot\left[\lambda \frac{\partial T}{\partial u}\left(u_{2}, \tau\right)-\lambda \frac{\partial T}{\partial u}\left(u_{1}, \tau\right)\right] \cdot l(\tau) \cdot d \tau
$$

where $l(\tau)=l_{0}+\Delta l(\tau)$ - is the $d u$ extension along the meniscus (tangentially to it); $\Delta l(\tau)$ - lengthening of the RE along the meniscus as the function of time $\tau_{1} \leq \tau \leq \tau_{2}$.

\section{Change of the heat content of $d u$ due to the metal flows from the core}

The meniscus stretching is accompanied by metal influx from the core of the strand. The temperature of this metal is equal to the temperature of the liquid metal, which was not cooled. In this case the heat, which entered into $d u$ is proportional to the extension of the $d u$ along the meniscus $\Delta l(\tau)$. The contribution to the $d u$ thermal equilibrium from the metal, can be determined as a difference in the values of the heat content of outgoing metal at $\tau_{2}$ and at $\tau_{1}$ :

$$
d Q_{F}(\tau)=c \cdot \rho \cdot b \cdot T_{M} \cdot\left[l\left(\tau_{2}\right)-l\left(\tau_{1}\right)\right] \cdot d u
$$

After substitution of $d Q_{\Delta}, d Q_{V}$ and $d Q_{F}$ into equation of heat balance (4.1) we get: 


$$
\begin{gathered}
c \cdot \rho \cdot b \cdot\left[l(\tau) \cdot T\left(u, \tau_{2}\right)-l\left(\tau_{1}\right) \cdot T\left(u, \tau_{1}\right)\right] \cdot d u= \\
b \cdot\left[\lambda \frac{\partial T}{\partial u}\left(u_{2}, \tau\right)-\lambda \frac{\partial T}{\partial u}\left(u_{1}, \tau\right)\right] \cdot l\left(\tau_{2}\right) \cdot d \tau+c \cdot \rho \cdot b \cdot T_{M} \cdot\left[l\left(\tau_{2}\right)-l\left(\tau_{1}\right)\right] \cdot d u
\end{gathered}
$$

Equation (4.2) can be transformed:

$$
\begin{aligned}
& d Q_{V}=c \cdot \rho \cdot b \cdot \frac{\partial[l(\tau) \cdot T(u, \tau)]}{\partial \tau} \cdot d u \cdot d \tau= \\
& =c \cdot \rho \cdot b \cdot\left\{[l(\tau)] \cdot \frac{\partial\{T(u, \tau)\}}{\partial \tau}+T(u, \tau) \cdot \frac{\partial[l(\tau)]}{\partial \tau}\right\} \cdot d u \cdot d \tau
\end{aligned}
$$

After substitution $d Q_{V}$ into equation of heat balance (4.5) and transformation:

$$
\begin{aligned}
& \left.c \cdot \rho \cdot b \cdot\left\{[l(\tau)] \cdot \frac{\partial T(u, \tau)}{\partial \tau}\right\} \cdot d u \cdot d \tau=b \cdot\{l l(\tau)] \cdot \frac{\partial\left[\lambda \cdot \frac{\partial T}{\partial u}(u, \tau)\right]}{\partial u}\right\} \cdot d u \cdot d \tau+ \\
& +c \cdot \rho \cdot b \cdot\left\{T_{M} \cdot \frac{\partial[l(\tau)]}{\partial \tau}-T(u, \tau) \cdot \frac{\partial[l(\tau)]}{\partial \tau}\right\} \cdot d u \cdot d \tau
\end{aligned}
$$

After reducing on $d u \cdot d \tau$ the differential equation of heat balance takes the form (taking into account, that the $d u$ is the uniform prism):

$$
\begin{aligned}
& \lambda \cdot[l(\tau)] \cdot \frac{d^{2} T}{d u^{2}}+c \cdot \rho \cdot\left[T_{M}-T(u, \tau)\right] \cdot \frac{\partial[l(\tau)]}{\partial \tau}=[l(\tau)] \cdot c \cdot \rho \cdot \frac{d T}{d \tau} ; \text { or } \\
& \frac{d T}{d \tau}=\frac{\lambda}{c \cdot \rho} \cdot \frac{d^{2} T}{d u^{2}}+\frac{T_{M}-T(u, \tau)}{l(\tau)} \cdot \frac{\partial[l(\tau)]}{\partial \tau} .
\end{aligned}
$$

This differential equation corresponds to the classical form of the parabolic differential equation with the source function:

$$
\frac{d T}{d \tau}=\frac{\lambda}{c \cdot \rho} \cdot \frac{d^{2} T}{d u^{2}}+F(\tau),
$$


where $F(\tau)=\frac{T_{M}-T(u, \tau)}{l(\tau)} \cdot \frac{\partial[l(\tau)]}{\partial \tau}$ - source function;

\section{Initial conditions}

At $\tau^{\prime}$, when the first phase completes, the RE has the temperature in the whole volume:

$$
\left.T(u, \tau)\right|_{\tau=\tau^{\prime}}=T_{M}=\text { const }
$$

\section{Boundary conditions}

Boundary conditions are formulated for two $\mathrm{RE}$ bases: $\mathrm{BC}_{2}$ is located at the distance $\delta_{T}$ from the surface of meniscus:

$$
\left.T(u, \tau)\right|_{u_{2}=\delta_{T}}=T_{M}=\text { const }
$$

At the surface of the meniscus, boundary condition $\left(\mathrm{BC}_{1}\right)$ is:

$$
\left.\lambda \frac{\partial T}{\partial u}(u, \tau)\right|_{u=0}=q_{R E}\left(\tau, x_{0}\right)
$$

where $q_{R E}\left(\tau, x_{0}\right)$ - heat-flux density extracted from the base of the RE (it depends on the time of observation and coordinate of initial observation point). In the process of the meniscus stretching, RE is moving and, therefore heat-flux density is the function of the RE position (initial point is the point $x_{0}$ ).

\subsection{Equations which describe the dynamics of $R E$}

Functional description of the RE position is determined by meniscus displacement and stretching. The change of the position of the RE is the result of two simultaneous motions addition:

- displacement together with the meniscus resulting from meniscus height 
increasing;

- displacement resulting from meniscus stretching.

The RE heat state at a given moment of time is defined by the heat transfer from RE depending on the RE displacement from the wall, and additional superheat from the core of the strand depending on the RE stretching. We assume that the start of the change in the RE heat state coincided with the start of the second phase. For the solution of the differential equation of heat conductivity it is necessary to know the functional dependence of RE location and stretching on the meniscus height.

\section{$R E$ position as a function of the meniscus height}

In the end of the first phase the length of meniscus $L_{0}$ is equal (3.20):

$$
L_{0}=\int_{0}^{H_{G}} \sqrt{1+\left(\frac{\left(B \cdot x^{2}+\sin \theta_{0}\right)}{\sqrt{1-\left(B \cdot x^{2}+\sin \theta_{0}\right)^{2}}}\right)^{2}} \cdot d x,
$$

The length of the part of meniscus $L_{B_{0}}$ between point J and point $B\left(x_{0}\right)$ is equal:

$$
L_{B_{0}}=\int_{0}^{x_{0}} \sqrt{1+\left(\frac{\left(B \cdot x^{2}+\sin \theta_{0}\right)}{\sqrt{1-\left(B \cdot x^{2}+\sin \theta_{0}\right)^{2}}}\right)^{2}} \cdot d x
$$

If the height of meniscus will increase to $h\left(H_{h} \geq h \geq H_{G}\right)$, the meniscus length $L_{h}$ becomes:

$$
L_{h}=\int_{0}^{h} \sqrt{1+\left(\frac{\left(B \cdot x^{2}+\sin \theta_{0}\right)}{\sqrt{1-\left(B \cdot x^{2}+\sin \theta_{0}\right)^{2}}}\right)^{2}} \cdot d x
$$


Aspect ratio of meniscus : $\frac{L_{h}-L_{0}}{L_{0}}$.

Point $B(x)$ comes from point $B\left(x_{0}\right)$ into point $B\left(x_{h}\right)$ and length of the part of meniscus between point $\mathrm{J}$ and point $B\left(x_{h}\right)$ will be:

$$
L_{B_{h}}=L_{B_{0}} \cdot \frac{L_{h}}{L_{0}}
$$

The coordinate $x_{h}$ of the point $B\left(x_{h}\right)$ can be found from implicit equation:

$$
L_{B_{0}} \cdot \frac{L_{h}}{L_{0}}=\int_{0}^{x_{h}} \sqrt{1+\left(\frac{\left(B \cdot x^{2}+\sin \theta_{0}\right)}{\sqrt{1-\left(B \cdot x^{2}+\sin \theta_{0}\right)^{2}}}\right)^{2}} \cdot d x
$$

where $L_{h}$ - can be found from equation (4.13);

$L_{0}$ - can be found from equation (4.11);

$L_{B_{0}}$ - can be found from equation (4.12);

$x_{0}$ - is known a priory;

$x_{h}$ - unknown.

The equation (4.15) shows that $x_{h}=f\left(h, x_{0}\right)$

Coordinate $y\left(x_{h}, h\right)$ can be found from equation (3.13):

$$
y\left(x_{h}, h\right)=Y(h)-Y\left(x_{h}\right)
$$

Where $Y(h)$ and $Y\left(x_{h}\right)$ found from equation (3.14) and (3.15).

\section{RE stretching as a function of $h$}

Let us assume that RE width equal to $l_{0}$ when meniscus height equal to $H_{G}$. 
Then if the meniscus height equal to $H_{G}<h<H_{h}$ then RE will stretched to $l_{h}$.

$$
l_{h}=l_{0} \cdot \frac{L_{h}}{L_{0}}
$$

where $L_{h}=f(h)(4.13)$;

$L_{0}$ - can be found from equation (4.11).

\subsection{Transformation of the differential equation}

For further calculations we need transformation from variable $\tau$ to variable $h$. This single-valued conversion of variables leads to a significant simplification in the calculations (4.6-4.10). Let assume that during $\Delta \tau=\tau-\tau_{1}$ the top of solidified mark moved along axis $X$ and the height of the meniscus $h$ :

$$
h=H_{G}+V_{C} \cdot \Delta \tau=H_{G}+V_{C} \cdot\left(\tau-\tau_{1}\right),
$$

we start to consider the cooling process from the second phase when meniscus height already equal to $H_{G}$ ( see Figure 3.3 );

$V_{C}=$ const - the velocity of the displacement of the top of solidified mark.

At the time equal $\tau$ the length of meniscus equal to $L_{h}$ and the width of RE equal to $l_{h}$.

For the source function the derivative $\frac{\partial[l(\tau)]}{\partial \tau}$ can be determined from (4.11):

$$
\frac{\partial[l(\tau)]}{\partial \tau}=\frac{\partial\left[l_{h}\right]}{\partial\left(\frac{h}{V_{C}}\right)}=\frac{l_{0}}{L_{0}} \cdot V_{C} \cdot \frac{\partial L_{h}}{\partial h}
$$

In this case from the expression (4.7) it follows, that the sources function: 


$$
\begin{aligned}
& F(\tau)=\frac{T_{M}-T(u, \tau)}{l(\tau)} \cdot \frac{\partial[l(\tau)]}{\partial \tau}=\frac{T_{M}-T(u, \tau)}{l_{0} \cdot \frac{L_{h}}{L_{0}}} \cdot \frac{l_{0}}{L_{0}} \cdot V_{C} \cdot \frac{\partial L_{h}}{\partial h}= \\
& =\frac{T_{M}-T(u, \tau)}{L_{\tau}(h)} \cdot V_{C} \cdot \frac{\partial L_{h}}{\partial h}=F(h)
\end{aligned}
$$

$\frac{\partial L_{h}}{\partial h}$ can be determined from equation (4.12) by differentiation of integral:

$$
\begin{aligned}
& \frac{\partial L_{h}}{\partial h}=\frac{\partial\left\{\int_{0}^{h} \sqrt{1+\left[\frac{\left(B \cdot x^{2}+\sin \theta_{0}\right)}{\sqrt{1-\left(B \cdot x^{2}+\sin \theta_{0}\right)^{2}}}\right]^{2}} d x\right\}}{\partial h}, \text { or: } \\
& \frac{\partial L_{h}}{\partial h}=\sqrt{1+\left[\frac{\left(B \cdot h^{2}+\sin \theta_{0}\right)}{\sqrt{1-\left(B \cdot h^{2}+\sin \theta_{0}\right)^{2}}}\right]^{2}}
\end{aligned}
$$

Thus, source function became:

$$
\begin{gathered}
F(h)=\frac{T_{M}-T(u, h)}{L_{h}} \cdot V_{C} \cdot \sqrt{1+\left[\frac{\left(B \cdot h^{2}+\sin \theta_{0}\right)}{\sqrt{1-\left(B \cdot h^{2}+\sin \theta_{0}\right)^{2}}}\right]^{2}} \\
\text { where } L_{h}=\int_{0}^{h} \sqrt{1+\left(\frac{\left(B \cdot x^{2}+\sin \theta_{0}\right)}{\sqrt{1-\left(B \cdot x^{2}+\sin \theta_{0}\right)^{2}}}\right)^{2}} \cdot d x
\end{gathered}
$$$$
\text { Known, that } \frac{d T}{d \tau}=V_{C} \cdot \frac{d T}{d h}
$$

After substitution of this expression in (4.6), we obtain: 


$$
\begin{gathered}
\frac{d T}{d h}=\frac{\lambda}{V_{C} \cdot c \cdot \rho} \cdot \frac{d^{2} T}{d u^{2}}+\frac{T_{M}-T(u, h)}{L_{h}} \cdot \sqrt{1+\left[\frac{\left(B \cdot h^{2}+\sin \theta_{0}\right)}{\sqrt{1-\left(B \cdot h^{2}+\sin \theta_{0}\right)^{2}}}\right]^{2}}, \\
f(h)=\frac{T_{M}-T(u, h)}{L_{h}} \cdot \sqrt{1+\left[\frac{\left(B \cdot h^{2}+\sin \theta_{0}\right)}{\sqrt{1-\left(B \cdot h^{2}+\sin \theta_{0}\right)^{2}}}\right]^{2}} .
\end{gathered}
$$

\section{5. $\mathrm{BC}_{1}$ calculation}

To determine boundary condition the estimation of the heat-flux density from the meniscus to the water through the slag and the mold wall is required. We examine heat transfer from the RE at $\tau>\tau^{\prime}$.

\section{Basic assumptions}

Heat-flux density is determined according to the heat transfer through the multilayered wall. The coefficient of the liquid slag specific heat is more than 5 times lower than the coefficient of the specific heat of the liquid metal. Therefore for determination of the heat flux density function, we neglect the quantity of heat, introduced by liquid slag into the gap between the meniscus metal and the solid slag on the mold wall. We also neglect the heat, absorbed by liquid slag from the liquid metal, (low heat capacity of slag and its small quantity). Since boundary liquid slag - solid slag - is the boundary of the phase transition between liquid and solid slag, then the temperature of this boundary is constant and equal to the temperature of the slag crystallization (we neglect the interval of crystallization of slag). We assume the steady configuration of the slag rim observed during periodic displacements of meniscus. We consider only $1 \mathrm{D}$ heat transfer from RE to the examined the non-uniform prism, which is 
located at a distance $x$ from the beginning of coordinates. This prism is notes as the heattransfer prism. The centerline of heat-transfer prism is parallel to axis $Y$. The heat transfer prism consists consecutively from liquid slag, solid slag and water-cooled mold wall. One base of heat-transfer prism is the base of the RE (located on meniscus of liquid metal). Second base of the prism is part of the surface of the water-cooled mold wall. RE and the heat-transfer prism are inclined toward each other at the angle $\varphi$.

For evaluation of the heat exchange from the RE to the water, the law of stationary heat exchange was used. Since we examined the stationary heat exchange (from the RE to the cooling water), an equal quantity of heat passed through each part of the considered prism, i.e., heat-flux density in all parts (thermal resistances) is equal

$$
q=\lambda_{i} \cdot \frac{\left(T_{i+}-T_{i-}\right)}{h_{i}}=\alpha_{j} \cdot\left(T_{j+}-T_{j-}\right),
$$

where:

$q=\lambda_{i} \cdot \frac{\left(T_{i+}-T_{i-}\right)}{h_{i}}-$ heat-flux density according to Fourier's law of thermal conductivity;

$\lambda_{i}$ - the coefficient of the thermal conductivity of $i$-thermal resistance;

$\left(T_{i+}-T_{i-}\right)$ - the temperature differential in the $i$-thermal resistance ;

$h_{i}$ - the thickness of $i$-thermal resistance;

$q=\alpha_{j} \cdot\left(T_{j+}-T_{j-}\right)-$ heat-flux density according to the Newton's law of heat emission;

$\alpha_{j}$ - the thermal transfer coefficient of $j$-thermal resistance; 
$\left(T_{j+}-T_{j-}\right)-$ the temperature differential on the $j$ - boundary of two surfaces.

Considering structure of thermal resistance on the way from the surface of the meniscus to the cooling water, density of the thermal flux determined from the equation (without taking into account that the RE base is not perpendicular to the prism axis):

$$
q=\left(T_{m}-T_{w a t}\right) \cdot R_{\Delta T}
$$

where $R_{\Delta T}$ - thermal resistance on the way from the liquid metal meniscus to the cooling water.

\section{Heat-flux density in the gap}

Taking into account that the thermal resistance of the gap between liquid metal and mold wall, filled with solid and liquid slag has up to $80-90 \%$ of all thermal resistance on the way from the meniscus to the cooling water [42], we have:

$$
q \approx \frac{b \cdot\left(T_{m}-T_{w a t}\right)}{\left(\frac{\Delta h_{s l-f}}{\lambda_{s l-f}}+\frac{\Delta h_{s l}}{\lambda_{s l}}\right)}
$$

where $b$ varied from 0.8 to 0.9 depending on slag thickness, slag conductivity, mold wall material;

$$
\begin{aligned}
& \frac{\Delta h_{s l-f}}{\lambda_{s l-f}}-\text { heat conductivity of fluid slag; } \\
& \frac{\Delta h_{s l}}{\lambda_{s l}}-\text { heat conductivity of solid slag. }
\end{aligned}
$$

I.e. the change of heat flux was determined by the change of the slag thermal resistance which resulted from a change in the thickness of the layers of solid slag and liquid slag (it is determined by definition of RE position with coordinate $x$ ): 


$$
\frac{1}{R_{s l}}=\frac{\Delta h_{s l-f}}{\lambda_{s l-f}}+\frac{\Delta h_{s l}}{\lambda_{s l}} .
$$

Hence, heat-flux density (4.21) is a function of the thickness of the layers of solid and liquid slag.

During the estimation of the heat-flux density from the RE we consider not only RE position (coordinate $x$ ), but also angle between the RE and the axis $X$ (projection of the RE exothermal base on the axis $X$ ). Finally, heat-flux density from the RE with the correction on the angle between the ax of the heat-transfer prism and RE:

$$
q_{R E}\left(h, x_{0}\right)=\frac{b \cdot\left(T_{m}-T_{w a t}\right) \cdot \cos \varphi\left(x_{h}\right)}{\left[\frac{\Delta h_{s l-f}\left(x_{h}\right)}{\lambda_{s l-f}}+\frac{\Delta h_{s l}\left(x_{h}\right)}{\lambda_{s l}}\right]}
$$

For $x_{h}$ definition we use equation 4.15 , for $\cos \varphi\left(x_{h}\right)$ definition we use equation:

$$
\cos \varphi\left(x_{h}\right)=\frac{1}{\sqrt{1+\operatorname{tg}^{2} \varphi\left(x_{h}\right)}}=\frac{1}{\sqrt{1+\left(\frac{d y}{d x}\right)^{2}}}=\frac{1}{\sqrt{1+\left(\frac{\left(B \cdot x_{h}^{2}+\sin \theta_{0}\right)}{\sqrt{1-\left(B \cdot x_{h}^{2}+\sin \theta_{0}\right)^{2}}}\right)^{2}}}
$$

\subsection{Thermal boundary layer}

The meniscus and meniscus area as parts of the shell of the billet are subject of the action of the liquid metal flow. The typical distribution of flow near the liquid metal surface in the mold is shown on Figure 4.3 (standard technology of continuous casting of steel). 

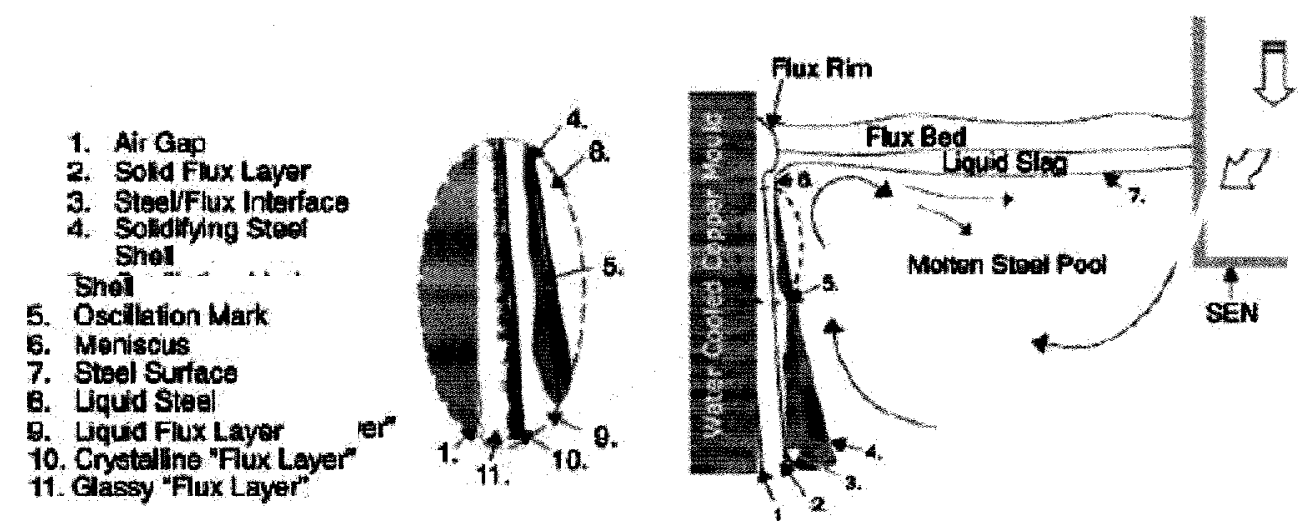

Figure 4. 3 Distribution of the liquid metal flows in the mold [40]

The layer of liquid metal near the meniscus consists of the thermal boundary layer (TBL) and the velocity boundary layer (VBL). Thickness of the TBL is functionally connected to the thickness of the VBL and for liquid metals thickness of the TBL exceeds the thickness of the VBL [41].

\section{Estimation of the TBL}

Thickness of the TBL can be defined as the function of VBL thickness $\delta$ on the basis of criterial equation (Prandtl number). For liquid metals it is possible [42] to use dependence:

$$
\delta \approx \delta_{T} \cdot \operatorname{Pr}^{\frac{1}{3}}
$$

where $\delta$ - the VBL thickness;

$\delta_{T}$ - the thickness of the TBL;

Pr - Prandtl number.

$$
\operatorname{Pr}=\frac{\mu \cdot c_{p}}{\lambda}
$$

where $\mu$-coefficient of kinematics viscosity of liquid metal; 
$\lambda$ - coefficient of thermal conductivity of liquid metal;

$c_{p}$ - the coefficient of heat capacity of liquid metal.

Estimation of the thickness of VBL is done on the basis of the criterial equation of the flow (Reynolds number):

$$
\delta \approx \frac{z}{\sqrt{\operatorname{Re}}}
$$

where $z$ - distance from the end of plate, where the flow began;

$\operatorname{Re}=\frac{\omega \cdot p}{\mu}-$ the Reynolds number;

$p$ - the characteristic size, determined from the dimensions of the liquid metal flow;

$\omega$ - the speed of the liquid metal flow.

Let us consider that the velocity of the liquid metal flow $\omega$ is directly proportional to the speed of casting (extraction speed of ingot from the mold is $V_{C}$ ), $\omega \approx k^{*} V_{C}$ where $k$ - coefficient of proportionality. After substituting $\mathrm{Re}, p, \omega, k, \delta$ in (14):

$$
\begin{aligned}
& \delta_{T} \approx \frac{\delta}{\operatorname{Pr}^{\frac{1}{3}}}=\frac{z}{\operatorname{Pr}^{\frac{1}{3}} \cdot \sqrt{\operatorname{Re}}}=\frac{z}{\left(\frac{\mu \cdot c_{p}}{\lambda}\right)^{\frac{1}{3}} \cdot \sqrt{\frac{\omega \cdot p}{\mu}}}=\frac{z \cdot \mu^{\frac{1}{6}}}{\left(\frac{c_{p}}{\lambda}\right)^{\frac{1}{3}} \cdot \sqrt{V_{C}} \cdot \sqrt{k \cdot p}}=\frac{C_{\delta}}{\sqrt{V_{C}}} \\
& \text { where } \\
& C_{\delta}=\frac{z \cdot \mu^{\frac{1}{6}}}{\left(\frac{c_{p}}{\lambda}\right)^{\frac{1}{3}} \cdot \sqrt{k \cdot p}}
\end{aligned}
$$


In the limits of the mark formation cycle it is possible to accept the physical characteristics of the liquid metal as constants: $\mu=$ const,$c_{p}=$ const, $\lambda=$ const. Taking into account that the meniscus length is small in comparison with the flow extension above the solidified shell, it is possible to accept that the flow parameters above the meniscus are the same as above solidified shell. I.e. for any point of meniscus $z=$ const,$p=$ const . Thus, it is possible to assume $C_{\delta}=$ const and

$$
\delta_{T} \approx \frac{\mathrm{const}}{\sqrt{V_{C}}}=\frac{C_{\delta}}{\sqrt{V_{C}}}
$$

Some thermophysical parameters in expression (4.26) are unknown a priori. The speed of the flow of liquid metal near meniscus for the specific case is also unknown; we do not know exact value of the distance from the end of plate $z$, where the flow began (equation 4.24). Hence, the direct determination of $\delta_{T}$ from equation (4.26) is not possible and $\delta_{T}$ was chosen as fitting parameter. The following procedure was developed for estimation of the thickness of the TBL. We assume that at the end of the $1^{\text {st }}$ stage meniscus is still liquid, i.e. its minimal temperature $(T)$ is not less than temperature of liquidus $\left(\mathrm{T}_{\mathrm{L}}\right)$. For some assigned value of $\delta_{T}$ at one fitting step we determine temperature distribution on meniscus (using the thermophysical model of meniscus). The iteration process is organized as follows. The minimum value $\mathrm{T}$ of the temperature distribution is compared with $\mathrm{T}_{\mathrm{L}}$. If $\left|T-T_{L}\right| \geq 0.2$ then we change value $\delta_{T}$ and repeat determination of the temperature distribution on meniscus and comparison $T$ and $T_{L}$, i.e. do the next fitting step. The process ends when $\left|T-T_{L}\right| \leq 0.2$. It has been found that value $\delta_{T}=0.3 \mathrm{~mm}$. 


\subsection{Summary of equations}

\section{Basic differential equation}

$$
\frac{d T}{d h}=\frac{\lambda}{V_{C} \cdot c \cdot \rho} \cdot \frac{d^{2} T}{d u^{2}}+f(h)
$$

\section{Source function}

$$
f(h)=\frac{T_{M}-T(u, h)}{L_{h}} \cdot \sqrt{1+\left[\frac{\left(B \cdot h^{2}+\sin \theta_{0}\right)}{\sqrt{1-\left(B \cdot h^{2}+\sin \theta_{0}\right)^{2}}}\right]^{2}},
$$

where $L_{h}$ - can be found from equation (4.9):

$$
L_{h}=\int_{0}^{h} \sqrt{1+\left(\frac{\left(B \cdot x^{2}+\sin \theta_{0}\right)}{\sqrt{1-\left(B \cdot x^{2}+\sin \theta_{0}\right)^{2}}}\right)^{2}} \cdot d x,
$$

$x_{h}$ - the coordinate determining RE position and can be found from equation:

$$
\begin{aligned}
& L_{B_{0}} \cdot \frac{L_{h}}{L_{0}}=\int_{0}^{x_{h}} \sqrt{1+\left(\frac{\left(B \cdot x^{2}+\sin \theta_{0}\right)}{\sqrt{1-\left(B \cdot x^{2}+\sin \theta_{0}\right)^{2}}}\right)^{2}} \cdot d x, \\
& L_{B_{0}}=\int_{0}^{x_{0}} \sqrt{1+\left(\frac{\left(B \cdot x^{2}+\sin \theta_{0}\right)}{\sqrt{1-\left(B \cdot x^{2}+\sin \theta_{0}\right)^{2}}}\right)^{2}} \cdot d x, \\
& L_{0}=\int_{0}^{H_{G}} \sqrt{1+\left(\frac{\left(B \cdot x^{2}+\sin \theta_{0}\right)}{\sqrt{1-\left(B \cdot x^{2}+\sin \theta_{0}\right)^{2}}}\right)^{2}} \cdot d x, \\
& H_{G}=\sqrt{\frac{-\sin \theta_{0}}{B}},
\end{aligned}
$$


Initial condition

$\left.T(u, h)\right|_{h=H_{G}}=T_{M}=$ const

Boundary conditions

$\left.T(u, h)\right|_{u=\delta_{T}}=T_{M}=$ const,

where $\delta_{T} \approx \frac{\text { const }}{\sqrt{V_{C}}}=\frac{C_{\delta}}{\sqrt{V_{C}}}$.

$\left.\lambda \frac{\partial T}{\partial u}(u, h)\right|_{u=u_{1}}=q_{R E}\left(h, x_{0}\right)$

where $q_{R E}\left(h, x_{0}\right)=\frac{(0,8 \ldots 0,9) \cdot\left(T_{m}-T_{w a l}\right) \cdot \cos \varphi\left(x_{h}\right)}{\left[\frac{\Delta h_{s l-f}\left(x_{h}\right)}{\lambda_{s l-f}}+\frac{\Delta h_{s l}\left(x_{h}\right)}{\lambda_{s l}}\right]}$,

$\Delta h_{s l}\left(x_{h}\right)=\Delta y+Y\left(H_{G}\right)-Y\left(x_{h}\right)$,

(Chapter 3.4)

$\Delta h_{s h-f}\left(x_{h}\right)=\left[Y(h)-Y\left(H_{h}\right)\right] \cap\left(H_{G}>x_{h}>0\right)+$

$+\left[Y(h)-Y\left(x_{h}\right)-Y\left(H_{h}\right)-Y\left(H_{G}\right)\right] \cap\left(x_{h}>H_{G}\right)$,

(Chapter 3.4)

$\cos \varphi\left(x_{h}\right)=\frac{1}{\sqrt{1+\left(\frac{\left(B \cdot x_{h}^{2}+\sin \theta_{0}\right)}{\sqrt{1-\left(B \cdot x_{h}^{2}+\sin \theta_{0}\right)^{2}}}\right)^{2}}}$

\subsection{Analysis of the model of thermal processes on meniscus}

A special program was developed for the temperature field of meniscus calculation (using MathCAD). This program was a continuation of the program which was developed for the model of the mechanical state of meniscus. Calculation was done for the second phase of the first stage of mark formation. Twenty points of observation were selected on the meniscus. For each point the differential equation of thermal 
conductivity was solved. In addition, the displacement of the observation point was taken into account. Thus, the values of temperatures of meniscuses were determined.

Initial data for evaluating of the meniscus thermal condition

Thermophysical characteristics published for some slag and steels are shown in tables 4.1 and 4.2 .

Table 4.1 Thermophysical characteristics of the mold slag

\begin{tabular}{|c|c|c|c|c|c|}
\hline \multicolumn{6}{|c|}{ Thermophysical characteristics of the mold slag } \\
\hline \multirow[b]{2}{*}{$\begin{array}{c}\text { Name } \\
\text { of parameters }\end{array}$} & \multirow[b]{2}{*}{ Notation } & \multirow[b]{2}{*}{ Unit } & \multicolumn{3}{|c|}{ Value of parameters } \\
\hline & & & $\begin{array}{l}\text { For steel } \\
0.05 \% \mathrm{C}\end{array}$ & $\begin{array}{l}\text { For } \\
\text { low } \\
\text { carbon } \\
\text { steel } \\
\end{array}$ & $\begin{array}{l}\text { For } \\
\text { medium- } \\
\text { carbon } \\
\text { steels steel }\end{array}$ \\
\hline $\begin{array}{l}\text { Temperature of slag on } \\
\text { the surface in the mold }\end{array}$ & $T_{s l}$ & ${ }^{\circ} \mathrm{C}$ & & & \\
\hline $\begin{array}{l}\text { Temperature of } \\
\text { crystallization of slag }\end{array}$ & & ${ }^{\circ} \mathrm{C}$ & 950 & 1043 & 1163 \\
\hline $\begin{array}{l}\text { Coefficient of heat } \\
\text { conductivity of solid } \\
\text { slag }\end{array}$ & $\lambda_{s l}$ & $\mathrm{~W} /\left(\mathrm{m}^{\circ} \mathrm{C}\right)$ & 1.5 & 1.73 & 1.83 \\
\hline $\begin{array}{l}\text { Thickness of the } \\
\text { solid slag on the } \\
\text { mold wall }\end{array}$ & $d_{s l}$ & $\mathrm{~mm}$ & & $0.3 \ldots 1.0$ & $0.4 \ldots 0.9$ \\
\hline $\mathrm{CaO} / \mathrm{SiO} 2$ & & & & 0.96 & 1.41 \\
\hline
\end{tabular}


Table 4.2 Thermophysical characteristics of steel

\begin{tabular}{|c|c|c|c|c|c|c|}
\hline \multicolumn{7}{|c|}{ Thermophysical characteristics of steel } \\
\hline \multirow[b]{2}{*}{$\begin{array}{c}\text { Name } \\
\text { of parameters }\end{array}$} & \multirow[b]{2}{*}{ Notation } & \multirow[b]{2}{*}{ Unit } & \multicolumn{4}{|c|}{ Value of parameters } \\
\hline & & & $\begin{array}{l}\text { Steel }^{1} \\
0.1- \\
.2 \% \mathrm{C}\end{array}$ & $\begin{array}{l}\text { Steel }^{2} \\
0.05 \% \mathrm{C}\end{array}$ & $\begin{array}{l}\text { Steel }^{3} \\
0.5 \% \mathrm{C}\end{array}$ & $\begin{array}{l}\text { Steel }^{4} \\
0.2 \% \mathrm{C}\end{array}$ \\
\hline $\begin{array}{l}\text { Temperature } \\
\text { Liquidus }\end{array}$ & $T_{L}$ & ${ }^{\circ} \mathrm{C}$ & 1510 & 1529 & 1495 & 1520 \\
\hline $\begin{array}{l}\text { Temperature } \\
\text { solidus }\end{array}$ & $T_{S}$ & ${ }^{\circ} \mathrm{C}$ & 1475 & 1509 & 1445 & 1480 \\
\hline $\begin{array}{l}\text { Density of } \\
\text { liquid metal }\end{array}$ & $\rho_{M}$ & $\mathrm{~kg} / \mathrm{m}^{3}$ & 7400 & 7400 & 7500 & 7500 \\
\hline $\begin{array}{l}\text { Coefficient of } \\
\text { thermal } \\
\text { conductivity of } \\
\text { liquid metal }\end{array}$ & $\lambda_{M}$ & $\mathrm{~W} /\left(\mathrm{m}^{\circ} \mathrm{C}\right)$ & 23.26 & & 23.2 & 29.1 \\
\hline $\begin{array}{l}\text { Coefficient of } \\
\text { heat capacity of } \\
\text { liquid metal }\end{array}$ & $C_{M}$ & $\mathrm{~kJ} /\left(\mathrm{kg}^{\circ} \mathrm{C}\right)$ & 0.691 & & 0.84 & 0.71 \\
\hline $\begin{array}{l}\text { thermal } \\
\text { diffusivity } \\
\text { coefficient of } \\
\text { liquid metal }\end{array}$ & $a \cdot 10^{-6}$ & $\mathrm{~m}^{2} / \mathrm{sec}$ & 4.546 & & 3.682 & 5.465 \\
\hline $\begin{array}{l}\text { Temperature in } \\
\text { the core (with } \\
\text { superheat) of } \\
\text { strand }\end{array}$ & $T_{M}$ & ${ }^{\circ} \mathrm{C}$ & 1540 & 1550 & 1515 & \\
\hline $\begin{array}{l}\text { Specific heat of } \\
\text { crystallization }\end{array}$ & $L$ & $\mathrm{~kJ} / \mathrm{kg}$ & & & 268 & 268 \\
\hline $\begin{array}{l}\text { Extraction } \\
\text { velocity }\end{array}$ & $V_{C}$ & $\mathrm{~m} / \mathrm{sec}$ & 0.2 & & & \\
\hline
\end{tabular}

Thermophysical characteristics of the mold slag mixtures used in experimental castings are shown in table 4.1. It is the medium carbon slag with $\mathrm{CaO} / \mathrm{SiO}_{2}$ equal to 1.41 . 


\section{The results of the temperatures determination}

The calculations were done for the $0,5 \%$-carbon low-alloy steel with the thermophysical characteristics, shown in the tables 4.1. The appropriate solutions of the equation for the mechanical equilibrium of meniscus are used as the initial data for the solution of the differential equation of thermal conductivity. The changes of the temperature at the meniscus points were considered from time, when meniscus has the height $h=H_{G}$ and its temperature was constant throughout all length and equal to temperature of metal in the ingot's core $T=T_{M}$. While the position of the RE point $B\left(x_{0}\right)$ moved and the RE temperature field was calculated in the process of RE displacement. The examples of these calculations are shown in Figures 4.5-4.9.

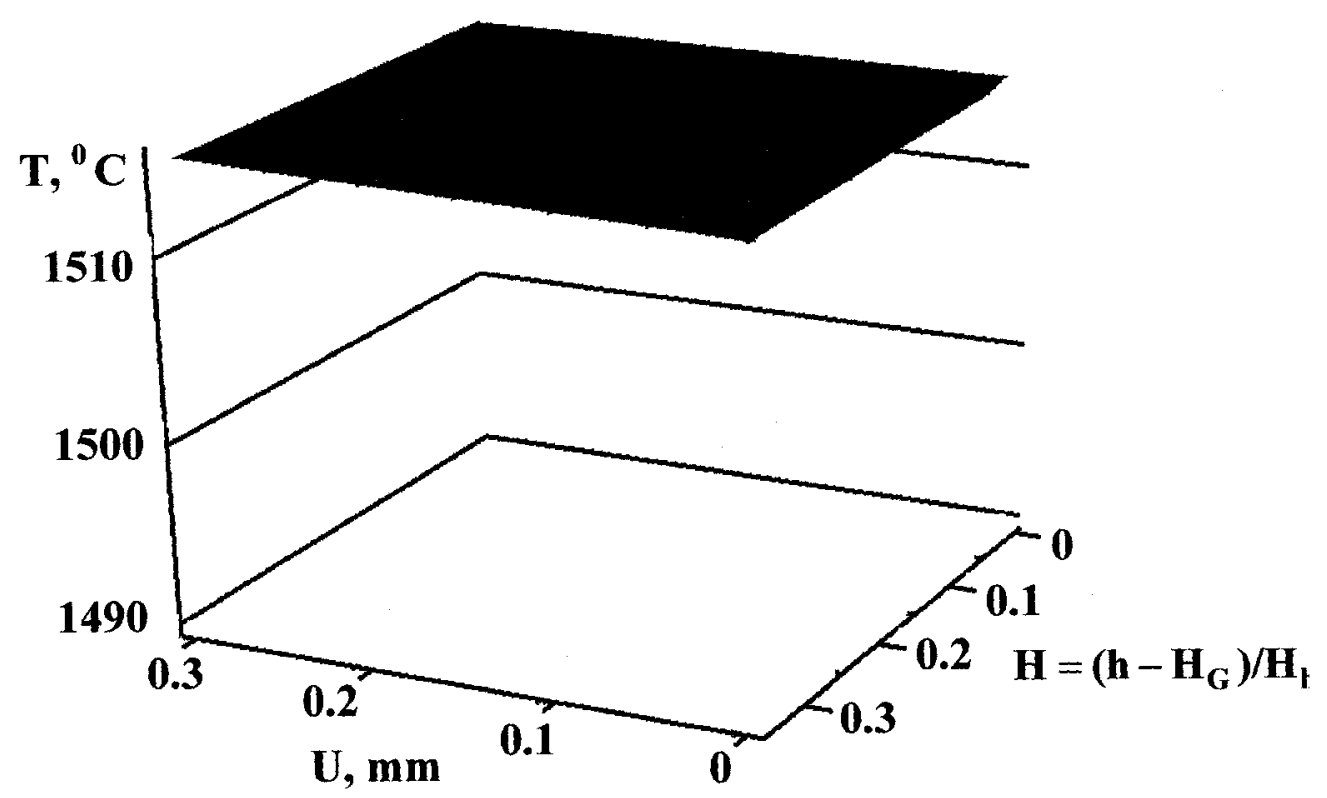

Figure 4.4 Variation of RE temperature resulting from the changes of the meniscus height and determined for $h=0.1 \cdot H_{G}, 3 \mathrm{D}$ view 
For the case shown in Figure 4.4 the casting temperature was $1515{ }^{\circ} \mathrm{C}$ and the point $B\left(x_{0}\right)$ is located at the distance $0.1 \cdot H_{G}$ from the surface of liquid metal. The axis $\mathrm{U}$ in Figure 4.4 is the distance along the RE centerline, the axis $\mathrm{H}$ is the parameter of the meniscus height $\left(H=\left(h-H_{G}\right) / H_{h}\right)$. In Figure 4.4 and its 2-D projection, Figure 4.5 we can see only small changes of metal temperature because of close location of $B\left(x_{0}\right)$ to the point $\mathbf{J}$.

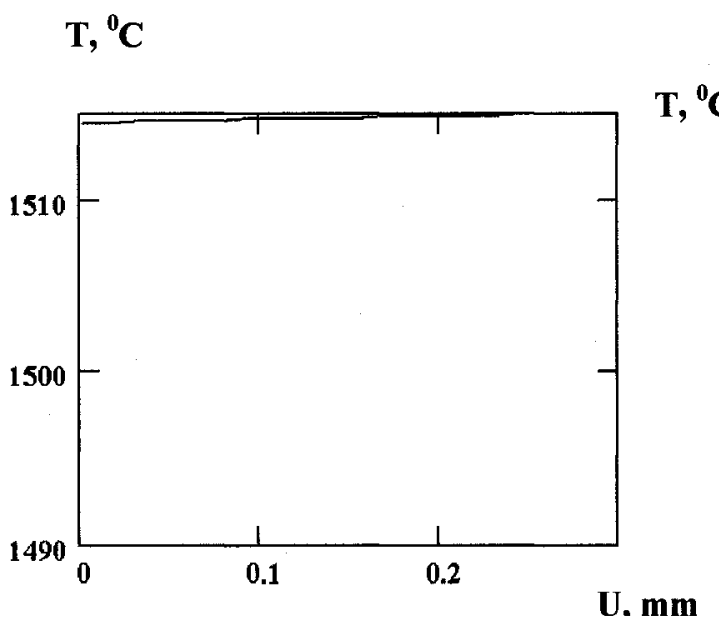

a) graph $T$ vs. $U,(H=0)$

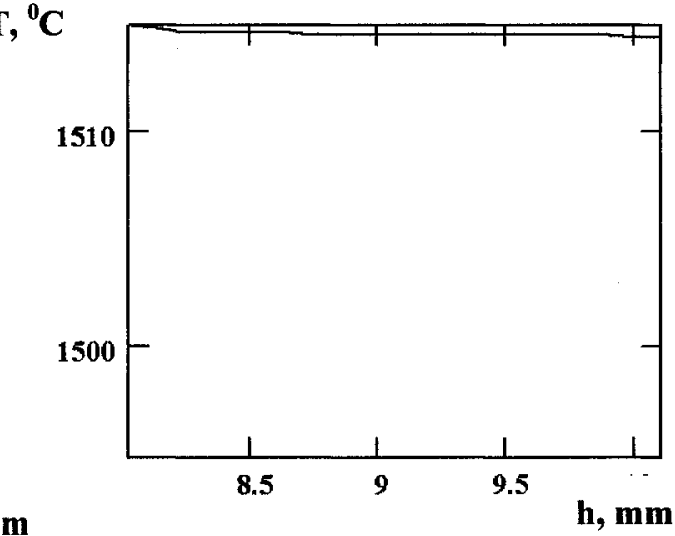

b) graph $\boldsymbol{T}$ vs. $\boldsymbol{h},(\boldsymbol{U}=\boldsymbol{(})$

Figure $4.52 \mathrm{D}$ views of variation of $\mathrm{RE}$ temperature resulting from the changes of the meniscus height and determined for $h=0.1 \cdot H_{G}$

For the case shown in Figure 4.6 the casting temperature is equal to $1515^{\circ} \mathrm{C}$ and the point $B\left(x_{0}\right)$ located at the distance $0.9 \cdot H_{G}$ from the surface of liquid metal. Here we have significant changes of temperature because of close location $B\left(x_{0}\right)$ to the mold wall. 


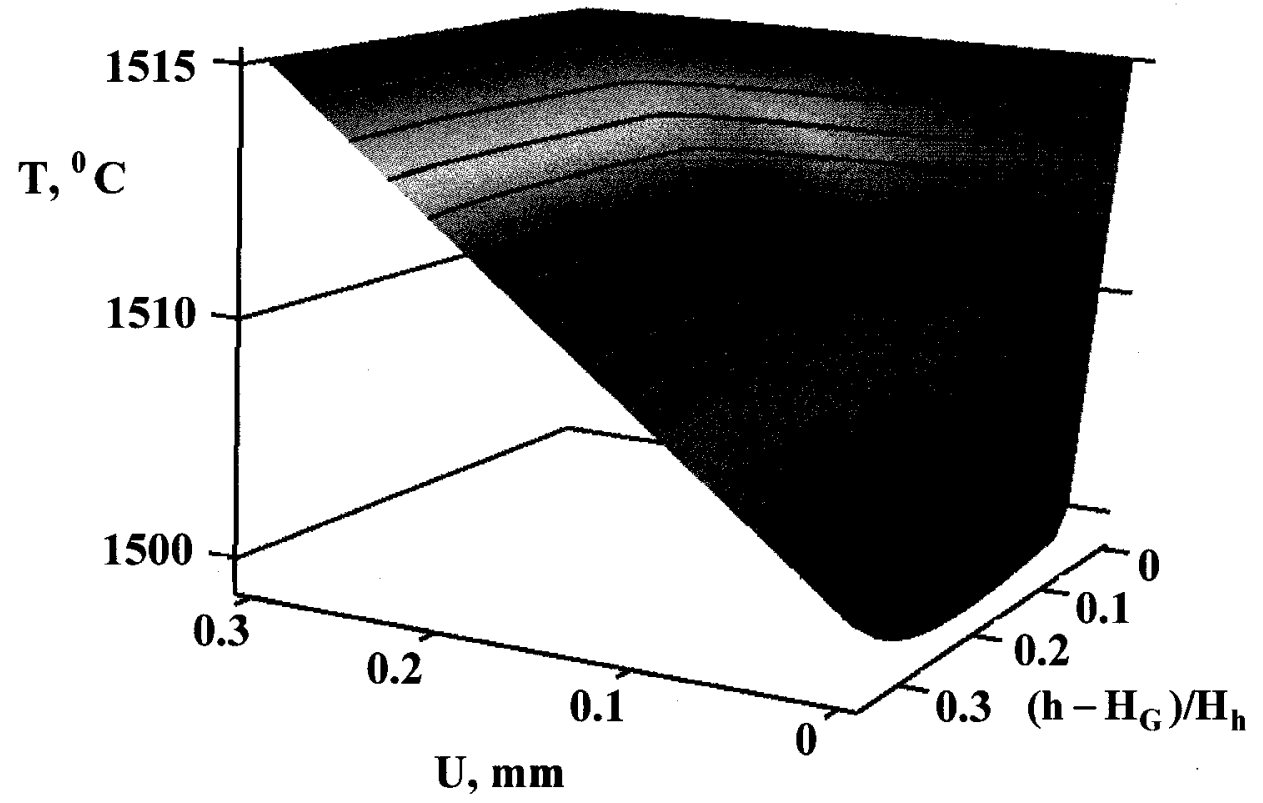

Figure 4.6 Temperature of RE changes resulting from the changes of the meniscus height and determined for $h=0.9 \cdot H_{G}, 3 \mathrm{D}$ view

Below 2-D images of the 3-D graph for better illustration of the dependences T vs. $U$ and T vs. $h$ are shown. 
$\mathbf{T},{ }^{0} \mathrm{C}$

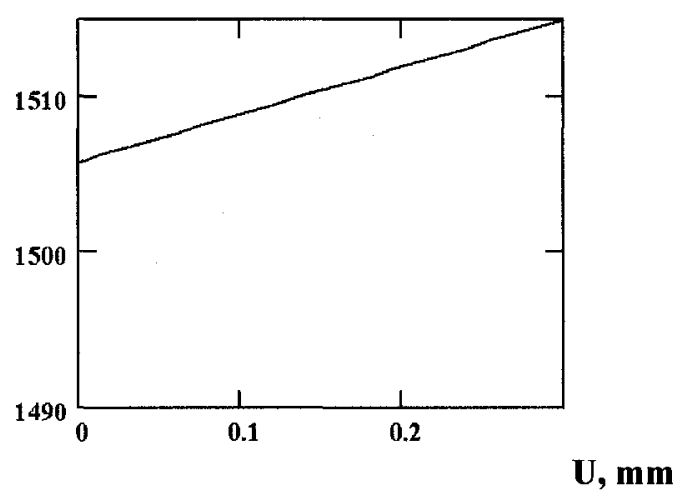

a) graph $T$ vs. $U,(H=0$,

$$
\mathbf{T},{ }^{0} \mathrm{C}
$$

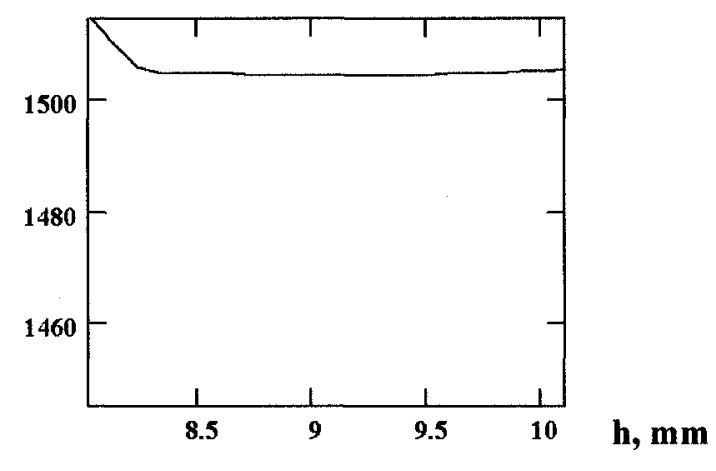

b) graph $\boldsymbol{T}$ vs. $\boldsymbol{h},(\boldsymbol{U}=0)$

Figure 4.7 2D views of temperature of RE changes resulting from the changes of the meniscus height and determined for $h=0.9 \cdot H_{G}$

\section{Representation and analysis of the meniscus temperatures}

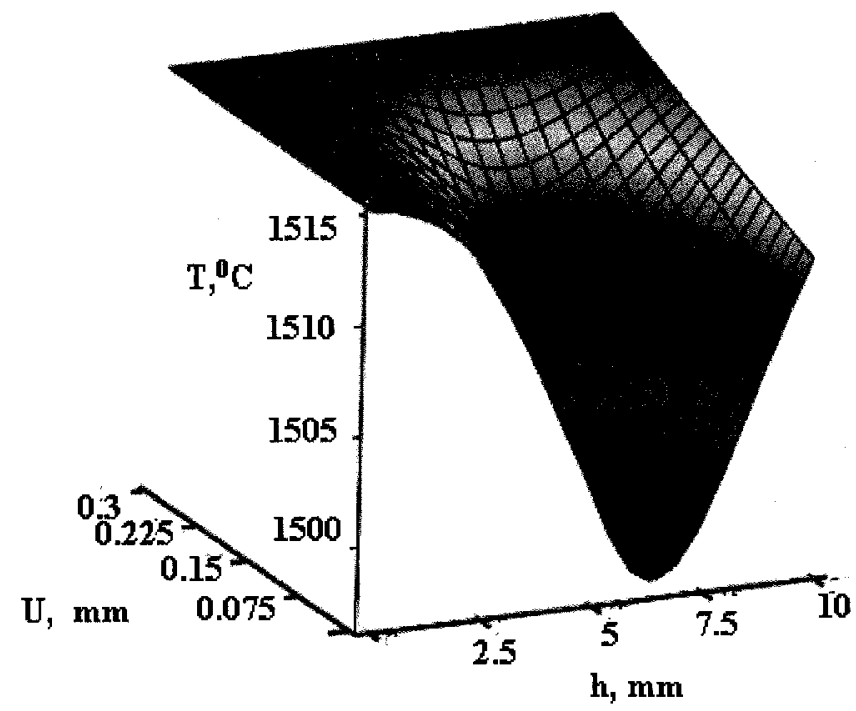

Figure 4.8 Temperature field of meniscus at the end of first stage $\left(h=H_{h}\right), 3 \mathrm{D}$ view

Resulting temperature field of the meniscus at the end of the first stage is shown on Figure 4.8. The set of the temperature values for this graph inferred from the sets of 
the twenty computed values of temperatures for different position of RE. Below are 2-D image of the 3-D graph (with the liquidus temperature) is shown.

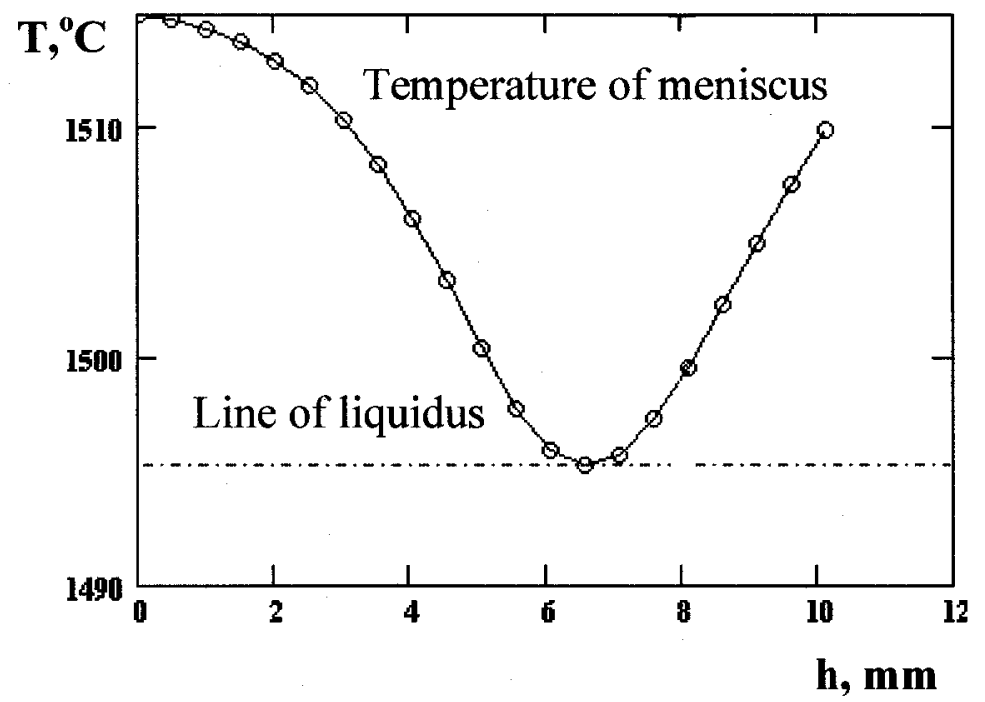

Figure 4.9 Temperatures of the meniscus at the end of first stage

As is evident, to the end of first stage of surface mark formation, curve for the temperature of meniscus is located above the temperature of liquidus. 


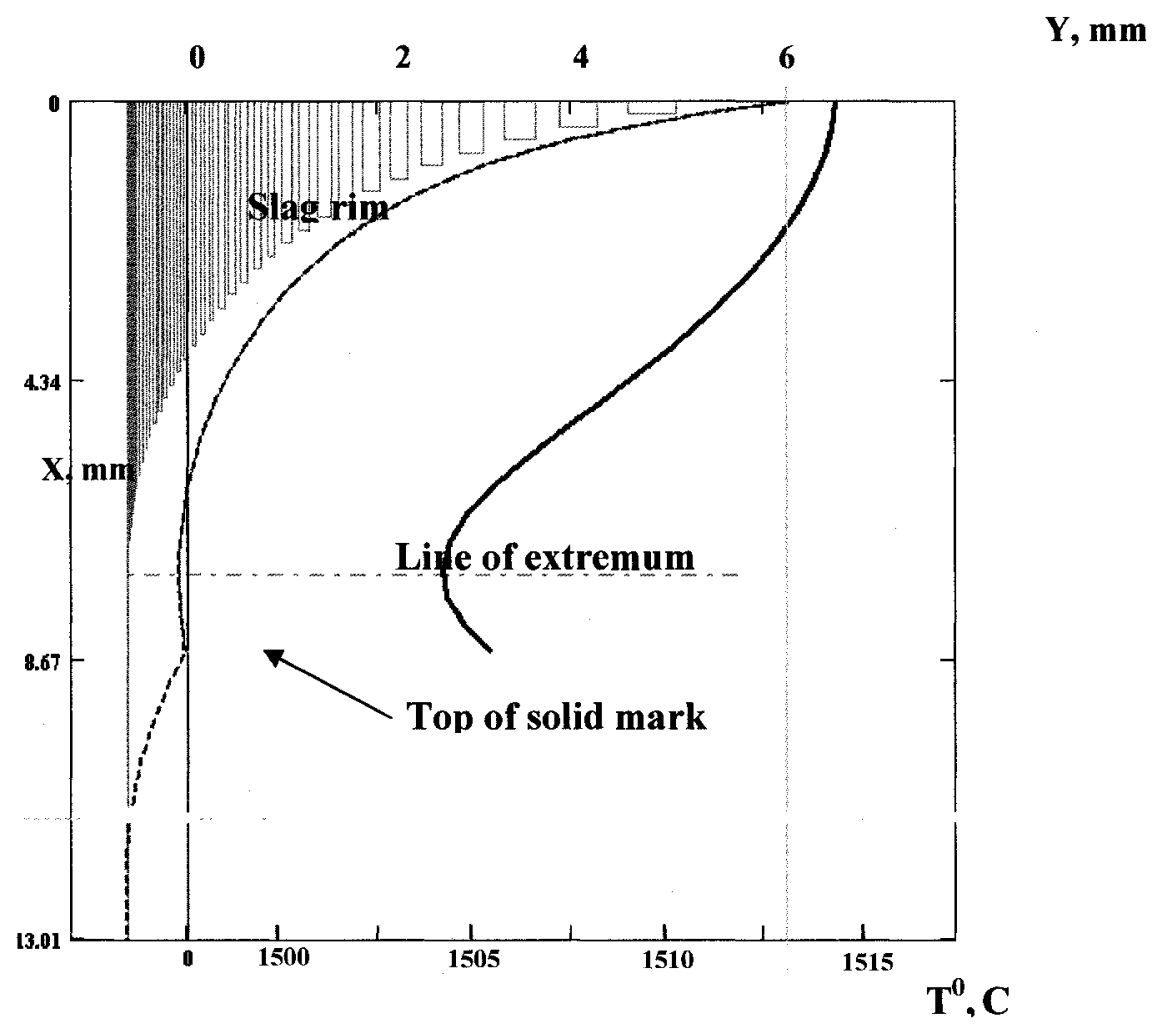

Figure 4.10 Calculated shape of meniscus (blue) and calculated meniscus temperature field (red)

In the Figure 4.10 the changing of the temperature of the meniscus along the meniscus height is shown. The blue dashed line is the calculated shape of meniscus, red line is the temperature distribution along the meniscus height.

After obtained meniscus temperature field at the end of first stage we can verify that $1 \mathrm{D}$ heat transfer equation can be used in proposed thermal model. Let the $q_{t}$ is the heat flux density in the direction tangent to meniscus and $q_{n}$ is the heat flux density in horizontal direction. The heat-flux density according to Fourier's law of thermal conductivity: $\quad q=\lambda \cdot \Delta T / h$ 
From Figures 4.9 and 4.10 and table 4.2 we have: $\Delta T=20^{\circ} C ; h=10 \mathrm{~mm}$;

$$
\lambda=23.2 \mathrm{~W} / \mathrm{m} \cdot{ }^{0} \mathrm{C} .
$$

$$
q_{t}=46,400 \mathrm{~W} / \mathrm{m}^{2}
$$

For $q_{n}$ we have: $\Delta T=1475^{\circ} \mathrm{C} ; h=4 m m ; \lambda=1.9 \mathrm{~W} / \mathrm{m} \cdot{ }^{0} \mathrm{C}$.

$$
q_{n}=700,600 \mathrm{~W} / \mathrm{m}^{2}
$$

hence $q_{t} / q_{n}=7 \%$. It confirms validity of our assumption about $1 \mathrm{D}$ heat transfer from the meniscus .

\subsection{Conclusions.}

- A mathematical model of the thermal state of meniscus was developed. Meniscus displacement and stretching were taken into consideration. In the estimation of the meniscus thermal state, the source function was introduced.

- Developed mechanical and thermal model of the meniscus can also be used for the mark formation study in the case of mold oscillation.

- $\quad$ The developed model can be further supplemented by the meniscus solidification calculation. It will permit to use the model for description of the meniscus thermal conditions at the second stage of mark formation. 


\section{Analysis of the adequacy of the developed model}

Approbation of the developed mechanical model was done for the purpose of testing the model by experimental data and possible correction model parameters. The level of correspondence between model and data was evaluated using some methods of mathematical statistics.

\subsection{Analysis of the adequacy of the mechanical model of the first stage of mark formation}

\section{Experimental data}

The data were obtained from the surface marks on real billets were used for adequacy test of the model. These data were represented by measurements of fixed

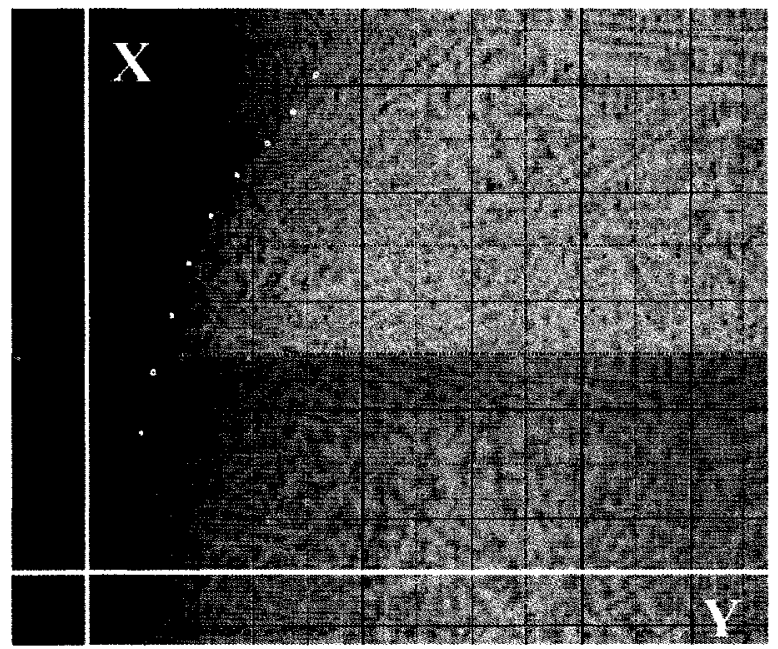

SCALE 1: $0.5 \mathrm{~mm}$

Figure 5.1 Photo of template with position of meniscus marked as yellow dots 
position of the meniscus, and were obtained by measurements of the templates images of surface marks. Figure 5.1 gives the sample of measurements for the medium-carbon lowalloyed steel. The experimental data values (Appendix B) represent a two-dimensional numerical file $x_{i}, y_{i}$. Quantity of pair's numbers we denote as $N$.

\section{Optimization of the model fitting parameters}

The developed model required a set of parameters that do not have an exact a priori determination. These fittings parameters are:

$H_{h}$ - height of the meniscus at the end of the first stage of mark formation, thus

$$
H_{G} \leq H_{h} \leq H_{\max }
$$

$\theta_{0}$ - initial angle of the meniscus ( Chapter 3.3).

Since the parameters $H_{h}$ and $\theta_{0}$ cannot be exactly assigned a priori, it is necessary to find them first.

The coordinate system of the theoretical model does not obviously coincide with coordinate system of measurements. The parameter, which corrects the value $x_{i}$ was introduced:

$$
z_{i}=x_{i}+r
$$

where $r$ - correction of initial point, which corrects the parameter $x ; r$ does not depend on the number of observation $i$.

Now equation 3.13 can be re-written as:

$$
y\left(x_{i}, H_{h}, \theta_{0}, r\right)=-Y\left(H_{h}, \theta_{0}\right)+Y\left(x_{i}, \theta_{0}, r\right),
$$


where $Y\left(H_{h}, \theta_{0}\right)=\int_{0}^{H_{h}} \frac{\left(B \cdot x^{2}+\sin \theta_{0}\right)}{\sqrt{1-\left(B \cdot x^{2}+\sin \theta_{0}\right)^{2}}} \cdot d x$

$$
Y\left(x_{i}, \theta_{0}, r\right)=\int_{0}^{x_{i}+r} \frac{\left(B \cdot x^{2}+\sin \theta_{0}\right)}{\sqrt{1-\left(B \cdot x^{2}+\sin \theta_{0}\right)^{2}}} \cdot d x
$$

Thus, during adequacy testing the following parameters were corrected: $H_{h}, \theta_{0}, r$.

The level of correspondence was evaluated using the residual sum of squares $(R S S) . R S S$ of the calculated and measured values:

$$
R S S=\sum_{i=1}^{N}\left[y_{i}-y\left(x_{i}, H_{h}, \theta_{0}, r\right)\right]^{2}
$$

where $x_{i}, y_{i}$ - pairs of numbers, which determine the position of the point on the meniscus, these pairs were found using experimental measurements;

$y\left(x_{i}, H_{h}, \theta_{0}, r\right)$ - predicted by the model.

The best approximation is obtained if we will get the minimum value of expression (5.2). From this condition fitting parameters were found (Table 5.1). Minimization was done using mathematical software written for "MathCAD" (Appendix B, "Adequacy test").

\section{Test of adequacy between experimental data and model}

The conclusion that the model is adequate to the experimental data was done on the basis of Fisher test. Fisher's test is just the determination of the ratio of the estimated variances of two distributions. If the following inequality (5.3) is satisfied, then the model is adequate to the experimental data.

$$
\frac{s_{a d}^{2}}{s_{r e p}^{2}} \leq F_{1, N-p-1}^{\alpha}
$$


where $s_{a d}^{2}=\frac{R S S}{N-p-1}-$ the variance of adequacy;

$N-p-1-$ the number of degree of freedom for variance of adequacy;

$N$ - the number of experimental data;

$p=3$ - the number of the parameters, determined by selection of their values for the best correspondence between experimental data and model;

$s_{\text {rep }}^{2}$ - variance of reproducibility;

1 - the number of the denominator degrees of freedom (for the variance of reproducibility);

$F_{1, N-p-1}^{\alpha}-$ Fisher ratio, the value of Fisher ratio we can find from the table of Fdistributions [43]. In this case the level of significance accepted as $\alpha=0,05$ (probability that the null hypothesis would be reject even if null hypothesis is true [44]).

The dispersion of reproducibility was evaluated as follows:

Within the present research it was found that the maximum error of positioning of the point on the mark surface is $\pm 0,25 \mathrm{~mm}$ (systematic error, i.e. half of scale, see Figure 5.1). Hence, the length of interval is $\Delta l=0,50 \mathrm{~mm}$. It is known that for the normal distribution $95 \%$ confidence interval corresponds to \pm 2 standard deviation. From here we can write: $\Delta l=4 \cdot S_{\text {rep }}$. Then the dispersion of reproducibility can be determined:

$$
s_{\text {rep }}^{2}=\left(\frac{\Delta l}{4}\right)^{2}
$$


By the fact that the image of template was increased by 20 times, the value of the dispersion of reproducibility needs to be corrected:

$$
s_{\text {rep }}^{2}=\left(\frac{\Delta l}{4 \cdot 20}\right)^{2}=\left(\frac{0,5}{4 \cdot 20}\right)^{2}=0.000039
$$

\subsection{Results of the model adequacy testing.}

Adequacy testing of the model was done for four samples, obtained from the surface of the different ingots. An example of the parameter $H_{h}$ and $\theta_{0}$ optimization results is given in Figure 5.2:

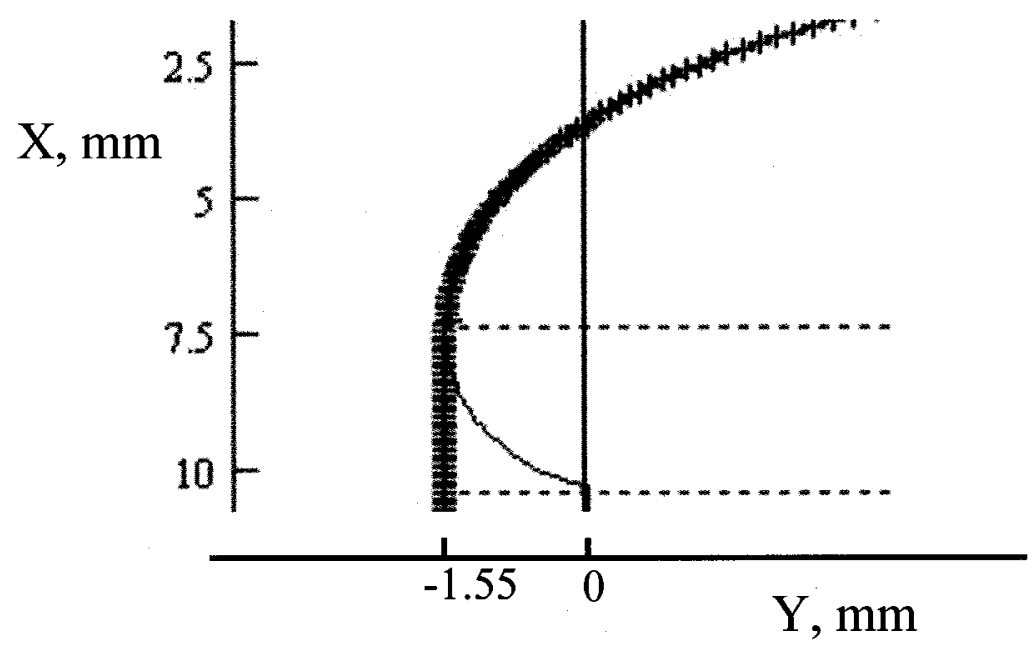

Figure 5.2 Results of optimization for the parameters $H_{h}$ and $\theta_{0}$, number of points $N=15 ; \theta_{0}=0,05^{\circ}$

green wide line - solid slag;

black line - meniscus;

blue crosses - experimental points

The results of calculations for four samples are given in the Table 5.1. 
Table 5.1 The results of calculations

\begin{tabular}{|c|c|c|c|c|c|c|c|c|}
\hline \multirow{2}{*}{$\begin{array}{l}\text { Sa } \\
\text { mp } \\
\text { les }\end{array}$} & \multirow{2}{*}{$\begin{array}{c}\text { Num } \\
\text { ber } \\
\text { of } \\
\text { point } \\
s\end{array}$} & \multicolumn{2}{|c|}{$\begin{array}{c}\text { Calculated } \\
\text { parameters of the } \\
\text { model }\end{array}$} & \multirow[b]{2}{*}{$R S S$} & \multirow[b]{2}{*}{$N-p-1$} & \multirow{2}{*}{$\frac{s_{a d}^{2}}{s_{r e p}^{2}}$} & \multirow[b]{2}{*}{$F_{1, N-p-1}^{\alpha}$} & \multirow{2}{*}{$\begin{array}{c}\text { Corres } \\
\text { ponden } \\
\text { ce }\end{array}$} \\
\hline & & $H_{h} / H_{\mathrm{ma}}$ & $\theta_{0}+90$ & & & & & \\
\hline 1 & 15 & 0.963 & 0.05 & \begin{tabular}{|l|l|}
$\mathbf{0 . 0 2 0 3 3}$ \\
\end{tabular} & 12 & 43.37 & 243.91 & yes \\
\hline 2 & 9 & 0.798 & 0.5 & 0.008617 & 6 & 36.76 & 233.99 & yes \\
\hline 3 & 5 & 0.877 & 0.05 & 0.005893 & 2 & 75.43 & 199.50 & yes \\
\hline 4 & 5 & $\mathbf{0 . 9 3 7}$ & 0.05 & 0.0095 & 2 & 121.60 & 199.50 & yes \\
\hline
\end{tabular}

Table 5.1 data shows, that the model corresponds well to the experimental data, obtained in varied conditions. The Proposed model has quantitative and qualitative correspondence. Qualitative correspondence can be seen in Figure 5.2. This figure demonstrates that the points, obtained on the solidified part of the meniscus, do not exceed the top of the solidified mark, what corresponds to the prediction of the model. The points correspond to the meniscus extremum (model presentation) also coincides well with the experimental data. 


\section{Conclusions. Advantages of the developed model}

The SM formation process occurs at the initial stage of solidification of the billet's shell and defines stability of continuous casting and quality of the billets surface. In order to describe the complex process of SM formation a two stage approach to the full cycle of SM formation was suggested. The first stage describes the changes of the meniscus position before touching the wall of the mold, after which the second stage begins. A mathematical model describing the first stage of the SM formation process was developed in this thesis. Oscillation factor which considerably complicates the modeling process was eliminated. Basic results of the modeling were tested during the continuous casting process in an immovable mold.

\section{Novel features of the mechanical model}

The developed mechanical model describes meniscus displacement and stretching during the first stage of SM formation process.

- The numerical analysis of the meniscus displacement and stretching during the first stage shows the existence of the two separate phases of meniscus movement. During the first phase meniscus moves away from the mold wall and during second phase meniscus comes to the mold wall.

- The top of the solidified mark is located at the same distance from the mold wall during the whole cycle of the mark formation;

- The upper meniscus after the first stage of mark formation is immovable. 
- The developed numerical model has been tested against the experimental data. The level of correspondence between simulated and measured data has been evaluated and shows that the model corresponds well to the experimental data.

- The model was used to completely describe the process of displacement and deformation of meniscus. Results generated by the mechanical model were further used in the simulation of the thermal processes on meniscus.

\section{Distinctive novel features of thermal model}

- For purpose of thermal analysis the equation of $1 \mathrm{D}$ transient heat transfer has been derived and the source function was obtained. Initial condition and boundary conditions were formulated on the basis of physical conception of mechanical model of SM formation process.

- The source function was obtained on the basis of detailed description of the meniscus stretching and considers the superheat which comes with portions of liquid metal from the core of billet to the meniscus.

- The numerical model of the temperature distribution on meniscus during its evolution was developed.

- The thermal model was used to predict of the thickness of the thermal boundary layer $\left(\delta_{T}\right)$ accepting that at the end of the first phase the minimal temperature of the meniscus equals to the temperature of liquidus. 


\section{Bibliography}

1. Irving, W.R. "Continuous casting of steel", The Institute of Materials, London 1993 2. J. Savage, W.H. Pritchard, "The problem of Rupture of the Billet in the Continuous Casting Of Steel", the Journal of the Iron and Steel Institute, Vol. 178, November 1954, pp.269-277.

3. J. Elfsberg, "Oscillation Mark Formation in Continuous Casting Process", Casting of Metals, Royal Sweden Institute of Technology, 2003.

4. B.G. Thomas, "Continuous Casting: Modeling," The Encyclopedia of Advanced Materials, (J.Dantzig, A. Greenwell, J. Michalczyk, eds.) Pergamon Elsevier Science Ltd., Oxford, UK, Vol.2, 2001, 8p., (Revision 3, Oct. 12, 1999).

5. McGraw-Hill Dictionary of Physics, Sybil P. Parker (Editor in Chief), New-York, 1985.

6. Riboud P. V., Larrecq M., Steelmaking Conference Proceedings, Vol. 74, Washington D.C., USA, 1991, pp. 78-82.

7. Mills K. C., Steel Technology International, 1994.

8. Abratis H., Höfer F., Jünemann M., Sardemann J., Stoffel H., Stahl und Eisen 116 (1996), Nr. 4, pp. 85-91.

9. Pinheiro C. A., Samarasekara I.V., Brimacombe J.K., Iron and Steelmaker, October 1994, pp.55-56

10. Branion R.V., Mold Powders for Continuous Casting and Bottom Pour Teeming, Iron and Steel Society, AIME, pp. 3-14.

11. Mc Cauley W. L., Apelian D., Iron and Steelmaker, August 1983. 
12. Gray R., Marston H., Steelmaking Conference Proceedings, Vol. 74, Washington D.C., USA, 14-17 Apr 1991, pp. 93-102.

13. Szekeres E. S., "Overview of mold oscillation in continuous casting", Iron and steel Engineer, July 1996, pp. 29-37.

14. Wolf M. M., Mold Powders for Continuous Casting and Bottom Pour Teeming, Iron and Steel Society, AIME, pp. 33-44.

15. N.A. McPherson and R.E. Mercer. Ironmaking and Steelmaking. 1980, vol. 67, pp.167-79.

16. T. Okazaki, H. Tomono, K. Ozaki, and Y. Akabane: Tetsu-to-Hagane, 1982, vol. 68, p.S929.

17. H. Oka, Y. Eda, T. Koshikawa, H. Nakato, T. Nozaki, and Y. Habu: Tetsu-to-Hagane, 1983, vol. 69, p. S1032.

18. T. Kuwano, N. Shigematsu, F. Hoshi, and H. Ogiwara: Ironmaking and Steelmaking, 1983, vol.10, pp.75-81.

19. T. Emi, H. Nakato, Y. Iida, K. Emoto, R. Tachibana, T. Imai, and H. Bada: Proc. 61 st NOH-BOSC, 1978, pp.350-61.

20. Kawakami, T. Kitagawa, H. Mizukami, H. Uchibori, S.Miyahara, M. Suzuki, and Y. Shiratani: Tetsu-to- Hagane, 1981, vol.67, pp.1190-99.

21. N.A. McPherson, A.W. Hardie, and G. Patric: ISS Transactions, 1983, vol.3, pp.2136. 
22. Takeuchi E., Brimacombe J.K., "The Formation of Oscillation Marks in the Continuous Casting of Steel Slabs", Metallurgical Transactions B, Vol. 15 B, September 1984, pp. 493-509.

23. Waters, B.H.C., "Continuous casting of Non-Ferrous Metals, Parts V and VI", Metal Treatment \& Drop Forging, Vol.20, 1953, p.79 and 103.

24. Thornton, D. R., “ An Investigation on the Function of Ingot Mold Dressings”, Journal of the Iron and Steel Institute, vol. 7, July 1956, p.300-315.

25. Savage J., "A New Reciprocation Mold Cycle to Improve Surface Quality of Continuously Cast Steel”, Iron and Coal Trades Review, Vol. 182, 4, April 14, 1961, p.787-795.

26. Sato R.," Powder Fluxes for Ingot Making or Continuous Casting", Bull. Jap. Institute of Metals, Vol. 12, 1973 (No. 6), p. 391.

27. Sato R., "Powder Fluxes for Ingot Making and Continuous Casting", 62 nd $N$ ational Open Hearth and Basic Oxygen Steel Conference proceedings, Vol. 62, Detroit, Michigan, 25-28 Mar, American Institute of Mining, Metallurgical, and Petroleum Engineers, Vol.62, 1979, pp. 48-67.

28. Davies I.G., and Sharp R.M., "The Formation of Reciprocation Marks During Continuous Casting of Slabs", British Steel Corporation Technical Note No. PDN/433/77, 1977.

29. Saucedo I.G., Beech J., Davies G. J., "The Development of Surface in Steel Ingots and Strands", Proceedings of $6^{\text {th }}$ International Vacuum Metallurgy Conference on Special Melting: San Diego, California, April 23-27, 1979, pp. 885-904. 
30. Saucedo I. G., "Early Solidification During the Continuous Casting of Steel", $74^{\text {th }}$ Steelmaking Conference Proceedings, Vol. 74, Washington D.C., USA, 14-17 Apr 1991, pp. 79-89.

31. Tomono H., Ackermann P., Kurz W., Heinemann W., "Surface mark formation in continuous casting of steel", Proceedings of a Symposium: Continuous Casting of Small Cross Sections, Pittsburgh, Pa., 8 Oct 1980, Metallurgical Society of AIME, pp. 55-73.

32. Takeuchi E., Brimacombe J.K.,"Effect of Oscillation-Mark Formation on the Surface Quality of Continuously Cast Steel Slabs", Metallurgical Transactions B, Vol. 16B, September 1985, pp. 605-625

33. Samarasekera I.V., Brimacombe J.K., Bommaraju R., "Mold Behaviour and Solidification in the Continuous Casting of Steel Billets", ISS Transactions, Vol. 5, 1984, pp.79-94.

34. Suzuki T., Miyata Y., Kunieda T., J. Japan Inst. Metals, Vol. 50, No.2 (1986), pp.208-214

35. Delhalle A., Larrecq M., Petegnief J., Radot J.P., La Revue de Métallurgie -CIT, June 1989, pp.483-489.

36. Lainez E., Busturia J. C., "The E.L.V. Solidification Model in Continuous Casting Billet Molds Using Casting Powder", 1st European Conference on Continuous Casting, Florence, Italy September23-25, 1991, pp. 1.621-1.631.

37. J. Sengupta, H.J. Shin, B.G Thomas, S.H. Kim, "Micrograph evidence of meniscus solidification and sub-surface microstructure evolution in continuous cast ultralowcarbon steels", Acta Materialia, 54(2006),pp.1165-1173. 
38. Mikloukhine S, Tsukerman V., "The mechanism of the slag renewing during continuous casting with low extraction speed", proceeding of a $9^{\text {th }}$ Conference: Problems of ingots casting, Volgograd, USSR, 1990.

39. Joonpyo Park, Heetae Jeong, Hoyoung Kim and Jongkeun Kim, "Laboratory Scale Continuous Casting of Steel Billet with High Frequency Magnetic Field", ISIJ International, Vol. 42 (2002), No. 4, pp. 385-391.

40. Rajil Saraswat, A. B. Fox, K. C. Mills, P. D. Lee and B. Deo, "The factors affecting powder consumption of mold fluxes", Scandinavian Journal of Metallurgy Vol. 33, 2004, pp. 85-91

41. Hermann Schlighting, Boundary layer theory. New York, McGrow-Hill Book Company, 1968, p.271.

42. Samoylovich Y.A., Krulevitskiy S.A., Goriainov V.A., Kabakov Z.K. Heat processes in continuous casting of steel. Moscow, Metallurgy, 1982, p.152.

43. D. Hudson, Statistic for physics. Moscow, World, 1970.

44. W. T. Eadie, D. Dryard, F.E. James, M. Roos, B. Sadoulet, "Statistical methods in experimental physics". Nort-Holland Publishing Company - Amsterdam-London, 1971 
Appendix A

Thermophysical model of meniscus for $1^{\text {st }}$ stage formation 
Parametric repres. of solution

Parameter of limiting value of meniscus $\mathrm{dbh}$

Parameter of top of solidified mark displacement dd

Liquid steel density, $\mathrm{Kg} / \mathrm{M}^{3}$

$$
\text { RoM : }=\mathbf{7 2 0 0}
$$

Liquid slag density, $\mathrm{Kg} / \mathrm{M}^{3}$

$$
\operatorname{RoS}:=\mathbf{2 6 6 7 . 3}
$$

Gravity acceleration, $\mathrm{M} / \mathrm{s}^{2}$

$$
\mathrm{g} 1:=9.807
$$

Coefficient of interphase tension, N/M

$$
\mathrm{SmS}:=\mathbf{1 . 2 0 5 8}
$$

$$
B:=\left[(\operatorname{RoM}-\operatorname{RoS}) \cdot \frac{\mathrm{g} 1}{2 \mathrm{SmS}(10)^{6}}\right]
$$

$\mathrm{B}=\mathbf{0 . 0 1 8}$

\section{Upper meniscus Overflow process}

Initial angle, degree

$$
\mathrm{Om}:=\mathbf{5}
$$

Calculated initial angle, radian

$$
\mathrm{Om} 1(\mathrm{Om}):=\frac{-\pi}{\mathbf{2}}+\frac{\mathrm{Om} \pi}{\mathbf{1 8 0}}
$$

sin of initial angle

$$
\operatorname{pp}(O m):=\sin (O m 1(O m)) \quad p p(O m)=-0.996
$$

Coordinate $\mathrm{x}=\mathrm{H}_{\mathrm{G}}$ along meniscus height, (point of

$$
\mathrm{HI}(\mathrm{Om}):=\sqrt{\frac{1-\mathrm{pp}(\mathrm{Om})}{\mathrm{B}}}
$$
extremum on meniscus) $y=y_{\max }$

$\mathrm{H}_{\text {max }}$, initial angle Omega $>--90^{0}$

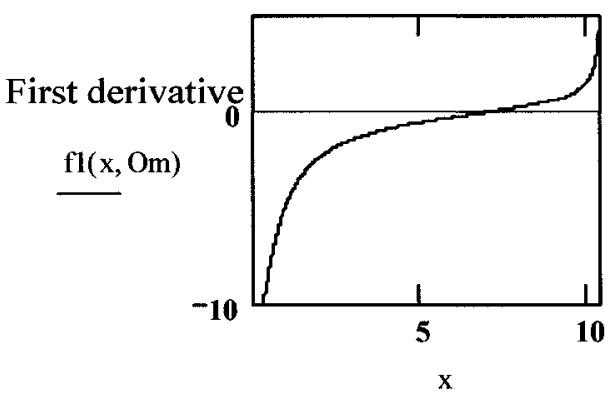

$$
\mathrm{H} 1(\mathrm{Om})=\mathbf{1 0 . 4 0 7}
$$

$$
\begin{aligned}
& \mathrm{hl}(\mathrm{Om}):=\sqrt{\frac{-\mathrm{pp}(\mathrm{Om})}{\mathrm{B}}} \\
& \mathrm{hl}(\mathrm{Om})=\mathbf{7 . 3 5 2} \\
& \mathrm{fl}(\mathrm{x}, \mathrm{Om}):=\frac{\left(\mathrm{pp}(\mathrm{Om})+\mathrm{B} \cdot \mathrm{x}^{2}\right)}{\sqrt{1-\left(\mathrm{pp}(\mathrm{Om})+\mathrm{B} \cdot \mathrm{x}^{2}\right)^{2}}}
\end{aligned}
$$


Assign limiting height of meniscus $\mathrm{H}_{h}=b b$

Parameter of limiting height of

meniscus $0<\mathrm{dbh}<1 \quad \mathrm{x}_{\mathrm{G}}<\mathrm{H}_{\mathrm{h}}<\mathrm{H}_{\text {ma }}$

$\mathrm{dbh}:=0.9$

$\mathrm{bb}(\mathrm{dbh}, \mathrm{Om})=\mathbf{1 0 . 1 0 1}$

$$
\begin{aligned}
& \widehat{b b(d b h, O m):=h 1(O m)+d b h(H 1(O m)-h 1(O m))} \\
& \mathrm{H} 1(\mathrm{Om})-\mathrm{bb}(\mathrm{dbh}, \mathrm{Om})=\mathbf{0 . 3 0 6}
\end{aligned}
$$

Junction point(meniscus and liquid surface of metal coord.

$$
\operatorname{Bh} 0(d b h, O m):=-\left[\int_{0}^{b b(d b h, O m)} \mathrm{fl}[x,(O m)] d x\right]
$$

Profile of rim

$\operatorname{BhO}(\mathrm{dbh}, \mathrm{Om})=\mathbf{1 4 . 3 1 4}$

Vertical coordinate axis located on the top of solidified mark

Rim line equation.

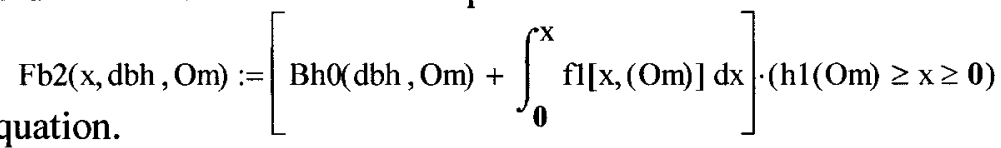

$\mathrm{Fb}(\mathrm{x}, \mathrm{dbh}, \mathrm{Om}):=\mathrm{Fb} 2(\mathrm{x}, \mathrm{dbh}, \mathrm{Om})+\mathrm{Fb} 2(\mathrm{~h} 1(\mathrm{Om}), \mathrm{dbh}, \mathrm{Om}) \cdot(\mathrm{x}>\mathrm{h} 1(\mathrm{Om}))$

Solid slag line equation

Initial location of the top of solidified mark $\delta x$ (along $F b 2(20, d b h, O m)=0$

axis X) $\mathrm{zz} 1 \quad \mathrm{Fb} 2(\mathrm{hl}(\mathrm{Om}), \mathrm{dbh}, \mathrm{Om})=\mathbf{- 1 . 5 5} \quad \mathrm{Fb}(\mathrm{hl}(\mathrm{Om}), \mathrm{dbh}, \mathrm{Om})=\mathbf{- 1 . 5 5}$

Given

Liquid meniscus length

In the end of 1 phase

$\mathrm{Fb}(\mathrm{z}, \mathrm{dbh}, \mathrm{Om})=\mathbf{0} \quad \mathrm{zzl}:=\operatorname{Find}(\mathrm{z}) \quad \mathrm{zzl}=\mathbf{3 . 9 7 9}$

Parameter of displacement of solidified mark dd

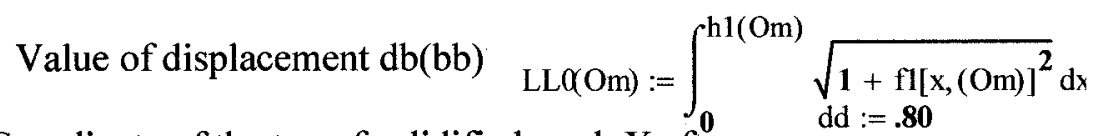

Coordinate of the top of solidified mark $X$ after its displacement $(\mathrm{bb} 1)=$ current height of meniscus h $\mathrm{db}(\mathrm{dd}, \mathrm{dbh}, \mathrm{Om})=\mathbf{4 . 8 9 8}$

Coordinate of the extremum point along $\mathrm{X},\left(\mathrm{y}=\mathrm{y}_{\max }\right)$ on solidified mark $\mathrm{db}(\mathrm{dd}, \mathrm{dbh}, \mathrm{Om}):=\mathrm{dd} \cdot(\mathrm{bb}(\mathrm{dbh}, \mathrm{Om})-\mathrm{zz})$ $\mathrm{bbl}(\mathrm{dd}, \mathrm{dbh}, \mathrm{Om}):=\mathrm{db}(\mathrm{dd}, \mathrm{dbh}, \mathrm{Om})+\mathrm{zz} 1$

Coordinate of junction point if $h$ bbl $(\mathrm{dd}, \mathrm{dbh}, \mathrm{Om})=\mathbf{8 . 8 7 7}$ $\mathrm{hh} 3(\mathrm{dd}, \mathrm{Om}):=\mathrm{h} 1(\mathrm{Om})+\mathrm{db}(\mathrm{dd}, \mathrm{dbh}, \mathrm{Om})$ $\mathrm{hh} 3(\mathrm{dd}, \mathrm{Om})=\mathbf{1 2 . 2 4 9}$ 


$$
\begin{gathered}
\text { Bh(dd, dbh, Om }):=-\left[\int_{0}^{b b l(d d, d b h, O m)} f 1[x,(O m)] d x\right] \\
B h(d d, d b h, O m)=\mathbf{1 5 . 5 0 8}
\end{gathered}
$$

Meniscus line equation, meniscus leaned on solidif. mark

$$
\begin{aligned}
& \mathrm{Fb} 3(\mathrm{x}, \mathrm{dd}, \mathrm{dbh}, \mathrm{Om}):=\left[\mathrm{Bh}(\mathrm{dd}, \mathrm{dbh}, \mathrm{Om})+\int_{0}^{\mathrm{x}} \mathrm{fl}[\mathrm{x},(\mathrm{Om})] \mathrm{dx}\right] \cdot(\mathrm{x} \leq \mathrm{bb} 1(\mathrm{dd}, \mathrm{dbh}, \mathrm{Om})) \\
& \mathrm{x}:=\mathbf{5} \quad \mathrm{Fb} 3(\mathrm{x}, \mathrm{dd}, \mathrm{dbh}, \mathrm{Om})=\mathbf{0 . 3 7 3} \quad \mathrm{Fb} 3(\mathrm{zz} 1, \mathbf{1}, \mathrm{dbh}, \mathrm{Om})=-\mathbf{2 . 5 5 5} \times \mathbf{1 0}^{-\mathbf{6}}
\end{aligned}
$$

Meniscus line equation, meniscus leaned on solidif. mark + section of solid. mark + solid slag.

$\mathrm{Fb} 4(\mathrm{x}, \mathrm{dd}, \mathrm{dbh}, \mathrm{Om}):=\mathrm{Fb} 2(\mathrm{x}-\mathrm{db}(\mathrm{dd}, \mathrm{dbh}, \mathrm{Om}), \mathrm{dbh}, \mathrm{Om}) \cdot(\mathrm{x}-\mathrm{db}(\mathrm{dd}, \mathrm{dbh}, \mathrm{Om})>\mathrm{zz} 1)+\mathrm{Fb} 2(\mathrm{~h} 1(\mathrm{Om}), \mathrm{dbh}, \mathrm{Om}) \cdot(\mathrm{x}-\mathrm{db}(\mathrm{dd}, \mathrm{dbh}, \mathrm{Om}) \geq \mathrm{h} 1(\mathrm{Om}))+\mathrm{Fb}$

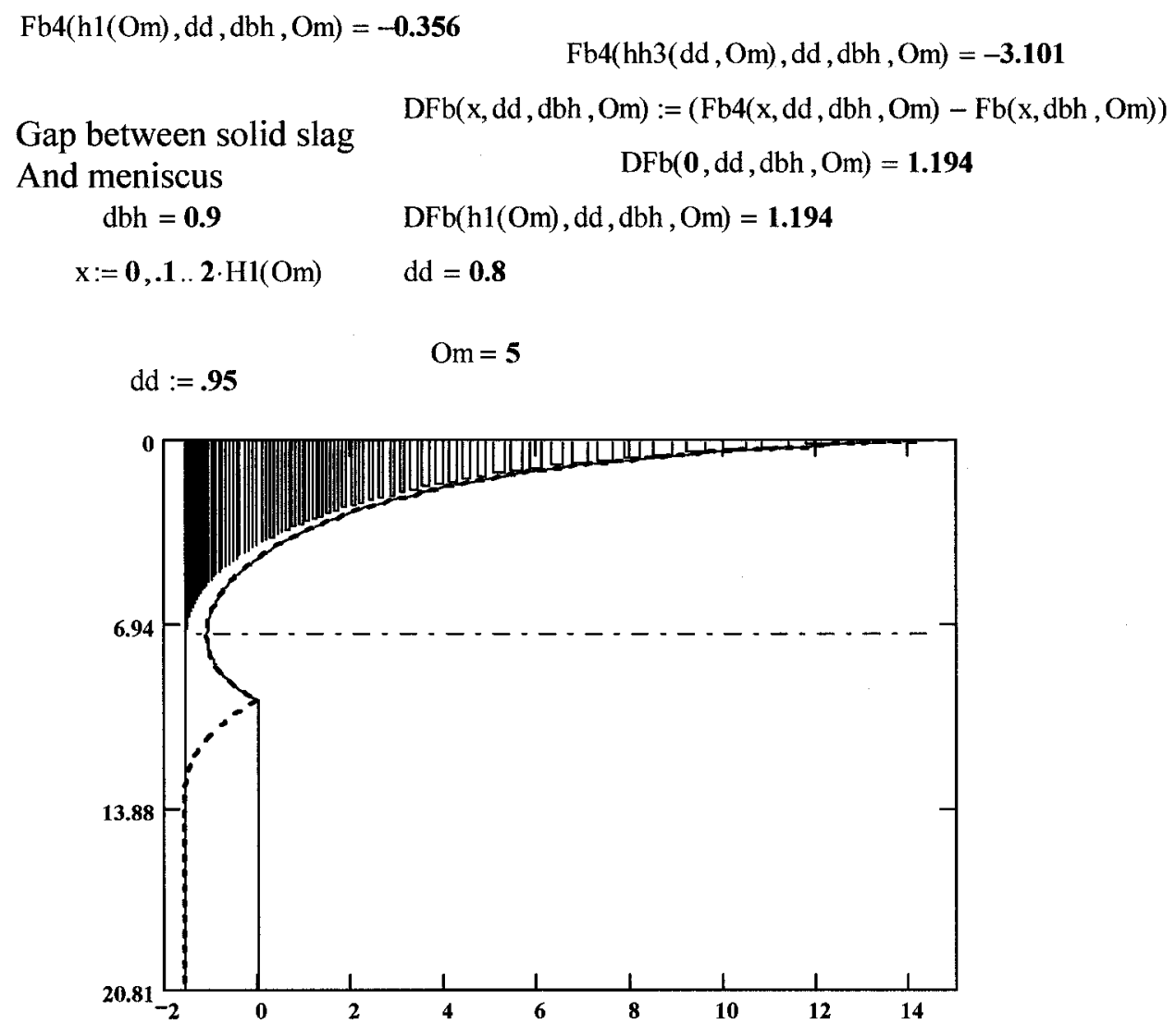


Meniscus height parameter dd if The volume $=\max$ $(0<\mathrm{dd}<1)$

$$
\begin{aligned}
& \mathrm{dd} 0:=\frac{\mathrm{h} 1-\mathrm{zz} 1}{\mathrm{db}(0.9)} \\
& \mathrm{dd} 0=\mathbf{0 . 6 6}
\end{aligned}
$$

Initial position of observation point on the bases part of meniscus for Temperature changes

Assign $\mathrm{B}\left(\mathrm{x}_{0}\right)$ with coordinate $\mathrm{x}=\mathrm{Bx}(0<\mathrm{Bx}<\mathrm{bbl}(\mathrm{dd} 0, \mathrm{dbh}))$

Parameter of position $\mathrm{xx}(0<\mathrm{xx}<1)$

Find coordinate $\mathrm{x} B\left(\mathrm{x}_{0}\right)$ along $\mathrm{X}(0<\mathrm{Bx}<\mathrm{hh}(\mathrm{dd} 0, \mathrm{dbh})$ 
$\mathrm{Bx} Q(\mathrm{xx}):=\mathrm{xxbb} 1(\mathrm{dd} 0, \mathrm{dbh}, \mathrm{Om})$

$$
\mathrm{xx}:=.5
$$

$Y x(x x):=F b 3(B x \propto(x x), d d 0, d b h, O m)$

$\mathrm{Yx}(\mathrm{xx})=\mathbf{1 . 4 5 6}$

Parameter of displacement

of solid mark from the base position $1>\mathrm{dd} 01>\mathrm{dd} 0$

Meniscus length up to the point $\mathrm{B}_{0}(\mathrm{x})$

$$
\operatorname{LLBX}(x x):=\int_{0}^{B x O(x x)} \sqrt{1+f 1[x,(O m)]^{2}} d x
$$

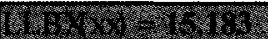

Liquid meniscus length after top displ.to dd 01

Meniscus lengthening after top displ. from base position Meniscus length. from point $\mathrm{B}\left(\mathrm{x}_{0}\right)$ to $\mathrm{B}(\mathrm{x})$

$$
\operatorname{LL}(x x, d d 01):=\operatorname{DLL}(d d 01) \cdot \operatorname{LLBX}(x x)
$$

$$
\operatorname{LL}(x x, d d 01)=15.885
$$

$\operatorname{LLx}(x x, \mathrm{dd} 01)=\mathbf{1 5 . 8 8 5}$

$$
\operatorname{LL}(B b x):=\int_{0}^{B b x} \sqrt{1+f 1[x,(O m)]^{2}} d x
$$

DL(xx, dd01, Bbx) := LLx(xx, dd01) - LL(Bbx)

$\mathrm{dd} 01:=1 \quad \mathrm{xx}:=1$

$B b x:=.1$ Given $\quad$ DL $(x x, \mathrm{dd} 01, \mathrm{Bbx})=\mathbf{0}$

$\operatorname{Bbx} 1(x x, d d 01)=10.101$

Tangent in point $\mathrm{B}(\mathrm{x})$ : $\cos$

$$
\cos (x x, d d 01)=0.467
$$

Thickness of solid slag in point $\mathrm{B}(\mathrm{x})$ :

DY0

$$
\mathrm{x}:=\mathrm{h} \mathbf{1}(\mathrm{Om})
$$

$\operatorname{DY} Q(x, d b h, O m)=0$

$\mathrm{dd}:=\mathbf{0 . 8}$ 
Finding the point $\mathrm{B}(\mathrm{c})$, which cam to the top

Gap between meniscus and solid

slag in point $\mathrm{B}(\mathrm{x})$ : $\mathrm{DFb}$

$\operatorname{DFb}(\mathrm{x}, \mathrm{dd}, \mathrm{dbh}, \mathrm{Om})=\mathbf{1 . 1 9 4}$

Meniscus length after top displ.

$$
\mathrm{dd}:=\mathbf{1}
$$

Meniscus length to the final position $B(c) b b 1(d d 0, d b h, O m)=\mathbf{8 . 0 2 2}$

Length of the base part of meniscus

$$
\text { LLB }(0, \mathrm{dbh}, \mathrm{Om})=\mathbf{1 5 . 1 3 8}
$$

Meniscus length to $B(c)$

$$
\operatorname{LLB}(\mathrm{dd} 0, \mathrm{dbh}, \mathrm{Om})=\mathbf{1 9 . 6 2}
$$

$$
\operatorname{ULL}(\mathrm{dbh}, \mathrm{Om}):=\frac{\operatorname{LLB}(\mathrm{dd}, \mathrm{dbh}, \mathrm{Om})}{\operatorname{LLB}(\mathrm{dd} 0, \mathrm{dbh}, \mathrm{Om})} \operatorname{ULL}(\mathrm{dbh}, \mathrm{Om})=\mathbf{1 . 1 3 5}
$$

Liquid meniscus lengthening in respect to base

$$
\operatorname{LL}(\mathrm{dbh}, \mathrm{Om})=\mathbf{1 3 . 3 4}
$$

$$
\operatorname{LLC}(\mathrm{dbh}, \mathrm{Om}):=\frac{\operatorname{LLB}(0, \mathrm{dbh}, \mathrm{Om})}{\operatorname{ULL}(\mathrm{dbh}, \mathrm{Om})}
$$

$$
\operatorname{LL}(B x):=\int_{0}^{B x} \sqrt{1+f l(x, O m)^{2}} d x
$$

Coordinate $\mathrm{x}$ finding for point $\mathrm{B}(\mathrm{c})$ : $\mathrm{x}=\mathrm{Bcx}$

$$
\operatorname{DLQ}(\mathrm{dbh}, \mathrm{Om}, \mathrm{Bx})=\mathbf{0}
$$

$\operatorname{DLC}(d b h, O m, B x):=\operatorname{LLQ}(d b h, O m)-\operatorname{LL}(B x)$

$$
B \mathbf{B}:=.1 \quad \text { Given }
$$

$$
\mathrm{Bcx}(\mathrm{dbh}, \mathrm{Om}) \mathbf{2 . 8 6 4}
$$

Coordinate $\mathrm{y}$ finding for $\mathrm{B}(\mathrm{c}): \mathrm{x}=\mathrm{Yc} 01$

$$
\operatorname{By}(\mathrm{dbh}, \mathrm{Om})=\mathbf{2 . 8 9 3}
$$

$$
\mathrm{By}(\mathrm{dbh}, \mathrm{Om}):=\mathrm{Fb} 3(\mathrm{Bcx}(\mathrm{dbh}, \mathrm{Om}), \mathrm{dd} 0, \mathrm{dbh}, \mathrm{Om})
$$

Parameter of coordinate $x$ for point $\mathrm{B}_{0}(\mathrm{c}): \mathrm{xc}=\mathrm{Bcx}$

$$
\mathrm{xc}:=\frac{\mathrm{Bcx}(\mathrm{dbh}, \mathrm{Om})}{\mathrm{bb} 1(\mathrm{dd} 0, \mathrm{dbh}, \mathrm{Om})} \quad \mathrm{xc}=\mathbf{0 . 3 5 7}
$$

Coordinate $\mathrm{B}_{\mathrm{h}}(\mathrm{c})$ after meniscus stopped

$$
\operatorname{LL}(\mathrm{h} 1(\mathrm{Om}))=18.946
$$

$$
\operatorname{LL}(\mathrm{Bbx} 2):=\int_{0}^{\mathrm{Bbx} 2} \sqrt{1+\mathrm{f} 1[\mathrm{x},(\mathrm{Om})]^{2}} \mathrm{dx}
$$

The liquid meniscus length if the liq. slag vol.=max

$$
\operatorname{LLB} Q \mathrm{dd} 0, \mathrm{dbh}, \mathrm{Om})=\mathbf{1 9 . 6 2}
$$

Initial position of the point of observation (for temperature calc.) 
Meniscus length till the point $\mathrm{B}_{0}(\mathrm{c}) \mathrm{x}:=\mathrm{xc}$

dd01 := 1

$$
\operatorname{LLC}(\mathrm{dbh}, \mathrm{Om})=\mathbf{1 3 . 3 4}
$$

Meniscus length after top displacement to 1

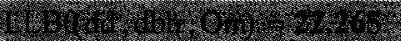
Meniscus lengthening after the top DLL(dd01):= $\frac{\operatorname{LBB}(\mathrm{dd} 01, \mathrm{dbh}, \mathrm{Om})}{\operatorname{LLB}(\mathrm{dd} 0, \mathrm{dbh}, \mathrm{Om})}$
displacement

$$
\operatorname{DLL}(\mathrm{dd} 01)=\mathbf{1 . 1 3 5}
$$

Liquid meniscus length till point $B(c)$ after top displacement from the base position till the end of first stage $\operatorname{LLx}(\mathrm{xx}, \mathrm{dd} 01):=\operatorname{DLL}(\mathrm{dd} 01) \cdot \operatorname{LLBX}(\mathrm{xx})$ Coordinate $\mathrm{x}$ for point $\mathrm{B}(\mathrm{c})$ finding: $\mathrm{x}=\mathrm{Bx} 1$

$\operatorname{LLx}(x x, d d 01)=\mathbf{1 5 . 1 3 8}$

$$
\operatorname{LLx}(x x, d d 01)=\mathbf{1 5 . 1 3 8}
$$

$$
\operatorname{LL}(\mathrm{Bbx}):=\int_{0}^{\mathrm{Bbx}} \sqrt{1+\mathrm{f} 1[\mathrm{x},(\mathrm{Om})]^{2}} \mathrm{dx}
$$

$\operatorname{DL}(x x, \operatorname{dd} 01, B b x):=\operatorname{LL}(x x, d d 01)-\operatorname{LL}(B b x)$

$$
\text { Bbx:=.1 Given } \operatorname{DL}(\mathrm{xx}, \mathrm{dd} 01, \mathrm{Bbx})=\mathbf{0} \quad \mathrm{xx}:=\mathrm{xc}
$$

$\operatorname{Bbxl}(\mathrm{xx}, \mathrm{dd} 01)=3.979 \quad \mathrm{Bby} 3:=\mathrm{Fb} 3(\mathrm{Bbx} 1(\mathrm{xx}, \mathrm{dd} 01), \mathrm{dd} 01, \mathrm{dbh}, \mathrm{Om})$

$\mathrm{x}:=\mathbf{0}, .2 . .2 \cdot \mathrm{H} 1(\mathrm{Om}) \quad \mathrm{dbh}=\mathbf{0 . 9} \quad \mathrm{Om}=\mathbf{5} \quad \mathrm{dd}:=\mathrm{dd} 0$

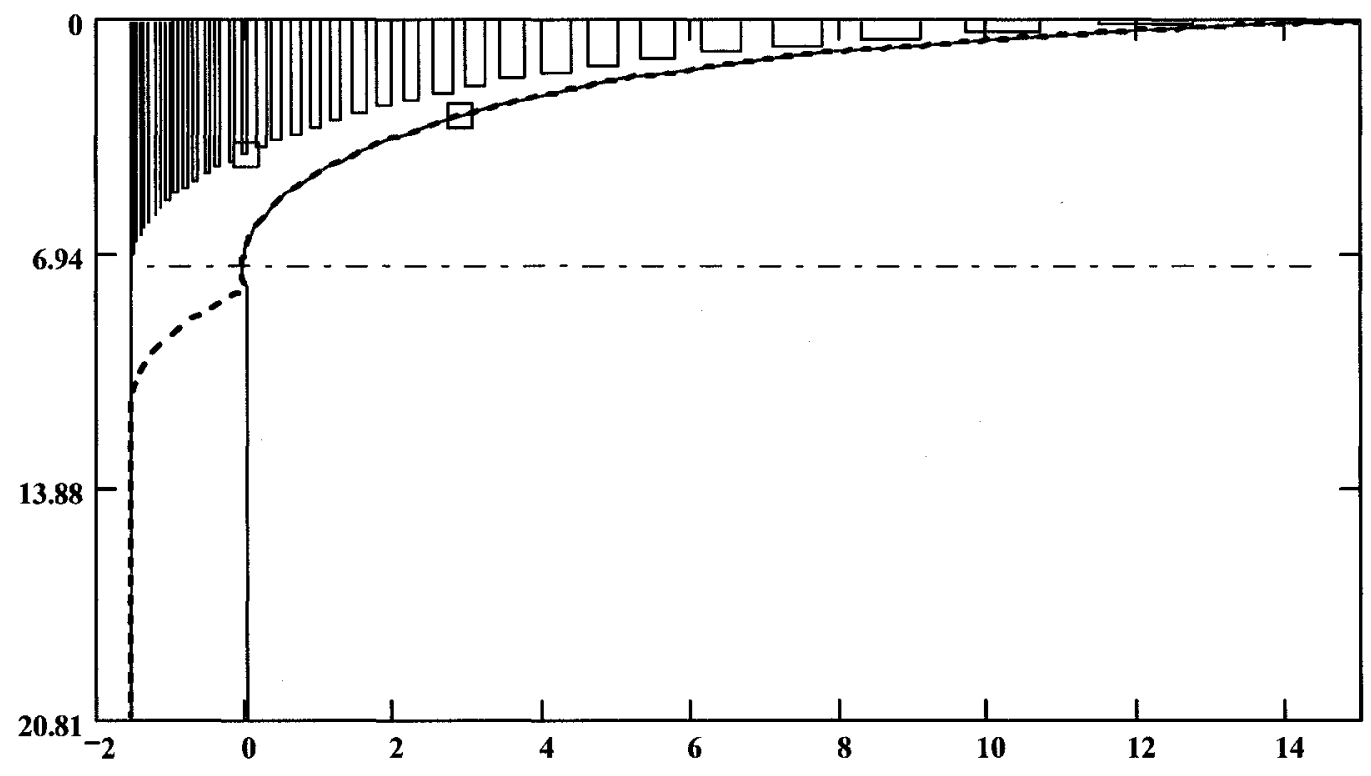


Heat constants

Coef. of solid slag heat conductivity

$\mathrm{Ksl} \equiv \mathbf{1 . 8 3}$

Coef. of liquid slag heat conductivity

Ksl_f : $=\mathbf{2}$

Solid slag thickness outside rim, MM

$\mathrm{Ds} \mathbf{1} \equiv \mathbf{1 . 5}$

Extraction speed, $\mathrm{Mm} / \mathrm{sec}$

$\mathrm{VV} \equiv \mathbf{3 . 3 3}$

Thermal diffusivity $\mathrm{RE} \mathrm{Mm}^{2} / \mathrm{sec}$

$A \mathrm{~m} \equiv \mathbf{3 . 6 8}$

Coef. of liquid metal heat conductivity

$\mathrm{Ktm} \equiv \mathbf{2 3 . 2}$

Thickness of disturbance layer (RE length)

$\mathrm{Lm}:=. \mathbf{3}$

Water temperature

$\mathrm{Tw} \equiv \mathbf{1 5}$

Liquid metal temperature (with superheat)

$\mathrm{Tm} \equiv \mathbf{1 5 1 5}$

Temperature solidus

Tsol $\equiv \mathbf{1 4 4 5}$

Temperature liquidus

Tlik $\equiv \mathbf{1 4 9 5}$

Differential equation of unsteady state heat transfer

$$
\begin{aligned}
& \text { dd } 0=0.66 \quad x x:=x c \quad \text { dd }:=1 \quad \text { bbl }(\mathrm{dd}, \mathrm{dbh}, \mathrm{Om})=\mathbf{1 0 . 1 0 1} \\
& \mathrm{T} 1:=1-\mathrm{dd} 0-\mathbf{0 0 0 0 0 1}
\end{aligned}
$$

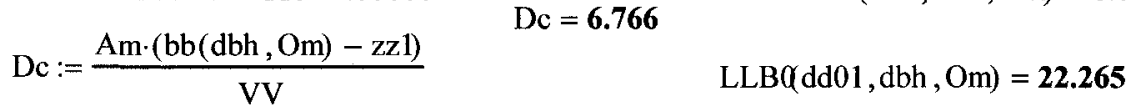

$$
\begin{aligned}
& \text { dd01:=1 } \quad \text { fl }(B b x 1(x x, d d 01), O m)=-\mathbf{0 . 9 9 2} \quad \operatorname{COS}(x x, d d 01)=\mathbf{0 . 7 1} \\
& \mathrm{DY} Q(\mathrm{xx}, \mathrm{dd} 01, \mathrm{Om})=\mathbf{1 2 . 1 1 9} \mathrm{dd} 0=\mathbf{0 . 6 6} \quad \mathrm{dbh}=\mathbf{0 . 9} \quad \mathrm{Om}=\mathbf{5} \quad \mathrm{Bbx}(\mathrm{xx}, \mathrm{dd} 0)=\mathbf{2 . 8 6 4} \\
& \operatorname{DFb}(B b x 1(x x, d d 01), d d 01, d b h, O m)=0 \quad(f 1(B b x 1(x x, d d 01), O m))^{2}=\mathbf{0 . 9 8 5}
\end{aligned}
$$

$$
\begin{aligned}
& u_{t}(x, t)=D c \cdot u_{x x}(x, t)+\frac{(T m-u(x, t)) \cdot(b b(d b h, O m)-z z l)}{\operatorname{LLB}(t+d d 0, d b h, O m)} \cdot \sqrt{1+f l(B b x 1(x x, t+d d 0), O m)^{2}} \\
& \mathrm{u}(\mathrm{x}, \mathbf{0})=\mathrm{Tm} \quad \text { spacepts } \equiv \mathbf{5} \text { timepts } \equiv \mathbf{1 0} \\
& u_{x}(\mathbf{0}, t)=\frac{[(T m-T w) \cdot \mathbf{0 . 8} \cdot \operatorname{COS}(x x, t+d d 0)]}{\left.\left.\llbracket\left(\frac{D Y \alpha(B b x 1(x x, t+d d 0), d b h, O m)+D s l}{K s l}\right)+\frac{D F b(B b x l(x x, t+d d 0), t+d d 0, d b h, O m)}{K s 1 \_f}\right] \cdot K \ln \right]}
\end{aligned}
$$




$$
\mathrm{u}(\mathrm{Lm}, \mathrm{t})=\mathrm{Tm} \quad \mathrm{u}:=\operatorname{Pdesolve}\left[\mathrm{u}, \mathrm{x},\left(\begin{array}{c}
0 \\
\mathrm{Lm}
\end{array}\right), \mathrm{t},\left(\begin{array}{c}
0 \\
\mathrm{~T} 1
\end{array}\right), \text {, spacepts , timepts }\right]
$$

$H H h(t):=b b 1(d d 0, d b h, O m)+(b b 1(1, d b h, O m)-b b 1(0, d b h, O m)) \cdot t$

$\mathrm{A}:=\operatorname{CreateMesh}(\mathrm{u}, \mathbf{0}, \mathrm{Lm}, \mathbf{0}, \mathrm{T} 1)$

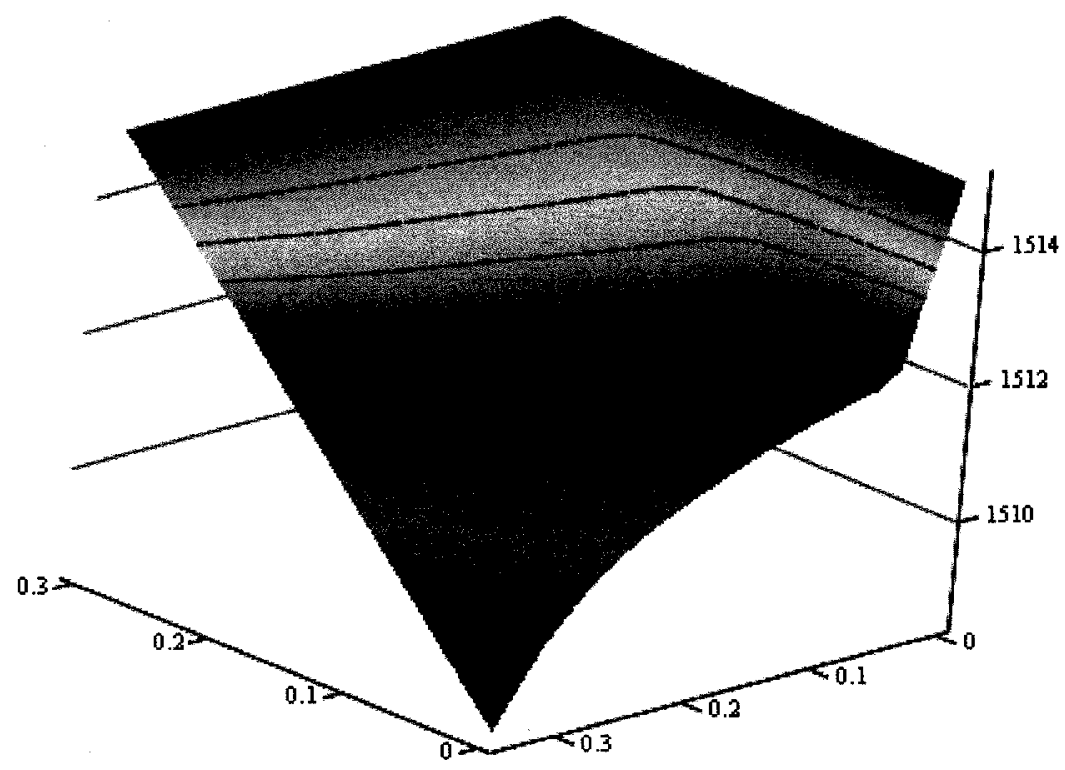

$$
\begin{gathered}
u(0, T 1)=1.50856 \times 10^{3} \quad x x=0.357 \\
n:=20 \quad i:=0 . . n \quad j:=0 . . n \quad x L_{1}:=\frac{L m}{n} \cdot i \quad x T_{i}:=\frac{T 1 \cdot i}{n}
\end{gathered}
$$$$
\mathrm{HT}_{\mathrm{i}}:=\mathrm{bb} 1(\mathrm{dd} 0, \mathrm{dbh}, \mathrm{Om})+(\mathrm{bbl}(1, \mathrm{dbh}, \mathrm{Om})-\mathrm{bbl}(0, \mathrm{dbh}, \mathrm{Om})) \cdot\left(\mathrm{xT}_{\mathrm{i}}\right)
$$

$$
\begin{aligned}
\mathrm{UU}_{\mathbf{0}, \mathrm{i}}:=\mathrm{u}\left(\mathrm{xL}_{\mathrm{i}}, \mathrm{Tl}\right) \quad \mathrm{UU}_{\mathbf{0}, \mathbf{0}}=\mathbf{1 . 5 0 9} \times \mathbf{1 0}^{\mathbf{3}} \quad \mathrm{UT}_{\mathrm{i}, 0}:=\mathrm{u}\left(\mathbf{0}, \mathrm{xT} \mathrm{T}_{\mathrm{i}}\right) & \mathrm{UU}_{\mathbf{0 , 0}}=\mathbf{1 . 5 0 9} \times \mathbf{1 0}^{\mathbf{3}} \\
\operatorname{TTU}_{\mathrm{i}, \mathrm{j}}:=\mathrm{u}\left(\mathrm{xL}_{\mathrm{i}}, \mathrm{xT}_{\mathrm{j}}\right) &
\end{aligned}
$$



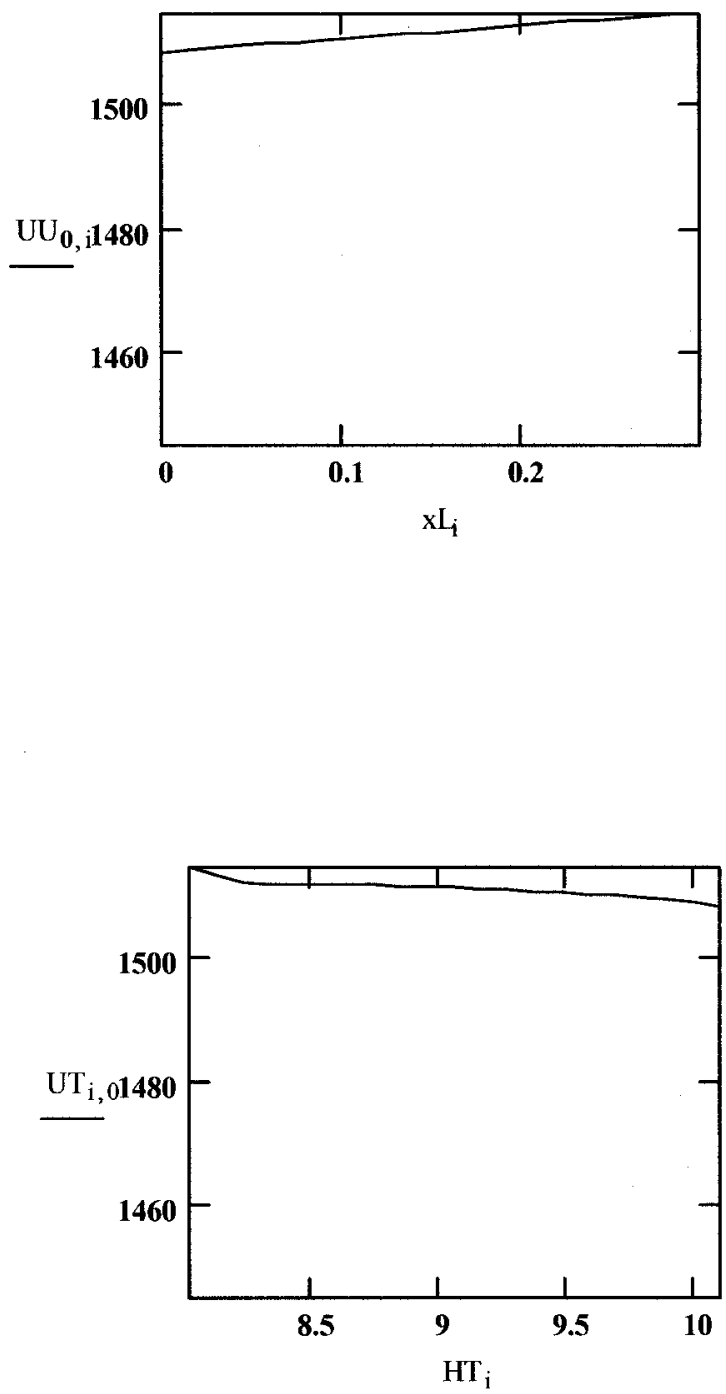

Reproduced with permission of the copyright owner. Further reproduction prohibited without permission. 


$$
\mathrm{xx}:=\mathbf{0}
$$

Given

$$
\begin{aligned}
& u_{t}(x, t)=D c \cdot u_{x x}(x, t)+\frac{(T m-u(x, t)) \cdot(b b(d b h, O m)-z z 1)}{L L B Q t+d d 0, d b h, O m)} \cdot \sqrt{1+f 1(B b x 1(x x, t+d d 0), O m)^{2}} \\
& \mathrm{u}(\mathrm{x}, \mathbf{0})=\mathrm{Tm} \\
& u_{x}(\mathbf{0}, t)=\frac{[(T m-T w) \cdot 0.8 \cdot \operatorname{COS}(x x, t+d d 0)]}{\left.\left[\left(\frac{D Y \alpha(B b x l(x x, t+d d 0), d b h, O m)+D s l}{K s l}\right)+\frac{D F b(B b x 1(x x, t+d d 0), t+d d 0, d b h, O m)}{K s l \_f}\right] \cdot K t m\right]} \\
& \mathrm{u}(\mathrm{Lm}, \mathrm{t})=\mathrm{Tm} \\
& \mathrm{u}:=\text { Pdesolve }\left[\mathrm{u}, \mathrm{x},\left(\begin{array}{c}
\mathbf{0} \\
\mathrm{Lm}
\end{array}\right), \mathrm{t},\left(\begin{array}{c}
\mathbf{0} \\
\mathrm{T} 1
\end{array}\right) \text {, spacepts , timepts }\right] \\
& \mathrm{UU}_{\mathbf{0}, \mathrm{i}}:=\mathrm{u}\left(\mathrm{xL}_{1}, \mathrm{~T} 1\right) \quad \mathrm{UU}_{\mathbf{0}, \mathbf{0}}=1.515 \times 10^{3} \quad \mathrm{UH}_{\mathbf{0}, \mathrm{i}}:=\mathrm{u}\left(\mathbf{0}, \mathrm{xT}_{\mathrm{i}}\right) \\
& \mathrm{xx}:=\mathbf{0 . 0 5} \quad \text { Given } \\
& u_{t}(x, t)=D c \cdot u_{x x}(x, t)+\frac{(T m-u(x, t)) \cdot(b b(d b h, O m)-z z 1)}{L L B Q t+d d 0, d b h, O m)} \cdot \sqrt{1+f 1(B b x 1(x x, t+d d 0), O m)^{2}} \\
& \mathrm{u}(\mathrm{x}, \mathbf{0})=\mathrm{Tm} \\
& u_{x}(\mathbf{0}, t)=\frac{[(T m-T w) \cdot 0.8 \cdot \operatorname{CoS}(x x, t+d d 0)]}{\left.\left[\left(\frac{D Y(B b x 1(x x, t+d d 0), d b h, O m)+D s l}{K s l}\right)+\frac{D F b(B b x 1(x x, t+d d 0), t+d d 0, d b h, O m)}{K s 1 \_f}\right] \cdot K t m\right]}
\end{aligned}
$$




$$
\begin{aligned}
& \mathrm{u}(\mathrm{Lm}, \mathrm{t})=\mathrm{Tm} \\
& \mathrm{u}:=\operatorname{Pdesolve}\left[\mathrm{u}, \mathrm{x},\left(\begin{array}{c}
\mathbf{0} \\
\mathrm{Lm}
\end{array}\right), \mathrm{t},\left(\begin{array}{c}
\mathbf{0} \\
\mathrm{T} 1
\end{array}\right), \text {, spacepts , timepts }\right] \\
& \mathrm{UU}_{1, \mathrm{i}}:=\mathrm{u}(\mathrm{xL}, \mathrm{T} 1) \quad \mathrm{UU}_{1, \mathbf{0}}=\mathbf{1 . 5 1 5} \times \mathbf{1 0}^{3} \quad \mathrm{UH}_{1, \mathrm{i}}:=\mathrm{u}\left(\mathbf{0}, \mathrm{xT}_{\mathrm{i}}\right) \\
& \mathrm{xx}:=\mathbf{0 . 1} \quad \text { Given } \\
& u_{t}(x, t)=D c \cdot u_{x x}(x, t)+\frac{(T m-u(x, t)) \cdot(b b(d b h, O m)-z z l)}{L L B(t+d d 0, d b h, O m)} \cdot \sqrt{1+f l(B b x l(x x, t+d d 0), O m)^{2}} \\
& \mathrm{u}(\mathrm{x}, \mathbf{0})=\mathrm{Tm} \\
& u_{x}(\mathbf{0}, t)=\frac{[(\mathrm{Tm}-\mathrm{Tw}) \cdot \mathbf{0 . 8} \cdot \operatorname{COS}(\mathrm{xx}, \mathrm{t}+\mathrm{dd} 0)]}{\left.\left.\llbracket\left(\frac{\mathrm{DY} 0(\mathrm{Bbxl}(\mathrm{xx}, \mathrm{t}+\mathrm{dd} 0), \mathrm{dbh}, \mathrm{Om})+\mathrm{Dsl}}{\mathrm{Ksl}}\right)+\frac{\mathrm{DFb}(\mathrm{Bbxl}(\mathrm{xx}, \mathrm{t}+\mathrm{dd} 0), \mathrm{t}+\mathrm{dd} 0, \mathrm{dbh}, \mathrm{Om})}{\mathrm{Ksl} f}\right] \cdot \mathrm{Ktm}\right]} \\
& \mathrm{u}(\mathrm{Lm}, \mathrm{t})=\operatorname{Tm} \quad \mathrm{u}:=\operatorname{Pdesolve}\left[\mathrm{u}, \mathrm{x},\left(\begin{array}{c}
0 \\
\mathrm{Lm}
\end{array}\right), \mathrm{t},\left(\begin{array}{c}
0 \\
\mathrm{~T} 1
\end{array}\right), \text {, spacepts }, \text { timepts }\right] \\
& \mathrm{UU}_{2, \mathrm{i}}:=\mathrm{u}\left(\mathrm{xL}_{1}, \mathrm{~T} 1\right)
\end{aligned}
$$

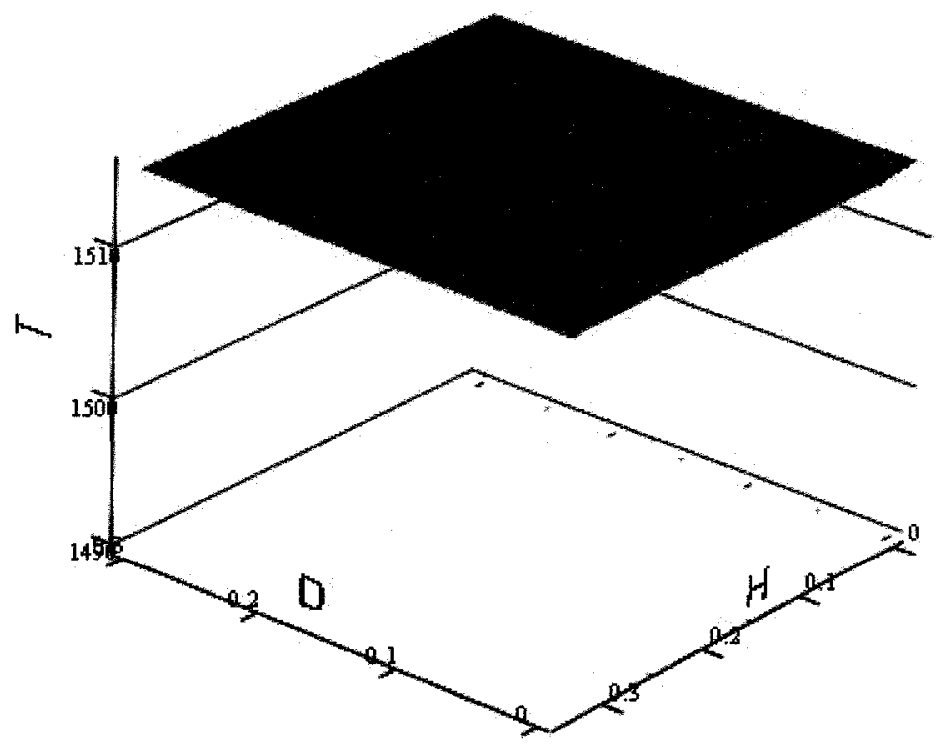



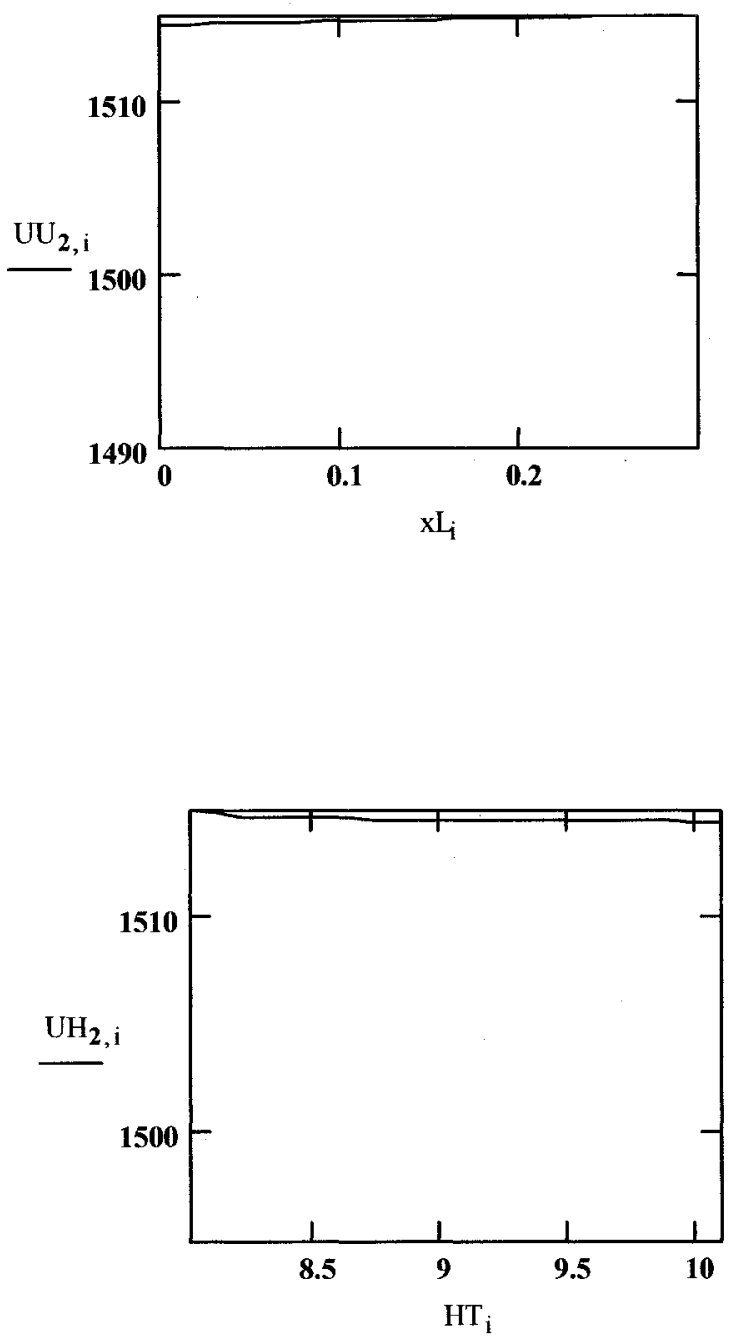

$$
\begin{gathered}
\mathrm{UU}_{2, \mathrm{i}}:=\mathrm{u}\left(\mathrm{xL}_{1}, \mathrm{~T} 1\right) \quad \mathrm{UU}_{2,0 \mathrm{i}}=\mathbf{1 . 5 1 4} \times \mathbf{1 0}^{3} \\
\mathrm{xx}:=\mathbf{0 . 1 5} \quad \text { Given } \\
\mathrm{u}_{\mathrm{t}}(\mathrm{x}, \mathrm{t})=\mathrm{Dc} \cdot \mathrm{u}_{\mathrm{xx}}(\mathrm{x}, \mathrm{t})+\frac{(\mathrm{Tm}-\mathrm{u}(\mathrm{x}, \mathrm{t})) \cdot(\mathrm{bb}(\mathrm{dbh}, \mathrm{Om})-\mathrm{zzl})}{\mathrm{LLB}(\mathrm{t}+\mathrm{dd} 0, \mathrm{dbh}, \mathrm{Om})} \cdot \sqrt{1+\mathrm{fl}(\mathrm{Bbx} 1(\mathrm{xx}, \mathrm{t}+\mathrm{dd} 0), \mathrm{Om})^{2}} \\
\mathrm{u}(\mathrm{x}, \mathbf{0})=\mathrm{Tm}
\end{gathered}
$$




$$
\begin{aligned}
& u_{x}(\mathbf{0}, t)=\frac{[(T m-T w) \cdot 0.8 \cdot \operatorname{Cos}(x x, t+d d 0)]}{\left.\left[\left(\frac{D Y 0(B b x l(x x, t+d d 0), d b h, O m)+D s l}{K s l}\right)+\frac{D F b(B b x 1(x x, t+d d 0), t+d d 0, d b h, O m)}{K s l_{-} f}\right] \cdot K t m\right]} \\
& \mathrm{u}(\mathrm{Lm}, \mathrm{t})=\operatorname{Tm} \quad \mathrm{u}:=\operatorname{Pdesolve}\left[\mathrm{u}, \mathrm{x},\left(\begin{array}{c}
0 \\
\mathrm{Lm}
\end{array}\right), \mathrm{t},\left(\begin{array}{c}
\mathbf{0} \\
\mathrm{T} 1
\end{array}\right) \text {, spacepts , timepts }\right] \\
& \mathrm{UU}_{\mathbf{3}, \mathrm{i}}:=\mathrm{u}\left(\mathrm{xL}_{\mathrm{i}}, \mathrm{Tl}\right) \quad \mathrm{UU}_{\mathbf{3}, \mathbf{0}}=\mathbf{1 . 5 1 4} \times \mathbf{1 0}^{\mathbf{3}} \quad \mathrm{UH}_{\mathbf{3}, \mathrm{i}}:=\mathrm{u}\left(\mathbf{0}, \mathrm{xT}_{\mathrm{i}}\right) \\
& \text { Given } \quad \mathrm{xx}:=\mathbf{0 . 2} \\
& u_{t}(x, t)=D c \cdot u_{x x}(x, t)+\frac{(T m-u(x, t)) \cdot(b b(d b h, O m)-z z l)}{L L B(\alpha t+d d 0, d b h, O m)} \cdot \sqrt{1+f 1(B b x l(x x, t+d d 0), O m)^{2}} \\
& \mathrm{u}(\mathrm{x}, \mathbf{0})=\mathrm{Tm} \\
& u_{x}(\mathbf{0}, t)=\frac{[(T m-T w) \cdot 0.8 \cdot \operatorname{COS}(x x, t+d d 0)]}{\left.\left.\llbracket\left(\frac{D Y(B b x l(x x, t+d d 0), d b h, O m)+\operatorname{Dsl}}{K s l}\right)+\frac{D F b(B b x l(x x, t+d d 0), t+d d 0, d b h, O m)}{K s l \_f}\right] \cdot K t m\right]} \\
& \mathrm{u}(\mathrm{Lm}, \mathrm{t})=\mathrm{Tm} \quad \mathrm{u}:=\operatorname{Pdesolve}\left[\mathrm{u}, \mathrm{x},\left(\begin{array}{c}
\mathbf{0} \\
\mathrm{Lm}
\end{array}\right), \mathrm{t},\left(\begin{array}{c}
\mathrm{O} \\
\mathrm{T} 1
\end{array}\right), \text { spacepts , timepts }\right] \\
& \mathrm{UU}_{4, \mathrm{i}}:=\mathrm{u}\left(\mathrm{xL}_{\mathrm{i}}, \mathrm{T} 1\right) \quad \mathrm{UU}_{4,0}=1.513 \times 10^{3} \quad \mathrm{UH}_{4, \mathrm{i}}:=\mathrm{u}\left(\mathbf{0}, \mathrm{xT} \mathrm{T}_{\mathrm{i}}\right) \\
& \text { Given } \quad \mathrm{xx}:=\mathbf{0 . 2 5} \\
& u_{t}(x, t)=D c \cdot u_{x x}(x, t)+\frac{(T m-u(x, t)) \cdot(b b(d b h, O m)-z z l)}{L L B Q t+d d 0, d b h, O m)} \cdot \sqrt{1+f l(B b x l(x x, t+d d 0), O m)^{2}} \\
& \mathrm{u}(\mathrm{x}, \mathbf{0})=\mathrm{Tm} \\
& u_{x}(\mathbf{0}, t)=\frac{[(T m-T w) \cdot 0.8 \cdot \operatorname{Cos}(x x, t+d d 0)]}{\left.\left[\left(\frac{D Y \alpha(B b x l(x x, t+d d 0), d b h, O m)+D s l}{K s l}\right)+\frac{D F b(B b x 1(x x, t+d d 0), t+d d 0, d b h, O m)}{K s l \_f}\right] \cdot K t m\right]}
\end{aligned}
$$




$$
\begin{aligned}
& \mathrm{u}(\mathrm{Lm}, \mathrm{t})=\mathrm{Tm} \\
& \mathrm{u}:=\text { Pdesolve }\left[\mathrm{u}, \mathrm{x},\left(\begin{array}{c}
\mathbf{0} \\
\mathrm{Lm}
\end{array}\right), \mathrm{t},\left(\begin{array}{c}
0 \\
\mathrm{~T} 1
\end{array}\right), \text { spacepts , timepts }\right] \\
& \mathrm{UU}_{5, \mathrm{i}}:=\mathrm{u}\left(\mathrm{xL}_{1}, \mathrm{~T} 1\right) \quad \mathrm{UU}_{\mathbf{5 , 0}}=\mathbf{1 . 5 1 2} \times \mathbf{1 0}^{3} \quad \mathrm{UH}_{\mathbf{5}, \mathrm{i}}:=\mathrm{u}\left(\mathbf{0}, \mathrm{xT}_{\mathrm{i}}\right) \\
& \text { Given } \quad \mathrm{x}: \mathbf{= 0 . 3} \\
& u_{t}(x, t)=D c \cdot u_{x x}(x, t)+\frac{(T m-u(x, t)) \cdot(b b(d b h, O m)-z z l)}{L L B(t+d d 0, d b h, O m)} \cdot \sqrt{1+f 1(B b x l(x x, t+d d 0), O m)} \\
& \mathrm{u}(\mathrm{x}, \mathbf{0})=\mathrm{Tm} \\
& \mathrm{u}_{\mathrm{x}}(\mathbf{0}, \mathrm{t})=\frac{[(\mathrm{Tm}-\mathrm{Tw}) \cdot \mathbf{0 . 8} \cdot \operatorname{COS}(\mathrm{xx}, \mathrm{t}+\mathrm{dd} 0)]}{\left.\left[\left(\frac{\mathrm{DY}(\mathrm{Bbxl}(\mathrm{xx}, \mathrm{t}+\mathrm{dd} 0), \mathrm{dbh}, \mathrm{Om})+\mathrm{Dsl}}{\mathrm{Ksl}}\right)+\frac{\mathrm{DFb}(\mathrm{Bbxl}(\mathrm{xx}, \mathrm{t}+\mathrm{dd} 0), \mathrm{t}+\mathrm{dd} 0, \mathrm{dbh}, \mathrm{Om})}{\mathrm{Ksl} f}\right] \cdot \mathrm{Ktm}\right]} \\
& \mathrm{u}(\mathrm{Lm}, \mathrm{t})=\operatorname{Tm} \quad \mathrm{u}:=\operatorname{Pdesolve}\left[\mathrm{u}, \mathrm{x},\left(\begin{array}{c}
0 \\
\mathrm{Lm}
\end{array}\right), \mathrm{t},\left(\begin{array}{c}
0 \\
\mathrm{~T} 1
\end{array}\right) \text {, spacepts , timepts }\right] \\
& \mathrm{UU}_{6, \mathrm{i}}:=\mathrm{u}\left(\mathrm{xL}_{\mathrm{i}}, \mathrm{Tl}\right) \quad \mathrm{UU}_{\mathbf{6}, 0}=\mathbf{1 . 5 1 1} \times \mathbf{1 0}^{3} \quad \mathrm{UH}_{6, \mathrm{i}}:=\mathrm{u}\left(\mathbf{0}, \mathrm{xT}_{\mathrm{i}}\right) \\
& \text { Given } \quad \mathrm{xx}:=\mathbf{0 . 3 5} \\
& u_{t}(x, t)=D c \cdot u_{x x}(x, t)+\frac{(T m-u(x, t)) \cdot(b b(d b h, O m)-z z l)}{L L B q(t+d d 0, d b h, O m)} \cdot \sqrt{1+f l(B b x 1(x x, t+d d 0), O m)^{2}} \\
& \mathrm{u}(\mathrm{x}, \mathbf{0})=\mathrm{Tm} \\
& u_{x}(\mathbf{0}, t)=\frac{[(T m-T w) \cdot 0.8 \cdot \cos (x x, t+d d 0)]}{\left.\left[\left(\frac{D Y a(B b x l(x x, t+d d 0), d b h, O m)+D s l}{K s l}\right)+\frac{D F b(B b x 1(x x, t+d d 0), t+d d 0, d b h, O m)}{K s l \_f}\right] \cdot K t m\right]} \\
& \mathrm{u}(\mathrm{Lm}, \mathrm{t})=\mathrm{Tm} \quad \mathrm{u}:=\operatorname{Pdesolve}\left[\mathrm{u}, \mathrm{x},\left(\begin{array}{c}
0 \\
\mathrm{Lm}
\end{array}\right), \mathrm{t},\left(\begin{array}{c}
0 \\
\mathrm{~T} 1
\end{array}\right), \text {, spacepts , timepts }\right]
\end{aligned}
$$




$$
\begin{aligned}
& \mathrm{UU}_{7, \mathrm{i}}:=\mathrm{u}(\mathrm{xL}, \mathrm{T} 1) \\
& U_{7,0}=1.509 \times 10^{3} \quad U_{7, i}:=u\left(0, x T_{i}\right) \\
& \mathrm{xx}:=\mathbf{0 . 4} \quad \text { Given } \\
& u_{t}(x, t)=D c \cdot u_{x x}(x, t)+\frac{(T m-u(x, t)) \cdot(b b(d b h, O m)-z z 1)}{L L B Q t+d d 0, d b h, O m)} \cdot \sqrt{1+f 1(B b x 1(x x, t+d d 0), O m)} \\
& \mathrm{u}(\mathrm{x}, \mathbf{0})=\mathrm{Tm} \\
& u_{x}(\mathbf{0}, t)=\frac{[(T m-T w) \cdot \mathbf{0 . 8} \cdot \operatorname{COS}(x x, t+d d 0)]}{\left.\left.\llbracket\left(\frac{D Y 0(B b x l(x x, t+d d 0), d b h, O m)+D s l}{K s l}\right)+\frac{D F b(B b x l(x x, t+d d 0), t+d d 0, d b h, O m)}{K s l f f}\right] \cdot K t m\right]} \\
& \mathrm{u}(\mathrm{Lm}, \mathrm{t})=\mathrm{Tm} \\
& \mathrm{u}:=\text { Pdesolve }\left[\mathrm{u}, \mathrm{x},\left(\begin{array}{c}
\mathbf{0} \\
\mathrm{Lm}
\end{array}\right), \mathrm{t},\left(\begin{array}{c}
\mathbf{0} \\
\mathrm{T} 1
\end{array}\right) \text {, spacepts , timepts }\right] \\
& \mathrm{UU}_{\mathbf{8}, \mathrm{i}}:=\mathrm{u}(\mathrm{xL}, \mathrm{T} 1) \quad \mathrm{UU}_{\mathbf{8}, 0}=\mathbf{1 . 5 0 7} \times 10^{3} \quad \mathrm{UH}_{\mathbf{8}, \mathrm{i}}:=\mathrm{u}\left(\mathbf{0}, \mathrm{xT}_{\mathrm{i}}\right) \\
& \text { Given } \quad \mathrm{xx}:=\mathbf{0 . 4 5} \\
& u_{t}(x, t)=D c \cdot u_{x x}(x, t)+\frac{(T m-u(x, t)) \cdot(b b(d b h, O m)-z z l)}{L L B(t+d d 0, d b h, O m)} \cdot \sqrt{1+f 1(B b x 1(x x, t+d d 0), O m)^{2}} \\
& \mathrm{u}(\mathrm{x}, \mathbf{0})=\mathrm{Tm} \\
& u_{x}(\mathbf{0}, t)=\frac{[(T m-T w) \cdot \mathbf{0 . 8} \cdot \operatorname{COS}(x x, t+d d 0)]}{\left.\left[\left(\frac{D Y 0(B b x l(x x, t+d d 0), d b h, O m)+D s l}{K s l}\right)+\frac{D F b(B b x 1(x x, t+d d 0), t+d d 0, d b h, O m)}{K s l \_f}\right] \cdot K t m\right]} \\
& \mathrm{u}(\mathrm{Lm}, \mathrm{t})=\mathrm{Tm} \quad \mathrm{u}:=\operatorname{Pdesolve}\left[\mathrm{u}, \mathrm{x},\left(\begin{array}{c}
0 \\
\mathrm{Lm}
\end{array}\right), \mathrm{t},\left(\begin{array}{c}
0 \\
\mathrm{~T} 1
\end{array}\right) \text {, spacepts , timepts }\right] \\
& \mathrm{UU}_{9, \mathrm{i}}:=\mathrm{u}\left(\mathrm{xL}_{\mathrm{i}}, \mathrm{T} 1\right) \quad \mathrm{UU}_{\mathbf{9}, \mathbf{0}}=\mathbf{1 . 5 0 4} \times \mathbf{1 0}^{\mathbf{3}} \quad \mathrm{UH}_{\mathbf{9}, \mathrm{i}}:=\mathrm{u}\left(\mathbf{0}, \mathrm{xT} \mathrm{T}_{\mathrm{i}}\right) \\
& \mathrm{xx}:=0.5
\end{aligned}
$$


Given

$$
\begin{aligned}
& u_{t}(x, t)=D c \cdot u_{x x}(x, t)+\frac{(T m-u(x, t)) \cdot(b b(d b h, O m)-z z 1)}{\operatorname{LLB}(t+d d 0, d b h, O m)} \cdot \sqrt{1+f l(B b x 1(x x, t+d d 0), O m)^{2}} \\
& \mathrm{u}(\mathrm{x}, \mathbf{0})=\mathrm{Tm} \\
& u_{x}(0, t)=\frac{[(T m-T w) \cdot 0.8 \cdot \operatorname{COS}(x x, t+d d 0)]}{\left.\left[\left(\frac{D Y \alpha(B b x 1(x x, t+d d 0), d b h, O m)+D s l}{K s l}\right)+\frac{D F b(B b x 1(x x, t+d d 0), t+d d 0, d b h, O m)}{K s l f}\right] \cdot K \operatorname{tr}\right]} \\
& \mathrm{u}(\mathrm{Lm}, \mathrm{t})=\mathrm{Tm} \quad \mathrm{u}:=\operatorname{Pdesolve}\left[\mathrm{u}, \mathrm{x},\left(\begin{array}{c}
\mathbf{0} \\
\mathrm{Lm}
\end{array}\right), \mathrm{t},\left(\begin{array}{c}
0 \\
\mathrm{~T} 1
\end{array}\right) \text {, spacepts , timepts }\right] \\
& \mathrm{UU}_{10, \mathrm{i}}:=\mathrm{u}\left(\mathrm{xL}_{\mathrm{i}}, \mathrm{T} 1\right) \quad \mathrm{UU}_{\mathbf{1 0}, \mathbf{0}}=\mathbf{1 . 5 0 1} \times \mathbf{1 0}^{3} \quad \mathrm{UH}_{\mathbf{1 0}, \mathrm{i}}:=\mathrm{u}\left(\mathbf{0}, \mathrm{xT}_{\mathrm{i}}\right) \\
& \text { Given } \quad x x:=\mathbf{0 . 5 5} \\
& u_{t}(x, t)=D c \cdot u_{x x}(x, t)+\frac{(T m-u(x, t)) \cdot(b b(d b h, O m)-z z l)}{\operatorname{LLB}(t+d d 0, d b h, O m)} \cdot \sqrt{1+f 1(B b x 1(x x, t+d d 0), O m)^{2}} \\
& \mathrm{u}(\mathrm{x}, \mathbf{0})=\mathrm{Tm} \\
& u_{x}(\mathbf{0}, t)=\frac{[(T m-T w) \cdot 0.8 \cdot \operatorname{COS}(x x, t+d d 0)]}{\left.\left[\left(\frac{D Y O(B b x 1(x x, t+d d 0), d b h, O m)+D s l}{K s l}\right)+\frac{D F b(B b x 1(x x, t+d d 0), t+d d 0, d b h, O m)}{K s l \_f}\right] \cdot K t m\right]} \\
& \mathrm{u}(\mathrm{Lm}, \mathrm{t})=\mathrm{Tm} \quad \mathrm{u}:=\operatorname{Pdesolve}\left[\mathrm{u}, \mathrm{x},\left(\begin{array}{c}
0 \\
\mathrm{Lm}
\end{array}\right), \mathrm{t},\left(\begin{array}{c}
0 \\
\mathrm{~T} 1
\end{array}\right) \text {, spacepts, timepts }\right] \\
& \mathrm{UU}_{11, \mathrm{i}}:=\mathrm{u}\left(\mathrm{xL}_{1}, \mathrm{~T} 1\right) \quad \mathrm{UU}_{11,0}=1.499 \times 10^{3} \quad \mathrm{UH}_{11, \mathrm{i}}:=\mathrm{u}\left(\mathbf{0}, \mathrm{xT}_{\mathrm{i}}\right) \\
& \text { Given } \quad \mathrm{xx}:=\mathbf{0 . 6} \\
& u_{t}(x, t)=D c \cdot u_{x x}(x, t)+\frac{(T m-u(x, t)) \cdot(b b(d b h, O m)-z z 1)}{\operatorname{LLB} Q t+d d 0, d b h, O m)} \cdot \sqrt{1+f 1(B b x 1(x x, t+d d 0), O m)^{2}}
\end{aligned}
$$




$$
\begin{gathered}
u(x, 0)=T m \\
u_{x}(\mathbf{0}, t)=\frac{[(T m-T w) \cdot 0.8 \cdot \operatorname{Cos}(x x, t+d d 0)]}{\left.\left[\left(\frac{D Y 0(B b x 1(x x, t+d d 0), d b h, O m)+D s l}{K s l}\right)+\frac{D F b(B b x 1(x x, t+d d 0), t+d d 0, d b h, O m)}{K s ! \_f}\right] \cdot K t m\right]}
\end{gathered}
$$$$
\mathrm{u}(\mathrm{Lm}, \mathrm{t})=\mathrm{Tm}
$$$$
\mathrm{u}:=\text { Pdesolve }\left[\mathrm{u}, \mathrm{x},\left(\begin{array}{c}
\mathbf{0} \\
\mathrm{Lm}
\end{array}\right), \mathrm{t},\left(\begin{array}{c}
\mathbf{0} \\
\mathrm{T} 1
\end{array}\right), \text { spacepts , timepts }\right]
$$$$
\mathrm{UU}_{12, \mathrm{i}}:=\mathrm{u}\left(\mathrm{xL}_{\mathrm{i}}, \mathrm{T} 1\right) \quad \mathrm{UU}_{12,0}=1.497 \times 10^{3} \quad \mathrm{UH}_{12, \mathrm{i}}:=\mathrm{u}\left(\mathbf{0}, \mathrm{xT}_{\mathrm{i}}\right)
$$$$
\mathrm{xx}:=\mathbf{0 . 6 5} \quad \text { Given }
$$$$
u_{t}(x, t)=D c \cdot u_{x x}(x, t)+\frac{(T m-u(x, t)) \cdot(b b(d b h, O m)-z z l)}{\operatorname{LLB} Q t+d d 0, d b h, O m)} \cdot \sqrt{1+f l(B b x 1(x x, t+d d 0), O m)^{2}}
$$$$
\mathrm{u}(\mathrm{x}, \mathbf{0})=\mathrm{Tm}
$$

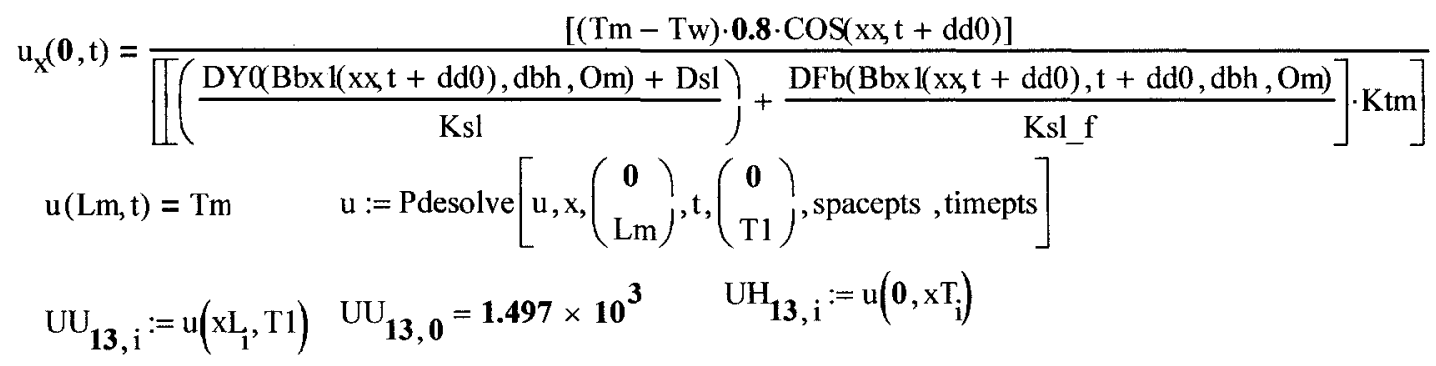$$
\text { Given } \quad \mathrm{xx}:=\mathbf{0 . 7}
$$$$
u_{t}(x, t)=D c \cdot u_{x x}(x, t)+\frac{(T m-u(x, t)) \cdot(b b(d b h, O m)-z z l)}{\operatorname{LLB}(t+d d 0, d b h, O m)} \cdot \sqrt{1+f 1(B b x 1(x x, t+d d 0), O m)}
$$$$
\mathrm{u}(\mathrm{x}, \mathbf{0})=\mathrm{Tm}
$$$$
u_{x}(0, t)=\frac{[(T m-T w) \cdot 0.8 \cdot \operatorname{COS}(x x, t+d d 0)]}{\left.\left[\left(\frac{D Y a(B b x l(x x, t+d d 0), d b h, O m)+D s l}{K s l}\right)+\frac{D F b(B b x l(x x, t+d d 0), t+d d 0, d b h, O m)}{K s l \_f}\right] \cdot K t m\right]}
$$ 


$$
\begin{aligned}
& \mathrm{u}(\mathrm{Lm}, \mathrm{t})=\mathrm{Tm} \\
& \mathrm{u}:=\operatorname{Pdesolve}\left[\mathrm{u}, \mathrm{x},\left(\begin{array}{c}
\mathbf{0} \\
\mathrm{Lm}
\end{array}\right), \mathrm{t},\left(\begin{array}{c}
\mathbf{0} \\
\mathrm{T} 1
\end{array}\right) \text {, spacepts , timepts }\right] \\
& \mathrm{UU}_{14, \mathrm{i}}:=\mathrm{u}\left(\mathrm{xL}_{\mathrm{i}}, \mathrm{T} 1\right) \\
& \text { Given } \quad \mathrm{xx}:=\mathbf{0 . 7 5} \\
& \mathrm{UU}_{14,0}=1.497 \times 10^{3} \quad \mathrm{UH}_{14, \mathrm{i}}:=\mathrm{u}\left(0, \mathrm{xT}_{\mathrm{i}}\right) \\
& u_{t}(x, t)=D c \cdot u_{x x}(x, t)+\frac{(T m-u(x, t)) \cdot(b b(d b h, O m)-z z 1)}{\operatorname{LLB} Q t+d d 0, d b h, O m)} \cdot \sqrt{1+f 1(B b x 1(x x, t+d d 0), O m)^{2}} \\
& \mathrm{u}(\mathrm{x}, \mathbf{0})=\mathrm{Tm} \\
& \mathrm{u}_{\mathrm{X}}(\mathbf{0}, \mathrm{t})=\frac{[(\mathrm{Tm}-\mathrm{Tw}) \cdot \mathbf{0 . 8} \cdot \operatorname{COS}(\mathrm{xx}, \mathrm{t}+\mathrm{dd} 0)]}{\left.\left[\left(\frac{\mathrm{DY}(\mathrm{Bbx} \mathbf{1}(\mathrm{xx}, \mathrm{t}+\mathrm{dd} 0), \mathrm{dbh}, \mathrm{Om})+\mathrm{Dsl}}{\mathrm{Ksl}}\right)+\frac{\mathrm{DFb}(\mathrm{Bbx} \mathbf{l}(\mathrm{xx}, \mathrm{t}+\mathrm{dd} 0), \mathrm{t}+\mathrm{dd} 0, \mathrm{dbh}, \mathrm{Om})}{\mathrm{Ksl} \_\mathrm{f}}\right] \cdot \mathrm{Ktm}\right]} \\
& \mathrm{u}(\mathrm{Lm}, \mathrm{t})=\mathrm{Tm} \quad \mathrm{u}:=\text { Pdesolve }\left[\mathrm{u}, \mathrm{x},\left(\begin{array}{c}
\mathbf{0} \\
\mathrm{Lm}
\end{array}\right), \mathrm{t},\left(\begin{array}{c}
\mathbf{0} \\
\mathrm{T} 1
\end{array}\right) \text {, spacepts , timepts }\right] \\
& \mathrm{UU}_{15, \mathrm{i}}:=\mathrm{u}(\mathrm{xL}, \mathrm{T} 1) \quad \mathrm{UU}_{15,0}=1.499 \times 10^{3} \quad \mathrm{UH}_{15, \mathrm{i}}:=\mathrm{u}\left(\mathbf{0}, \mathrm{xT}_{\mathrm{i}}\right)
\end{aligned}
$$$$
\text { Given } \quad \mathrm{xx}:=\mathbf{0 . 8}
$$$$
u_{t}(x, t)=D c \cdot u_{x x}(x, t)+\frac{(T m-u(x, t)) \cdot(b b(d b h, O m)-z z l)}{\operatorname{LLB}(t+d d 0, d b h, O m)} \cdot \sqrt{1+f 1(B b x 1(x x, t+d d 0), O m)^{2}}
$$$$
\mathrm{u}(\mathrm{x}, \mathbf{0})=\mathrm{Tm}
$$$$
u_{x}(\mathbf{0}, t)=\frac{[(T m-T w) \cdot \mathbf{0 . 8} \cdot \operatorname{Cos}(x x, t+d d 0)]}{\left.\left.\llbracket\left(\frac{D Y a(B b x 1(x x, t+d d 0), d b h, O m)+D s l}{K s l}\right)+\frac{D F b(B b x 1(x x, t+d d 0), t+d d 0, d b h, O m)}{K s l \_f}\right] \cdot K t m\right]}
$$ 


$$
\begin{aligned}
& u(\operatorname{Lm}, t)=T m \\
& \mathrm{u}:=\text { Pdesolve }\left[\mathrm{u}, \mathrm{x},\left(\begin{array}{c}
\mathbf{0} \\
\mathrm{Lm}
\end{array}\right), \mathrm{t},\left(\begin{array}{c}
0 \\
\mathrm{~T} \mathbf{1}
\end{array}\right), \text { spacepts , timepts }\right] \\
& \mathrm{UU}_{16, \mathrm{i}}:=\mathrm{u}\left(\mathrm{xL}_{\mathrm{i}}, \mathrm{Tl}\right) \\
& \mathrm{UU}_{16,0}=1.501 \times 10^{3} \quad \mathrm{UH}_{16, \mathrm{i}}:=\mathrm{u}\left(\mathbf{0}, \mathrm{xT}_{\mathrm{i}}\right) \\
& \text { Given } \quad \mathrm{xx}:=\mathbf{0 . 8 5} \\
& u_{t}(x, t)=D c \cdot u_{x x}(x, t)+\frac{(T m-u(x, t)) \cdot(b b(d b h, O m)-z z l)}{L L B(t+d d 0, d b h, O m)} \cdot \sqrt{1+f 1(B b x l(x x, t+d d 0), O m)^{2}} \\
& \mathrm{u}(\mathrm{x}, \mathbf{0})=\mathrm{Tm} \\
& u_{x}(\mathbf{0}, t)=\frac{[(T m-T w) \cdot \mathbf{0 . 8} \cdot \operatorname{COS}(x x, t+d d 0)]}{\left.\left.\llbracket\left(\frac{D Y 0(B b x l(x x, t+d d 0), d b h, O m)+D s l}{K s l}\right)+\frac{D F b(B b x 1(x x, t+d d 0), t+d d 0, d b h, O m)}{K s l \_f}\right] \cdot K t m\right]} \\
& \mathrm{u}(\mathrm{Lm}, \mathrm{t})=\mathrm{Tm} \\
& \mathrm{u}:=\operatorname{Pdesolve}\left[\mathrm{u}, \mathrm{x},\left(\begin{array}{c}
\mathbf{0} \\
\mathrm{Lm}
\end{array}\right), \mathrm{t},\left(\begin{array}{c}
\mathbf{0} \\
\mathrm{T} 1
\end{array}\right), \text { spacepts , timepts }\right] \\
& \mathrm{UU}_{17, \mathrm{i}}:=\mathrm{u}\left(\mathrm{xL}_{1}, \mathrm{~T} 1\right) \quad \mathrm{UU}_{17,0}=1.503 \times 10^{3} \quad \mathrm{UH}_{17, \mathrm{i}}:=\mathrm{u}\left(\mathbf{0}, \mathrm{xT}_{\mathrm{i}}\right) \\
& \text { Given } \quad \text { xx: }=0.9 \\
& u_{t}(x, t)=D c \cdot u_{x x}(x, t)+\frac{(T m-u(x, t)) \cdot(b b(d b h, O m)-z z l)}{L L B Q t+d d 0, d b h, O m)} \cdot \sqrt{1+f 1(B b x 1(x x, t+d d 0), O m)^{2}} \\
& \mathbf{u}(\mathbf{x}, \mathbf{0})=T \mathrm{~m}
\end{aligned}
$$

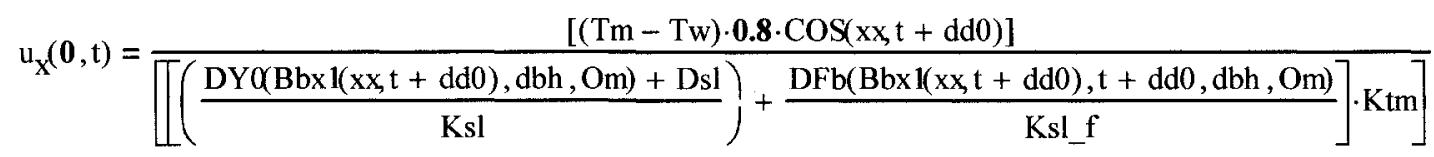




$$
\begin{gathered}
u(\mathrm{Lm}, \mathrm{t})=\operatorname{Tm} \\
\mathrm{u}:=\text { Pdesolve }\left[\mathrm{u}, \mathrm{x},\left(\begin{array}{c}
\mathbf{0} \\
\mathrm{Lm}
\end{array}\right), \mathrm{t},\left(\begin{array}{c}
0 \\
\mathrm{~T} 1
\end{array}\right), \text { spacepts , timepts }\right]
\end{gathered}
$$

$\mathrm{A}:=\operatorname{CreateMesh}(\mathbf{u}, \mathbf{0}, \mathrm{Lm}, \mathbf{0}, \mathrm{T} 1)$
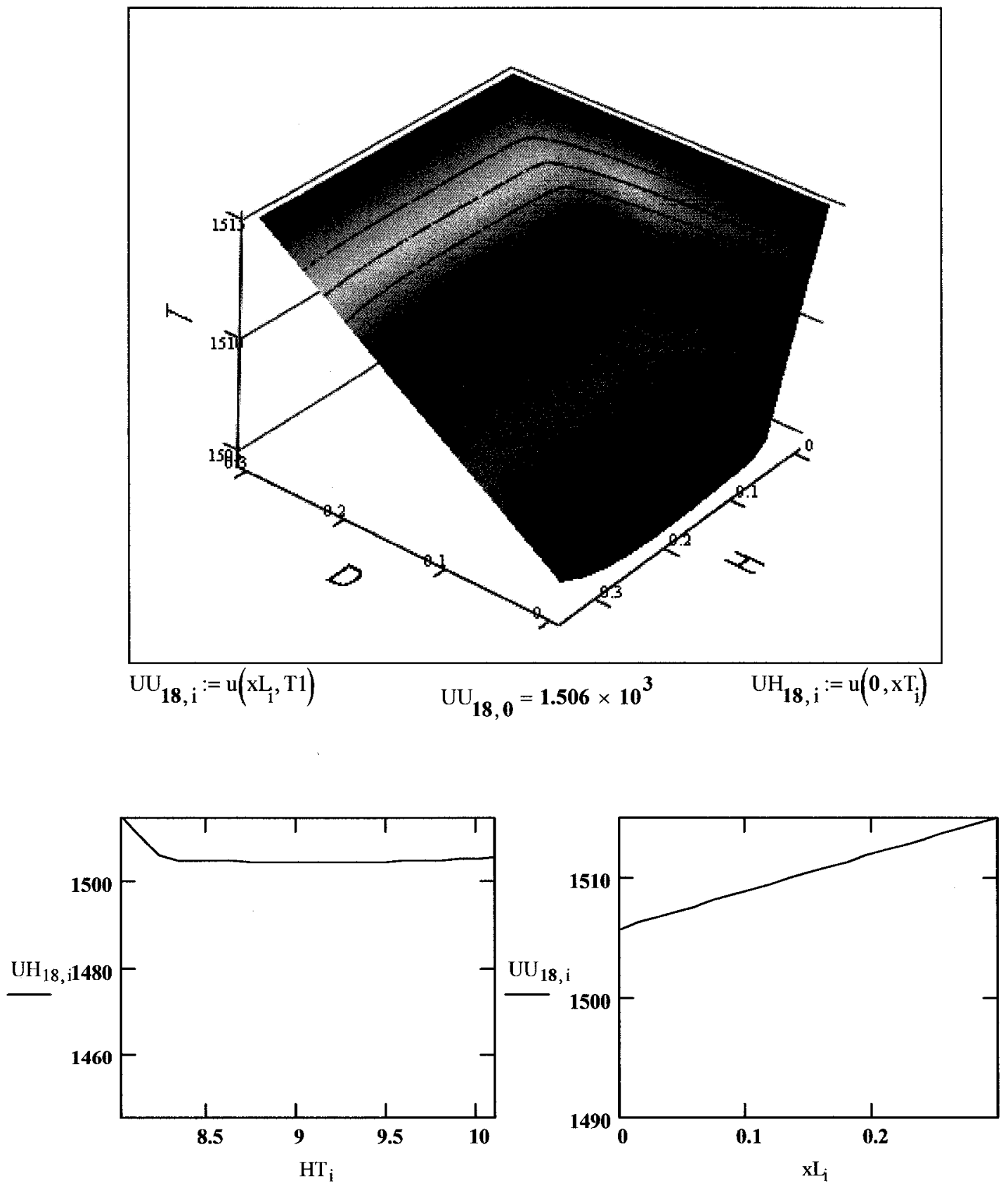
$\mathrm{xx}:=\mathbf{0 . 9 5}$

Given

$$
\begin{aligned}
& u_{t}(x, t)=D c \cdot u_{x x}(x, t)+\frac{(T m-u(x, t)) \cdot(b b(d b h, O m)-z z 1)}{\operatorname{LLB}(t+d d 0, d b h, O m)} \cdot \sqrt{1+f l(B b x l(x x, t+d d 0), O m)^{2}} \\
& \mathrm{u}(\mathrm{x}, \mathbf{0})=\mathrm{Tm} \\
& u_{x}(\mathbf{0}, t)=\frac{[(T m-T w) \cdot \mathbf{0 . 8} \cdot \operatorname{COS}(x x, t+d d 0)]}{\left[\left[\left(\frac{D Y o(B b x 1(x x, t+d d 0), d b h, O m)+D s l}{K s l}\right)+\frac{D F b(B b x 1(x x, t+d d 0), t+d d 0, d b h, O m)}{K s 1 \_f}\right] \cdot K t m\right]} \\
& \mathrm{u}(\mathrm{Lm}, \mathrm{t})=\mathrm{Tm} \\
& \mathrm{u}:=\text { Pdesolve }\left[\mathrm{u}, \mathrm{x},\left(\begin{array}{c}
\mathbf{0} \\
\mathrm{Lm}
\end{array}\right), \mathrm{t},\left(\begin{array}{c}
\mathbf{0} \\
\mathrm{T} 1
\end{array}\right) \text {, spacepts , timepts }\right] \\
& \mathrm{UU}_{19, \mathrm{i}}:=\mathrm{u}(\mathrm{xL}, \mathrm{T} 1) \quad \mathrm{UU}_{19,0}=1.508 \times 10^{3} \quad \mathrm{UH}_{19, \mathrm{i}}:=\mathrm{u}\left(\mathbf{0}, \mathrm{xT}_{\mathrm{i}}\right) \\
& \mathrm{xx}:=1
\end{aligned}
$$$$
\text { Given }
$$$$
\begin{gathered}
u_{t}(x, t)=D c \cdot u_{x x}(x, t)+\frac{(T m-u(x, t)) \cdot(b b(d b h, O m)-z z l)}{\operatorname{LLB} q t+d d 0, d b h, O m)} \cdot \sqrt{1+f l(B b x l(x x, t+d d 0), O m)^{2}} \\
u(x, 0)=T m
\end{gathered}
$$$$
u_{x}(0, t)=\frac{[(T m-T w) \cdot 0.8 \cdot \operatorname{COS}(x x, t+d d 0)]}{\left.\left[\left(\frac{D Y \alpha(B b x 1(x x, t+d d 0), d b h, O m)+D s l}{K s l}\right)+\frac{D F b(B b x 1(x x, t+d d 0), t+d d 0, d b h, O m)}{K s 1 \_f}\right] \cdot K t m\right]}
$$ 


$$
\begin{aligned}
& \mathbf{u}(\mathrm{Lm}, \mathrm{t})=\mathrm{Tm} \\
& \mathrm{u}:=\text { Pdesolve }\left[\mathrm{u}, \mathrm{x},\left(\begin{array}{c}
\mathbf{0} \\
\mathrm{Lm}
\end{array}\right), \mathrm{t},\left(\begin{array}{c}
\mathbf{0} \\
\mathrm{T} 1
\end{array}\right) \text {, spacepts , timepts }\right] \\
& \mathrm{XX}=\mathbf{1} \mathrm{dd} 0=\mathbf{0 . 6 6} \mathrm{t}:=\mathrm{T} 1 \mathrm{t}+\mathrm{dd} 0=\mathbf{B} \quad \mathrm{Bbx} 1(\mathrm{xx}, \mathrm{t}+\mathrm{dd} 0)=\mathbf{1 0 . 1 0 1} \\
& \operatorname{COS}(x x, t+d d 0)=\mathbf{0 . 4 6 7} \\
& \left.\mathrm{f} 1(\mathrm{Bbx} 1(\mathrm{xx}, \mathrm{t}+\mathrm{dd} 0), \mathrm{Om})^{2}=\mathbf{3 . 5 9 5} \quad \operatorname{LLB} Q \mathrm{t}+\mathrm{dd} 0, \mathrm{dbh}, \mathrm{Om}\right)=\mathbf{2 2 . 2 6 5} \\
& \begin{array}{l}
\mathrm{UU}_{\mathbf{2 0}, \mathrm{i}}:=\mathrm{u}\left(\mathrm{xL}_{\mathrm{i}}, \mathrm{T} 1\right) \quad \mathrm{UU}_{20,0}=1.51 \times \mathbf{1 0}^{3} \quad \mathrm{UH}_{20, \mathrm{i}}:=\mathrm{u}(\mathbf{0}, \mathrm{xT}) \\
\mathrm{j}:=\mathbf{0} . \mathrm{n} \quad \mathrm{UT}_{\mathrm{j}, \mathrm{i}}:=0.9975 \mathrm{Tlik} \quad \operatorname{LiK}_{\mathrm{j}, \mathrm{i}}:=\mathrm{Tlik} \quad \mathrm{xH}_{\mathrm{j}}:=\frac{\mathrm{bb}(\mathrm{dbh}, \mathrm{Om}) \cdot \mathrm{j}}{\mathrm{n}}
\end{array}
\end{aligned}
$$

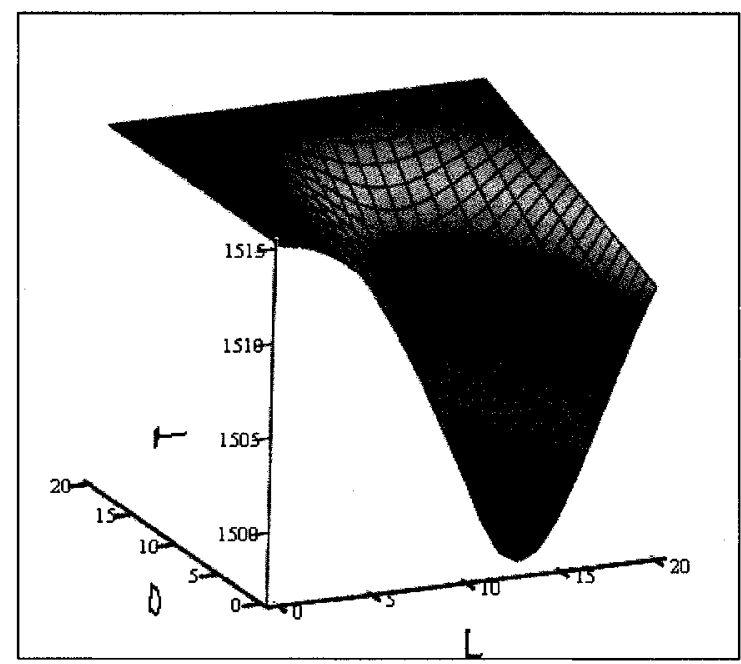

UU

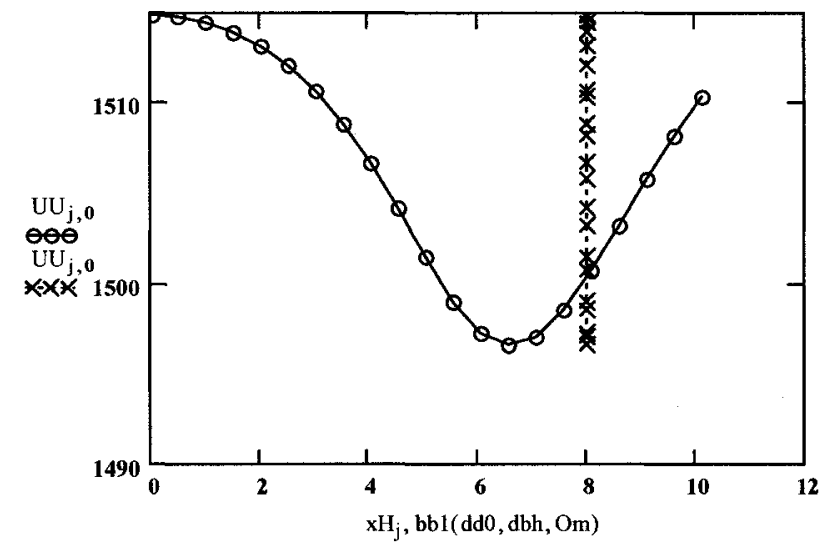




$$
\begin{aligned}
\mathrm{x} & :=\mathbf{0}, . \mathbf{2} . . \mathbf{2} \cdot \mathrm{H} 1(\mathrm{Om}) \\
\mathrm{dbh} & =\mathbf{0 . 9} \\
\mathrm{Om} & =\mathbf{5} \\
\mathrm{dd} & :=.9995 \\
\mathrm{kk} & :=\mathbf{5} \\
\mathrm{kk}: & =\mathrm{FRAME} \quad \mathrm{dd}:=\mathrm{dd} 0+(\mathbf{1}-\mathrm{dd} 0) \cdot \frac{\mathrm{kk}}{\mathrm{n}} \\
\mathrm{xHH}_{\mathrm{j}}: & : \frac{\mathrm{bb} 1(\mathrm{dd}, \mathrm{dbh}, \mathrm{Om}) \cdot \mathrm{j}}{\mathrm{n}}
\end{aligned}
$$

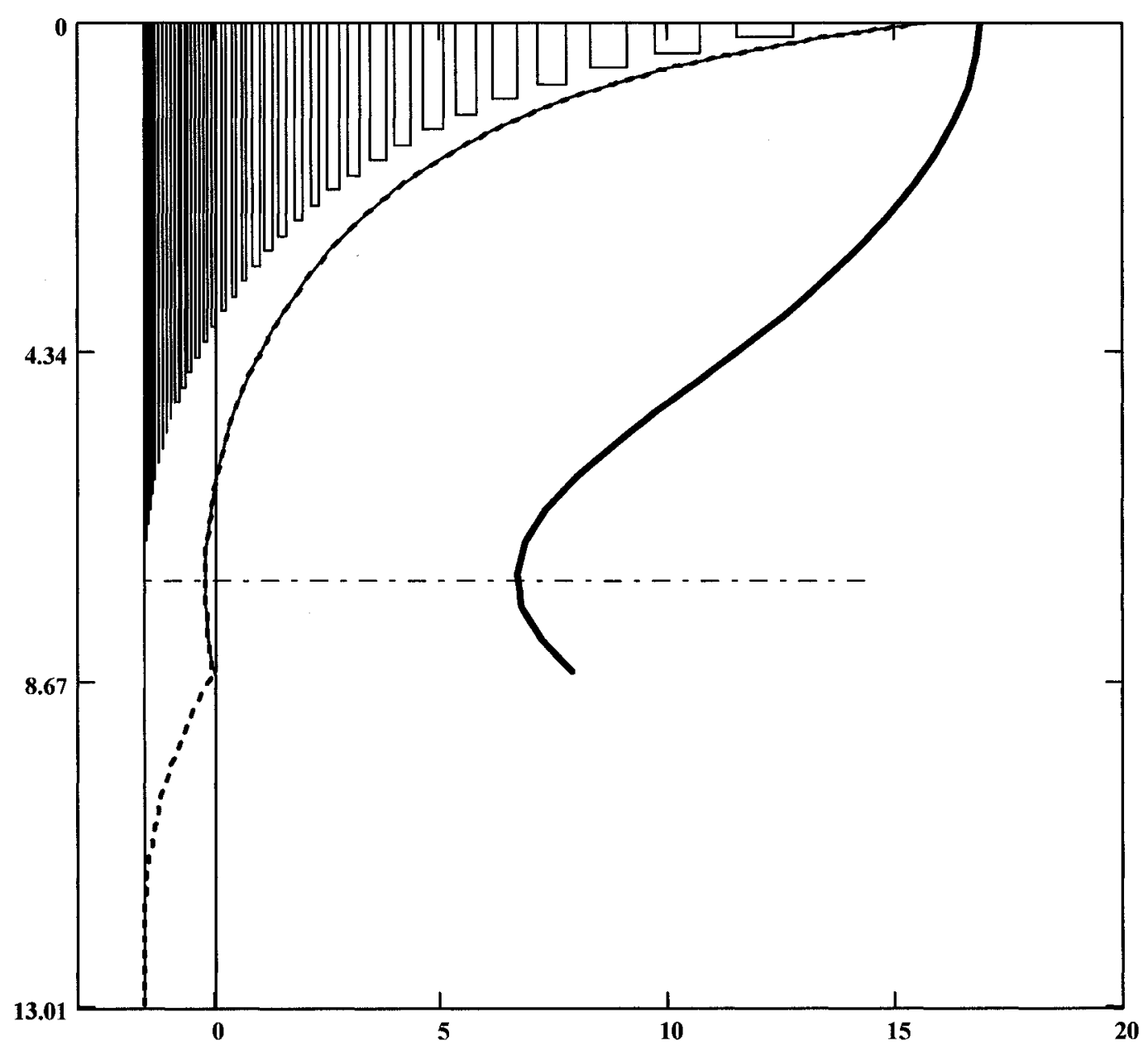


Appendix B

Adequacy test 
Physical characteristics of materials:

Density of liquid slag, $\mathrm{Kg} / \mathrm{M}^{3}$

Density of liquid steel, $\mathrm{Kg} / \mathrm{M}^{3}$

Gravity acceleration, $\mathrm{M} / \mathrm{s}^{2}$

Coefficient of interphase tension, $\mathrm{H} / \mathrm{M}$

$$
\begin{aligned}
& \mathrm{RoM}:=7200 \\
& \mathrm{RoS}:=2667.3 \\
& \mathrm{~g} 1:=9.807 \\
& \mathrm{SmS}:=1.2058
\end{aligned}
$$

Experimental data

$$
\text { MAS : }=\left(\begin{array}{cc}
0 & 0 \\
.95 & .11 \\
1.14 & .15 \\
1.34 & .21 \\
1.56 & .28 \\
1.76 & .37 \\
1.93 & .47 \\
2.13 & .58 \\
2.33 & .71 \\
2.51 & .84 \\
2.67 & .97 \\
2.84 & 1.11 \\
3.03 & 1.29 \\
3.19 & 1.47 \\
3.37 & 1.68 \\
3.57 & 1.93
\end{array}\right)
$$




$$
\mathrm{B}:=\left[(\mathrm{RoM}-\mathrm{RoS}) \cdot \frac{\mathrm{g} 1}{2 \cdot \mathrm{SmS} 10^{6}}\right] \quad \mathrm{B}=0.018
$$

Liquid metal overflow

$$
\begin{gathered}
\text { Omegal }:=.07 \\
\text { Omega }:=\frac{-\pi}{2}+\frac{\text { Omegal } \cdot \pi}{180} \\
\text { Omega }=-1.57 \\
\text { tan of initial angle } \\
\mathrm{tt}:=\tan (\text { Omega) } \\
\mathrm{tt}=-818.511
\end{gathered}
$$

sin of initial angle

$$
\begin{gathered}
\mathrm{pp}:=\frac{|\mathrm{tt}|}{\sqrt{1+(\mathrm{tt})^{2}}} \\
\mathrm{pp}=1
\end{gathered}
$$


Max meniscus height, if initial angle equal $90^{0}$

$$
\begin{aligned}
& H:=\sqrt{\frac{2}{B}} \\
& H=10.416
\end{aligned}
$$

Max meniscus height, if initial angle

equal $\mathrm{j}<90^{\circ}(\mathrm{pp}=\tan \mathrm{j})$

$$
\begin{gathered}
\mathrm{pp}=1 \\
\mathrm{H} 1:=\sqrt{\frac{1+\mathrm{pp}}{B}} \\
\mathrm{H} \mathrm{l}=10.416
\end{gathered}
$$

Coordinate (x) along meniscus height in which $\mathrm{y}=\mathrm{y}_{\max }$

$$
\begin{aligned}
& \mathrm{h}:=\sqrt{\frac{1}{\mathrm{~B}}} \\
& \mathrm{~h}=7.366 \\
& \mathrm{hl}:=\sqrt{\frac{\mathrm{pp}}{\mathrm{B}}} \\
& \mathrm{h} 1=7.366
\end{aligned}
$$

First derivative as a function $f(x)$

$$
f(x):=\frac{-\left(p p-B \cdot x^{2}\right)}{\sqrt{1-\left(p p-B \cdot x^{2}\right)^{2}}}
$$


Meniscus line $y=F(x)$

$$
\begin{aligned}
& F 1(x):=\int_{0}^{x} f l(x) d x \\
& F(x):=\int_{0.1}^{x} f(x) d x_{*}
\end{aligned}
$$

Define meniscus height using parameters $\mathrm{dbh}$

$$
\begin{aligned}
& \mathrm{dbh}:=0.9 \\
& \mathrm{~ms}:=2 \\
& \mathrm{bb}(\mathrm{dbh}):=\mathrm{hl}+\mathrm{dbh}(\mathrm{H} 1-\mathrm{hl})
\end{aligned}
$$

If we place coordinate origin into point of junction of meniscus and surface of liquid metal (ext. system), that coordinate of current location of the top of solidified mark Bh(dbh) - displacement of the coordinate system along $\mathrm{X}$

$$
B h(d b h):=\int_{0}^{b b(d b h)} f l(x) d x
$$

$\operatorname{Bh}(\mathrm{dbh})=-36.57$

Profile of rim. 
Equation of line of rim.

$F b 2(x, d b h):=-\left(B h(d b h)-\int_{0}^{x} f 1(x) d x\right) \cdot(b b(d b h) \geq x \geq 0)$

Equation of solid slag line

$F b(x, d b h):=F b 2(x, d b h) \cdot(x<h 1)+F b 2(h 1, d b h) \cdot(x \geq h 1)$

$\mathrm{Fb}(6, \mathrm{dbh})=-1.308$

Initial position of the top of solid mark on the rim (before displacement) zz1

aa $:=.0001$

$\mathrm{z}:=0+\mathrm{aa}$

Given

$\mathrm{Fb}(\mathrm{z}, \mathrm{dbh})=0$

$\operatorname{zzl}(\mathrm{z}, \mathrm{dbh}):=\operatorname{Find}(\mathrm{z})$

$\mathrm{zz} 1(\mathrm{z}, \mathrm{dbh})=3.996$

$\mathrm{rO}:=\operatorname{rows}(\mathrm{MAS})-1$

$\mathrm{rO}=15$

Base for counting $X$

$\mathrm{M}^{\langle 0\rangle}:=\overline{\left(\mathrm{zzl}(\mathrm{z}, \mathrm{dbh})+\mathrm{ms}+\mathrm{MAS}_{\mathrm{rO}, 0}-\mathrm{MAS}^{\langle 0\rangle}\right)}$
$\mathrm{i}:=0 . . \operatorname{rows}(\mathrm{M})-1$ 


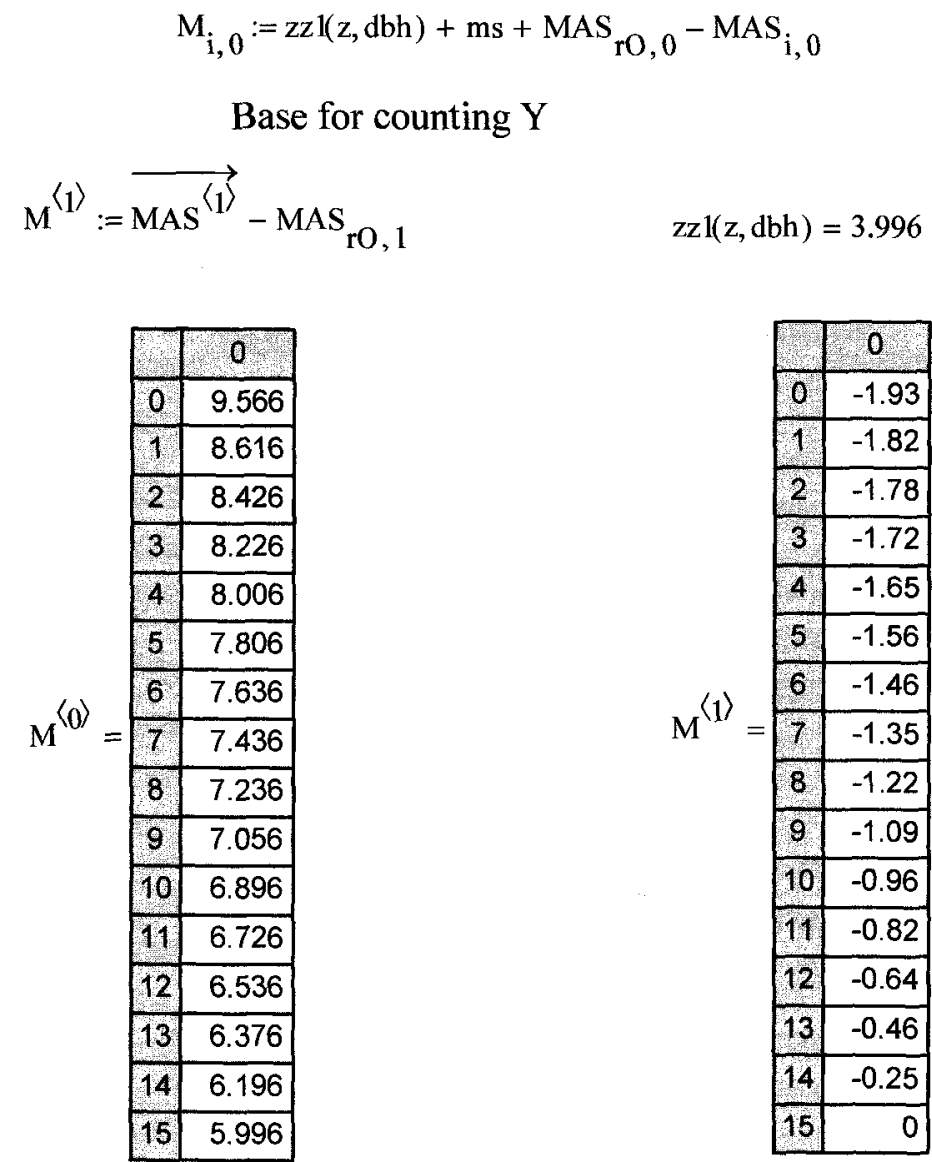

$$
\begin{aligned}
& \operatorname{mean}\left(\mathrm{M}^{\langle 1\rangle}\right)=-1.169 \\
& \mathrm{SMM}(\mathrm{dbh}, \mathrm{ms}):=\sum_{\mathrm{i}=0}^{\operatorname{rows}(\mathrm{M})-1}\left[\left[\left(\mathrm{Fb}\left(\mathrm{zz} 1(\mathrm{z}, \mathrm{dbh})+\mathrm{ms}+\mathrm{MAS}_{\mathrm{rO}, 0}-\mathrm{MAS}_{\mathrm{i}, 0}, \mathrm{dbh}\right)-\mathrm{M}_{\mathrm{i}, 1}\right)^{2}\right]\right] \\
& \mathrm{dbh}:=0.8 \quad \text { Given } \quad-1<\mathrm{ms}<1 \\
& \mathrm{P}:=\text { Minimize SMM, dbh, ms } \quad \mathrm{dbh} 1:=\mathrm{P}_{0} \quad \mathrm{dbh} 1=0.963 \\
& \mathrm{~ms}:=-2,-1.6 .2 \quad \mathrm{dbh}:=0.7,0.75 . .1 \quad \mathrm{dbh}:=\mathrm{P}_{0} \quad \mathrm{~ms}:=\mathrm{P}_{1}
\end{aligned}
$$




$$
\begin{aligned}
& \mathrm{i}:=0 . . \operatorname{rows}(\mathrm{M})-1 \quad \mathrm{M}_{\mathrm{i}, 0}:=\mathrm{zz} 1\left(\mathrm{z}, \mathrm{P}_{0}\right)+\mathrm{P}_{1}+\mathrm{MAS}_{\mathrm{rO}, 0}-\mathrm{MAS}_{\mathrm{i}, 0} \\
& \mathrm{x}:=0,1 . .2 \mathrm{H1} \quad \mathrm{b}:=10 \text { round }\left(2 \frac{\mathrm{HI}}{10}\right) \\
& \mathrm{P}=\left(\begin{array}{l}
0.963 \\
0.059
\end{array}\right) \quad \operatorname{SMM}\left(\mathrm{P}_{0}, \mathrm{P}_{1}\right)=0.02260957 \quad \mathrm{Fb}(\mathrm{h} 1, \mathrm{dbh})=-2.017 \quad \text { Omegal }=0.07 \\
& \mathrm{rO}=15 \quad \mathrm{zzl}\left(\mathrm{z}, \mathrm{P}_{0}\right)=3.57
\end{aligned}
$$

$X=$\begin{tabular}{|r|r|}
\hline & 0 \\
\hline 0 & -1.93 \\
\hline 1 & -1.82 \\
\hline 2 & -1.78 \\
\hline 3 & -1.72 \\
\hline 4 & -1.65 \\
\hline 5 & -1.56 \\
\hline 6 & -1.46 \\
\hline 7 & -1.35 \\
\hline 8 & -1.22 \\
\hline 9 & -1.09 \\
\hline 10 & -0.96 \\
\hline 11 & -0.82 \\
\hline 12 & -0.64 \\
\hline 13 & -0.46 \\
\hline 14 & -0.25 \\
\hline 15 & 0 \\
\hline
\end{tabular}

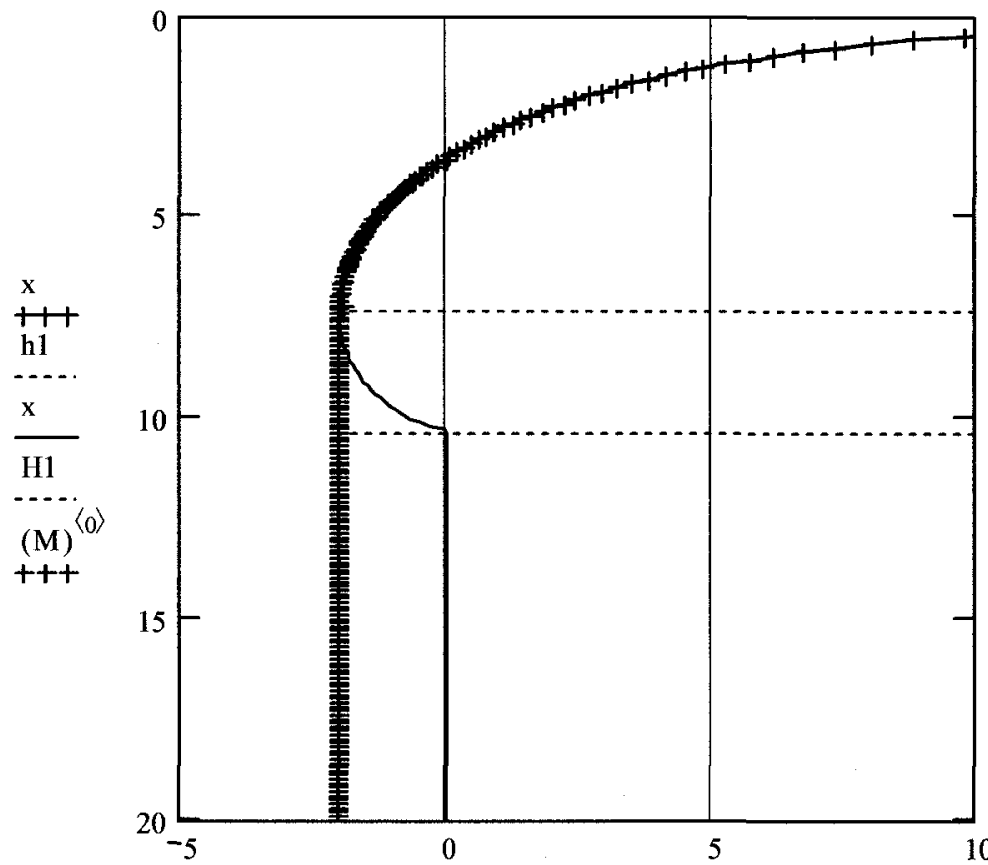

$$
\mathrm{Fb}(\mathrm{x}, \mathrm{dbh}), \mathrm{Fb}(\mathrm{x}, \mathrm{dbh}), \mathrm{Fb} 2(\mathrm{x}, \mathrm{dbh}), \mathrm{Fb}(\mathrm{x}, \mathrm{dbh}),(\mathrm{M})^{\langle 1\rangle}
$$

$\mathrm{FM}_{\mathrm{i}}:=\mathrm{Fb}\left(\mathrm{zzl}(\mathrm{z}, \mathrm{dbh})+\mathrm{ms}+\mathrm{MAS}_{\mathrm{rO}, 0}-\mathrm{MAS}_{\mathrm{i}, 0}, \mathrm{dbh}\right)$

$\mathrm{i}:=0 . . \operatorname{rows}(M)-1$

$$
\mathrm{X}:=\mathrm{M}^{\langle 1\rangle} \mathrm{Y}:=\mathrm{FM}
$$

$\mathrm{Y}=$\begin{tabular}{|c|c|}
\hline & 0 \\
\hline 0 & -2.013 \\
\hline 1 & -1.852 \\
\hline 2 & -1.792 \\
\hline 3 & -1.718 \\
\hline 4 & -1.598 \\
\hline 5 & -1.528 \\
\hline 6 & -1.437 \\
\hline 7 & -1.32 \\
\hline 8 & -1.19 \\
\hline 9 & -1.062 \\
\hline 10 & -0.939 \\
\hline 11 & -0.799 \\
\hline 12 & -0.63 \\
\hline 13 & -0.476 \\
\hline 14 & -0.291 \\
\hline 15 & -0.069 \\
\hline
\end{tabular}

